University of Louisville

ThinkIR: The University of Louisville's Institutional Repository

Electronic Theses and Dissertations

$5-2013$

\title{
Mathematics coaching in high school : the impact of coach and teacher interactions.
}

Eleanor Louise Pusey
University of Louisville

Follow this and additional works at: https://ir.library.louisville.edu/etd

\section{Recommended Citation}

Pusey, Eleanor Louise, "Mathematics coaching in high school : the impact of coach and teacher interactions." (2013). Electronic Theses and Dissertations. Paper 1168.

https://doi.org/10.18297/etd/1168

This Doctoral Dissertation is brought to you for free and open access by ThinkIR: The University of Louisville's Institutional Repository. It has been accepted for inclusion in Electronic Theses and Dissertations by an authorized administrator of ThinkIR: The University of Louisville's Institutional Repository. This title appears here courtesy of the author, who has retained all other copyrights. For more information, please contact thinkir@louisville.edu. 


\title{
MATHEMATICS COACHING IN HIGH SCHOOL:
} THE IMPACT OF COACH AND TEACHER INTERACTIONS

\author{
By \\ Eleanor Louise Pusey \\ B.A., Mathematics, Radford University, 1992 \\ M.S., North Carolina State University, 2003

\begin{abstract}
A Dissertation
Submitted to the Faculty of the

College of Education and Human Development of the University of Louisville

in Partial Fulfillment of the Requirements

for the Degree of
\end{abstract} \\ Doctor of Philosophy \\ College of Education and Human Development \\ University of Louisville \\ Louisville, Kentucky
}

May 2013 

MATHEMATICS COACHING IN HIGH SCHOOL: THE IMPACT OF COACH AND TEACHER INTERACTIONS

\author{
By \\ Eleanor Louise Pusey \\ B.A., Mathematics, Radford University, 1992 \\ M.S., North Carolina State University, 2003 \\ A Dissertation Approved on
}

March 7, 2013

by the following Dissertation Committee:

Dissertation Chair, Maggie B. McGatha

Jennifer M. Bay-Williams

William S. Bush

Melissa Evans-Andris 


\section{DEDICATION}

This dissertation is dedicated to my parents,

Mr. Robert Hollis Pusey and Mrs. Betty Boyd Pusey,

who loved, encouraged, and supported me throughout my education. 


\section{ACKNOWLEDGMENTS}

I would like to thank my dissertation chair, Dr. Maggie McGatha, for her insight, support, and feedback throughout this research study. She was extremely helpful and infinitely patient as my advisor, colleague, and friend. I would also like to thank the other members of my committee, Dr. Bill Bush, Dr. Jenny Bay-Williams, and Dr. Melissa Andris for their contributions, which strengthened my research.

I would like to thank all of my family for their encouragement and understanding especially when I missed family events and quality time during the holidays often from working on some phase of this study. I especially want to thank my father Bob for his advice and encouragement from start to finish. I also want to recognize my mother Betty who lost her battle with cancer while I was completing this program. She was often my inspiration and motivation not to give up and see this through to the end.

I would like to thank Dr. Vena Long, Dr. Bill Bush, and the members of the ACCLAIM Management Team for their vision and wisdom in managing this unique doctoral program and allowing me to participate in it. I would also like to acknowledge the members of the third cohort who made those three years of course work fun and memorable. A special thanks to Dianne, Lisa, Sandi, Geri, Wayne, Mick, and Sunny who made me laugh more than I thought possible while completing a doctoral program.

I would like to thank the faculty, staff, and students at Columbus Career and College Academy for reminding me daily why I love this profession.

Finally, I would like to thank my best friend and math-lete, Michelle Powell, for being my "rock" throughout this process and helping me make a new "friend," Kale. 
They both provided fun, cheap entertainment and a shoulder to cry on. I could not have made it through this without both of them cheering me on and keeping me sane. 


\begin{abstract}
MATHEMATICS COACHING IN HIGH SCHOOL:

THE IMPACT OF COACH AND TEACHER INTERACTIONS
\end{abstract}

Eleanor L. Pusey

May 10, 2013

This dissertation study examined a high school mathematics coach in the context of a three-year project called MAST (Mathematics Achievement Success Today) that provided summer content courses, lesson study, and mathematics coaching for high school teachers. This study focused in particular on the work of the MAST project coach as she interacted with classroom teachers and university faculty, and the subsequent impact of those interactions on both groups. The use of lesson study transformed the coach's role into group coaching, an area of the mathematics coaching literature with only two studies.

This study was mixed-methods study and used a combination of primary and secondary data. The secondary data were from the three-year MAST project and included coach and university faculty interviews, teacher surveys, teacher observations with the Reformed Teaching Observation Protocol (RTOP), a teacher focus group, audiotaped post conferences between the teachers and the coach, a coach's log, and document review 
of the coach's project duties. The researcher collected primary data after the project ended by conducting interviews with the coach and university faculty.

Some of the key findings about coaching interactions included the importance of the coach's rapport with teachers and the clarity of her role. Lesson study created a clear focus on student learning and helped teachers become more reflective. Changes to secondary teachers' practice included successful implementation of new strategies, a willingness to try new things, a greater focus on student thinking and engagement, and increased content knowledge. Their overall score and subscale scores on the RTOP corroborated these changes in teachers' practice.

A unique contribution of this study not found in the mathematics coaching literature was the inclusion of university faculty, who expressed varying levels of impact from interacting with the coach. Two faculty members expressed how working with the coach impacted their practice. The mathematician reported an increase in the use of "toys", better management of groups, greater sensitivity to gaps in student's knowledge, and the importance of differentiation. 


\section{TABLE OF CONTENTS}

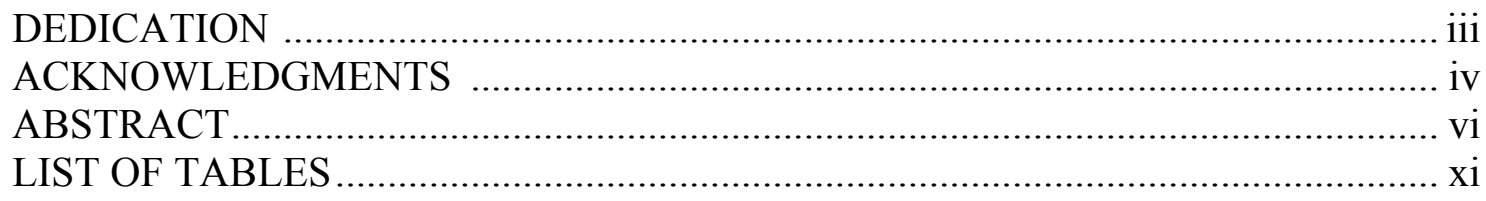

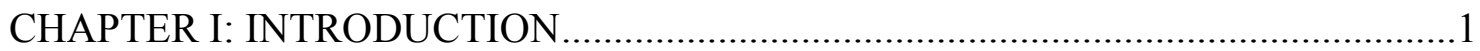

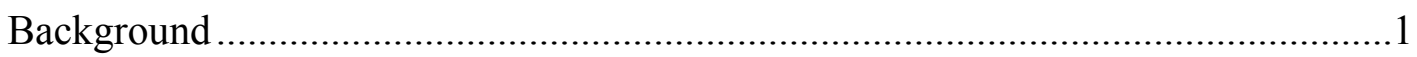

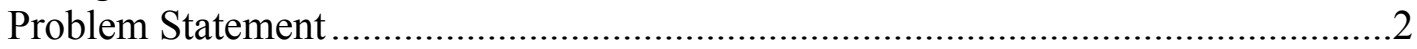

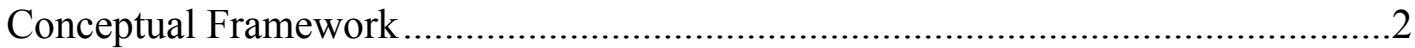

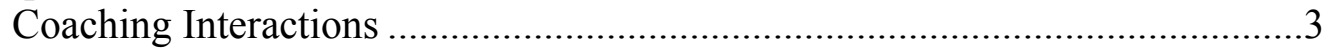

Follow-up to Professional Development .......................................................

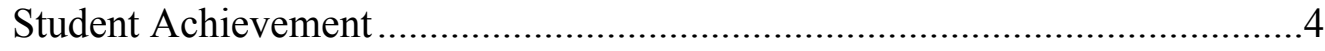

Gaps in the Literature..........................................................................

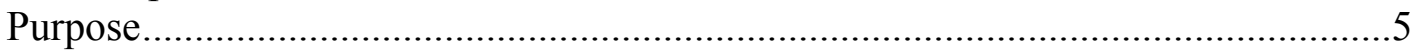

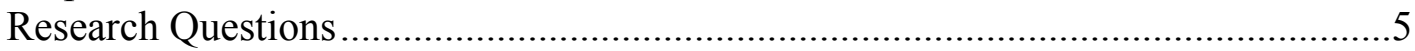

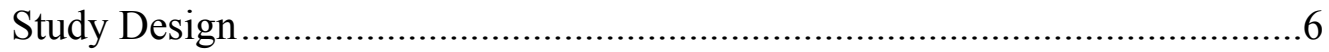

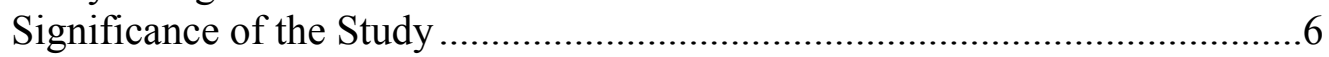

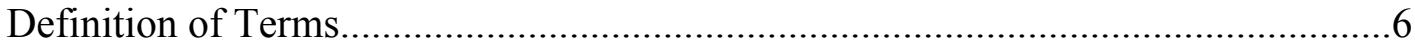

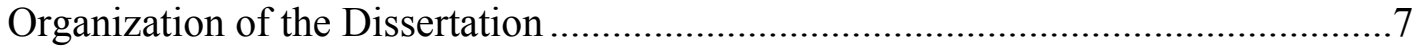

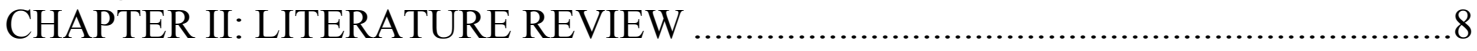

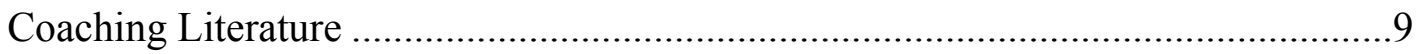

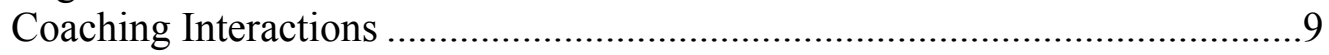

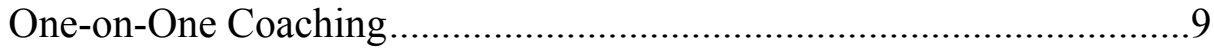

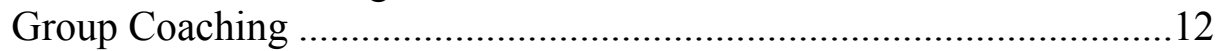

Summary .............................................................................14

Coaching as Follow-up to Professional Development...................................15

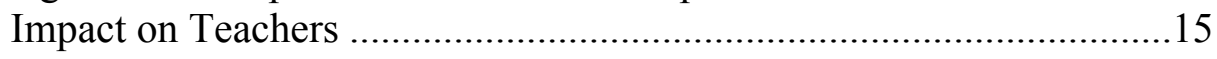

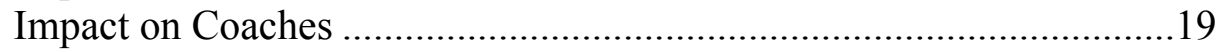

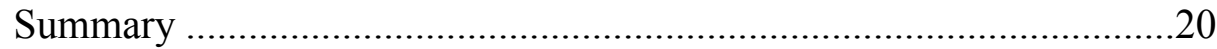

Coaching and Student Achievement .....................................................21

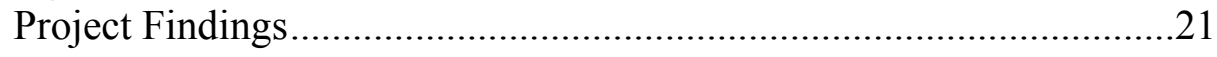

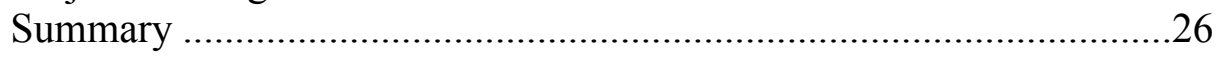

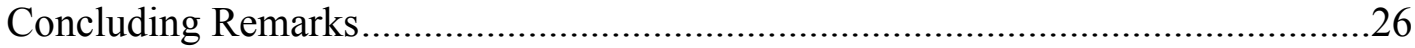

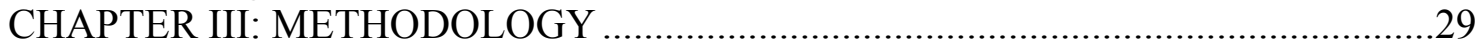

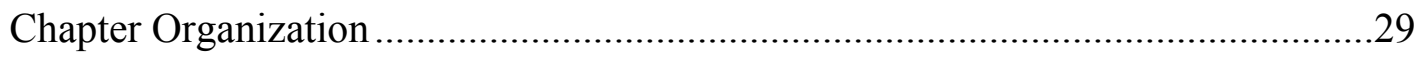

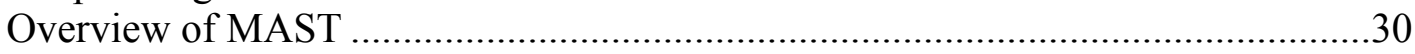

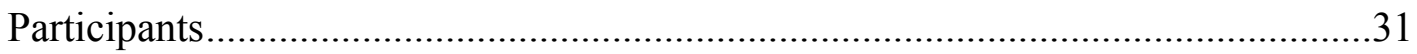

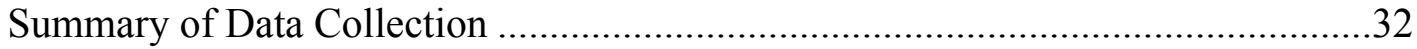




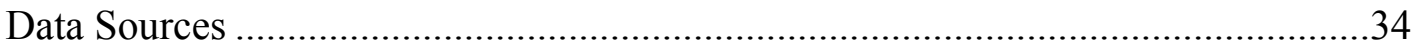

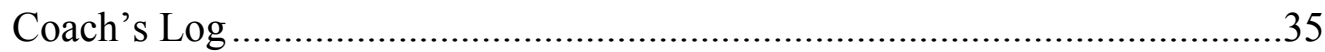

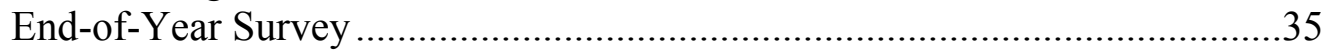

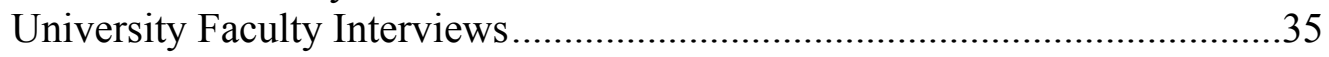

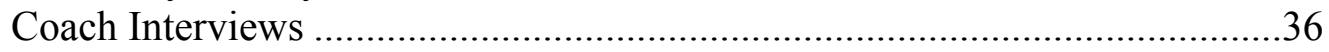

Lesson Study Post Conferences .....................................................................



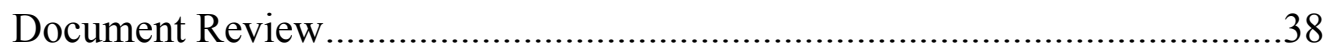

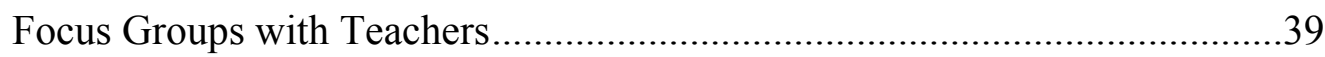

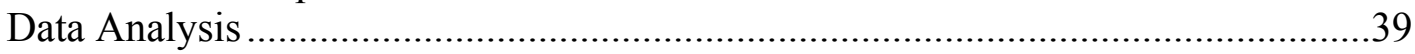

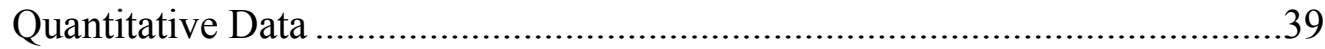

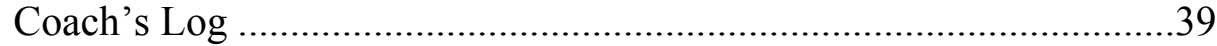

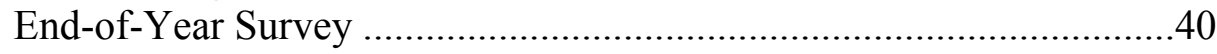

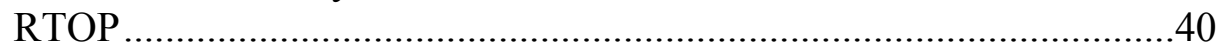

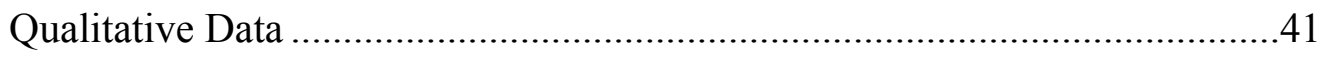

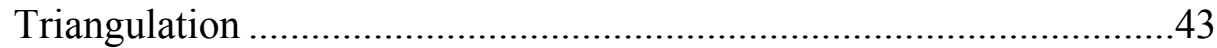

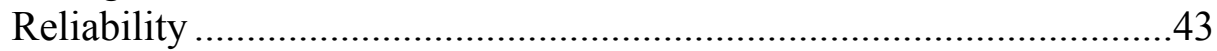

Researcher Credibility and Reflexivity ..............................................44

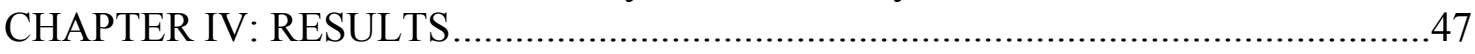

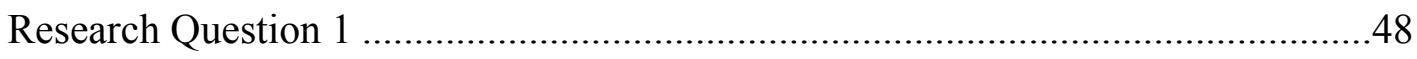

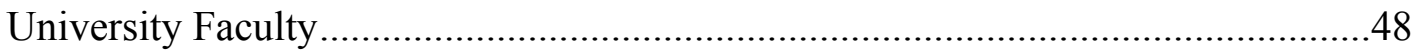

Whole Group Interactions ............................................................................49

Personal Rapport and Classroom Connection...........................................50

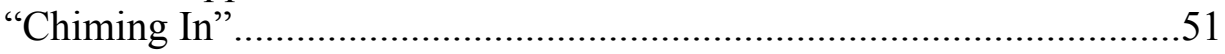

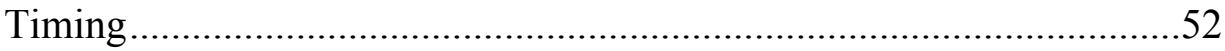

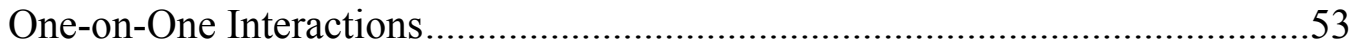

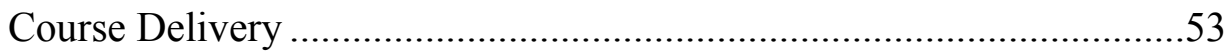

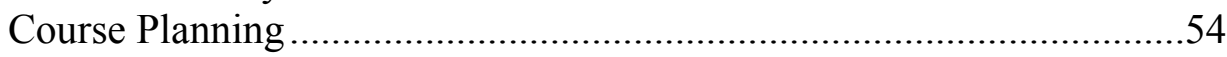

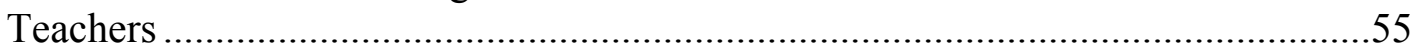

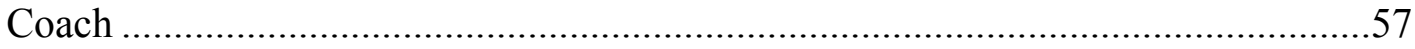

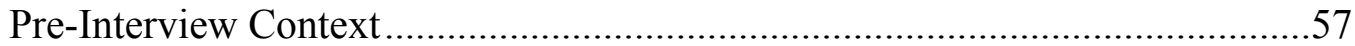

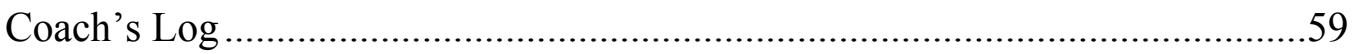

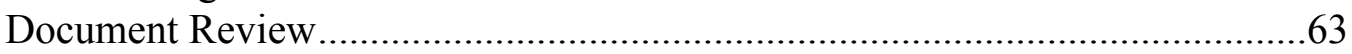

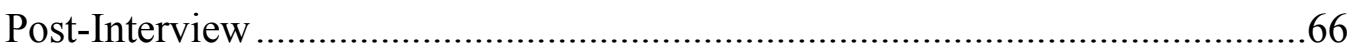

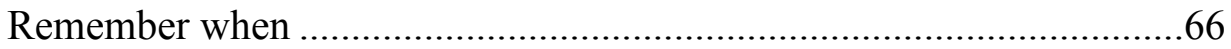

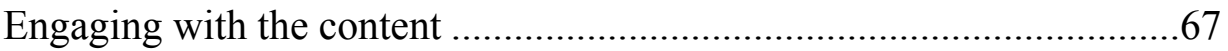

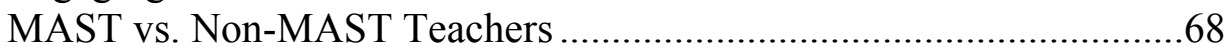

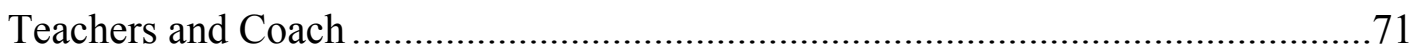

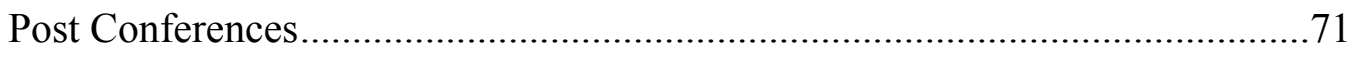

What is Lesson Study? ………………............................................

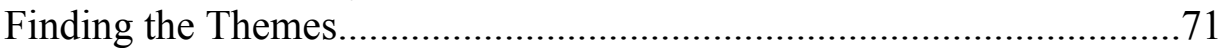

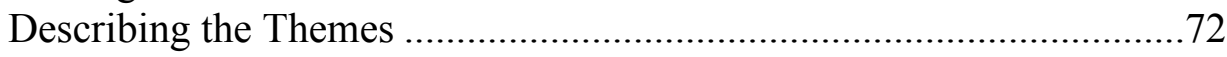

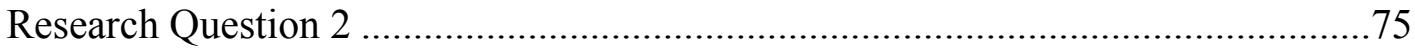

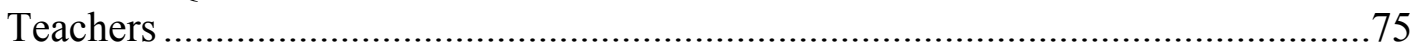

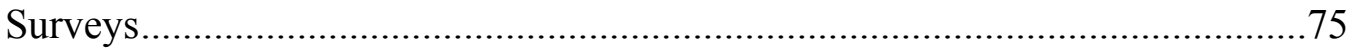

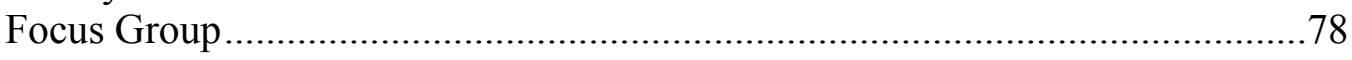




RTOP
Coach .
Impact on Teachers
"Willingness to Try"
Doing the Mathematics
Pedagogy
Leadership




\section{LIST OF TABLES}

TABLE

PAGE

1. Alignment of Data Sources to Research Questions 33,106

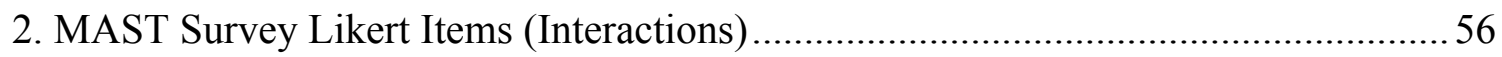

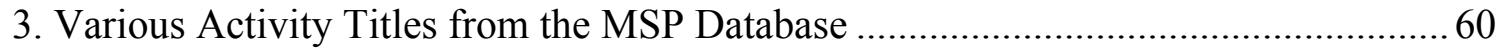

4. Summary of Activities from Coach's Log........................................................ 61

5. MAST Project Coach Responsibilities Aligned with Coach's Log............................ 64

6. MAST Project Coach Responsibilities Not Recorded in Coach's Log .....................65

7. Themes Across Lesson Study Post conference Sessions ........................................ 73

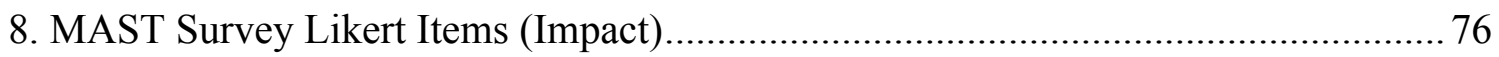

9. MAST 2012 Survey Open-Ended Items (Impact) .............................................. 77

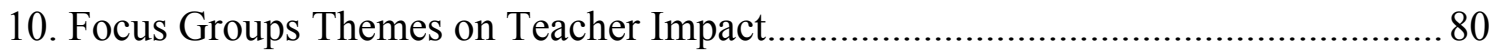

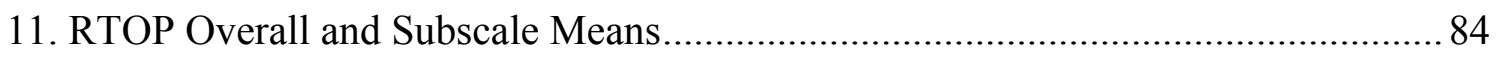




\section{CHAPTER I}

\section{Background}

Coaching is a popular strategy for professional development that increasingly more states and school systems are using to improve classroom instruction and enhance student achievement (Campbell \& Malkus, 2011; Grant \& Davenport, 2009; Knight, 2006; Poglinco \& Bach, 2004). Coaching has been around almost 30 years (Dossey, 1984; National Research Council, 1989) originating from peer coaching where teachers observed and gave feedback to each other as they implemented new practices (Joyce \& Showers, 1982). Today coaching is more commonly prevalent in which a coach works with many teachers to support student learning.

Coaches may be used in a variety of ways. A coach may be assigned a specific subject area such as reading or mathematics, or they may be responsible for multiple subject areas. A coach might be assigned at the district level, school level, or a particular grade level. In addition, coaches may work specifically with teachers on instructional strategies, assessment, subject matter, technology, or a combination of these activities depending on the priorities and needs determined by teachers and school administrators. Regardless of the model implemented, coaches represent a promising resource for schools and districts because they provide sustainable, long-term, embedded professional development (Becker \& Pence, 1999; Jones, Lubinski, Swafford, \& Thornton, 1994). Given the increased attention on coaching, important questions emerge: What actually happens when a coach works with a teacher or group of teachers? Do coaching sessions 
tend to focus on instructional practice, subject matter, or a combination of the two? Is coaching equally effective at all grade levels? A reasonable place to look for answers to these and other questions about coaching is in the current research literature on coaching.

\section{Problem Statement}

This study looked specifically at mathematics coaching. A number of school systems use coaching models in different configurations across different grade levels and different subjects; yet the models are not often substantiated by research. Evidence that supports mathematics coaching as an effective model of professional development is needed. Further evidence is needed to show that mathematics coaching is making a difference in teachers' practice and the nature of the interactions that facilitate change. These unanswered questions support the need for additional research on mathematics coaching.

\section{Conceptual Framework}

The published research on mathematics coaching is minimal (McGatha, 2009b; National Mathematics Advisory Panel, 2008); many papers and articles describe the work that mathematics coaches do, but only a small number can be classified as research. The findings in these studies are encouraging, suggesting that coaching is worthy of additional study. They also provide the foundation for what is already known about mathematics coaching. The mathematics coaching research that exists can be divided into three general categories: (a) coaching interactions, (b) follow-up to professional development, and (c) student achievement. I provide a brief overview of the mathematics coaching research in the following sections. 


\section{Coaching Interactions}

Research indicates that different levels of interaction often dictate the type of relationships between coaches and teachers and the subsequent level of engagement (Becker, 2001; McGatha, 2008). Coaches with better rapport were more effective in helping teachers change their practice. However, the findings are mixed in the research regarding whether it is better to be more direct or less direct, particularly if a desired outcome of coaching is to help the teacher become more reflective. This finding reinforces the challenge for a coach in choosing an appropriate plan of action that best meets the needs of a particular individual. Other challenges of mathematics coaching reported in the literature included lack of time, lack of trust, and lack of clarity in the coach's role (Ai \& Rivera, 2005). The role of the coach was clearer when the school and district leadership agreed on the coach's purpose (Gibbons, Garrison, \& Cobb, 2010). Other supportive school structures that improved a coach's influence were weekly meetings, common planning time, and focus on student learning (Alloway \& Jilk, 2010; Gibbons et al., 2010).

\section{Follow-up to Professional Development}

Coaching when paired with professional development was particularly effective in helping teachers implement new curricula, increase their mathematics content knowledge, and improve student engagement (Campbell, 1996; Campbell \& White, 1997; Cornett \& Knight, 2009; Race, Ho, \& Bower, 2002). These findings could be the result of customized support available from coaches that addressed teachers' fears and challenges associated with trying out new teaching strategies. These findings were not limited to coaching studies with elementary and secondary teachers, but also with 
teachers of early childhood and exceptional children (Kretlow, Wood, \& Cooke, 2011;

Rudd, Lambert, Satterwhite, \& Smith, 2009). Teachers' perceptions of coaching were positive (Becker \& Pence, 1999) and essential to the changes in teacher behavior. Teachers reported that coaching was responsible for helping them implement new instructional strategies and understand the content better than if they had not been coached and coaches reported that the approaches they used with teachers varied and were dependent on factors including the coach's personal preference, as well as the teachers' experience levels, beliefs and content knowledge (Barrett et al., 2002; Krupa \& Confrey, 2010; Olson, 2005; Olson \& Barrett, 2004).

\section{Student Achievement}

Several studies have found that grades 3-8 students whose teachers were coached, performed better on standardized and performance-based assessments of mathematics and across mathematical strands than students whose teachers were not coached (Balfanz, MacIver, \& Byrnes, 2006; Brosnan \& Erchick, 2010; Conaim, 2010; Foster \& Noyce, 2004; Zollinger, Brosnan, Erchick, \& Bao, 2010). However, simply coaching a teacher did not guarantee increases in student achievement (Campbell \& Malkus, 2009, 2011). Preparation and professional development of coaches in content, instruction, and leadership was also critical to their success (Barrett et al., 2002; Brosnan \& Erchick, 2010; Campbell, 2007; Campbell \& Malkus, 2009, 2011). In some cases, it took at least a year or longer to obtain gains in student achievement (Campbell, 1996). Given the considerable time, money, and resources needed to establish coaching programs, it is reasonable to question whether the research supports coaching as effective professional development model at all grade levels. 


\section{Gaps in the Literature}

The majority of studies reporting success with mathematics coaching have been conducted at the elementary or middle grades level (Balfanz et al., 2006; Barrett et al., 2002; Becker, 2001; Brosnan \& Erchick, 2010; Campbell, 1996; Campbell \& Malkus, 2009; Conaim, 2010; Foster \& Noyce, 2004; Gibbons et al., 2010; Kretlow et al., 2011; McGatha, 2008; Olson \& Barrett, 2004; Race et al., 2002; Zollinger et al., 2010). What is less known is if this same level of success can be expected at the secondary level. Only three studies explored mathematics coaching at the high school level (Alloway \& Jilk, 2010; Becker \& Pence, 1999; Krupa \& Confrey, 2010). These gaps in the research literature as well as recommendations for future research provided the primary rationale for this study.

\section{Purpose}

This study focused on a high school mathematics coach and her interactions with teachers and university faculty as part of a three-year project. Also, this study examined the impacts of coaching interactions on teachers' and university faculty practice.

\section{Research Questions}

The gaps in the existing research literature and the purpose of this study led to the following research questions:

1. What is the nature of a coach's interactions with secondary teachers and university faculty during the MAST project?

2. What was the impact of a coach's interactions during the MAST project?

a. To what extent did secondary teachers' practice change?

b. To what extent did university faculty practice change? 


\section{Study Design}

This study used a mixed-methods design, incorporating a combination of secondary data and primary data from a three-year project, Mathematics Achievement Success Today (MAST). Teachers in MAST received extensive professional development on mathematics content and pedagogy in addition to coaching.

\section{Significance of the study}

The study is significant because in general, it adds to the research literature on mathematics coaching and offers insights into improving educational practice by better understanding the work of coaches. In particular, this study provides a much needed exploration into coaching interactions at the high school level. The few research studies that described interactions between coaches and teachers have focused solely on the K-5

level (Becker, 2001; McGatha, 2008). Therefore, this study fills a gap in the literature by studying these critical coaching interactions in a high school context. In addition, this study describes the impact of those interactions on teacher and university faculty instructional practice.

\section{Definition of terms}

Mathematics Coach - an individual who supports and mentors the work of other mathematics teachers using a variety of activities including but not limited to modeling lessons, conducting observations, having pre- and post-lesson conferences, planning lessons and co-teaching. (Note there are numerous titles for this role that include mathematics specialist, lead teacher, resource teacher, etc. For the sake of clarity, I limit my use to mathematics coach throughout this document regardless of which title is used by the authors in the coaching research literature). 


\section{Organization of the dissertation}

Chapter 2 provides a more detailed review of the coaching literature, organized by themes within the three categories of research provided in this chapter. Chapter 3 describes the methodology used to characterize the coaching interactions and their impact. Chapter 4 reports the results from the data collected. Chapter 5 summarizes the implications of the results from Chapter 4, as well as limitations and avenues for future research in mathematics coaching. 


\section{CHAPTER II}

A call for elementary mathematics coaches began as early as 25 years ago (Dossey, 1984); yet it has recently gained popularity in the last 10 years (Association of Mathematics Teacher Educators, June 2010; Fennell, 2006; Reys \& Fennell, 2003; Shaughnessy, 2010). Mathematics coaching has become a very popular form of professional development implemented in school districts across the country at an everincreasing rate (Campbell \& Malkus, 2011; Grant \& Davenport, 2009; Knight, 2006; Poglinco \& Bach, 2004). Reasons for hiring coaches include: improving student achievement; closing achievement gaps; supporting teachers in implementing new programs or instructional strategies; supporting teachers' understanding of mathematics content; developing assessments; or a combination of these.

Although the original focus for coaching was in elementary mathematics, coaching has been utilized at every grade level in various configurations (Brosnan \& Erchick, 2010) and subject areas. Unfortunately, the implementation of coaching is far ahead of the research on coaching (McGatha, 2009a; National Mathematics Advisory Panel, 2008); consequently, the need for additional coaching research is urgent. The proposed study intends to investigate how mathematics coaches interact with teachers and the impact of those interactions, particularly at the high school level. The study will expand the coaching research and offer insights into practice. 


\section{Coaching Literature}

Many articles and books have been published on the subject of coaching, but only a handful can be classified as research, and even fewer are specific to mathematics coaching (Alloway \& Jilk, 2010; McGatha, 2009a; National Mathematics Advisory Panel, 2008); yet the findings suggest that coaching is yielding some positive results. In

general, coaching is another model for professional development primarily used to improve teachers' instructional practice. Unlike workshops or other forms of professional development, coaching is personalized, typically providing support and mentoring for an individual teacher. Ideally the teacher determines the goals of coaching, and the coach supports the teacher in pursuit of those goals using a variety of strategies (Campbell, 1996; Evered \& Selman, 1989).

The studies published on mathematics coaching generally fall into three categories that include: (a) studies focused on the coach and their interactions with teachers, (b) the effect of coaching as follow-up to professional development initiatives, and (c) the impact of coaching on student achievement. In the first category, the research can be further divided into studies describing one-on-one interactions with a coach and studies describing group interactions with a coach.

\section{Coaching Interactions}

One-on-one coaching. Case studies provide a rich source of data, particularly in the first category of coaching research-how mathematics coaches interact with mathematics teachers (Barrett et al., 2002; Becker, 2001; McGatha, 2008; Olson \& Barrett, 2004). Both Becker and McGatha interviewed and observed coaches working with elementary teachers. In the analysis of data, they described different categories of 
interaction between a coach and teacher. McGatha (2008) described these interactions as "levels of engagement" known as 'consulting', 'collaborating', and 'coaching', as characterized in Cognitive Coaching ${ }^{\mathrm{SM}}$ (Costa \& Garmston, 2002, as cited in McGatha, 2008). She suggested the level is dictated by the nature of the relationship and 'coaching' is the ideal level. This level occurs when the coach is least directive while the teacher is highly reflective. In contrast, Becker (2001) used different descriptors (collaborator, model, and director) to categorize the work of coaches in increasing levels of directness. Becker deemed the "director" as the most "effective." Determining which level or types of coaching interactions are "most effective" is described differently in the research depending on whether you ask the coach or the teacher.

The teachers in Becker's (2001) study reported the greatest satisfaction from their coaching interactions that occurred at the director level. At this level the coach prompted teachers to reflect on specific aspects of the lesson such as the delivery of the content, alternative approaches, and next steps for future lessons. The teachers recalled these events as particularly important and details that they would have otherwise overlooked had the coach not directed the teacher's reflection in that direction.

A teacher in McGatha's (2008) study indicated that the coaching experience was her best professional development experience and that the most valuable lesson came in seeing how students' work could direct the lesson. On the other hand, her primary criticism was not having adequate time to talk before and after a lesson. McGatha indicated that having the coach model lessons was most popular from the teachers' perspective; however, she questioned its value from a coach's perspective because the ultimate goal of coaching was to encourage teachers to be more reflective in their 
teaching. At the very least, if modeling is necessary and agreed upon by both parties, McGatha contended that both teacher and coach needed to be part of the planning process.

A third study paralleled McGatha's recommendation by describing how the level of coaching interactions changed over time. Race, Ho and Bower (2002) conducted a study involving 265 elementary teachers in high-risk schools in the Chicago area.

Coaches collected data on the teachers following a classroom visit using an implementation log. During classroom visits, researchers found that the coaches" "level of intervention" with the teacher changed over time becoming more teacher-directed and less coach-directed. This progression started with coaches modeling lessons for the teacher, transitioned to co-teaching lessons with the teacher, and ended with coaches observing while teachers taught the lesson. Race, Ho, and Bower also reported changes in teacher behavior. Findings about the level of coaching interaction and impact on teachers are important to consider together in analyzing the effectiveness of coaching interactions, particularly if the goal of coaching is teacher change. These additional findings on teacher impact will be reported in the second category of coaching research.

In contrast to McGatha's findings about modeling lessons, a fourth study reported that participating coaches perceived modeling lessons to be a key strategy in the first year of implementing a coaching program (Ai \& Rivera, 2005). Like Becker's study, the purpose of this study was to examine how teacher practice had been affected by coaching. However, unlike Becker and McGatha's studies, it was not a case study. This study involved observations and interviews of 160 teachers in grades K-12 and interviews of 73 administrators across 40 schools. In addition, teachers who had received some form 
of coaching over the course of that school year completed surveys. Ai and Rivera reported no significant differences in teacher practice between teachers who had been coached compared to those who had not. One explanation offered was that most teachers either did not get one-on-one time with a coach or had limited exposure to the observation cycle (pre- and post-conversations) or modeling of lessons by the coach. An important contribution of this study was the description of the barriers that Ai and Rivera believed made their coaches less "effective." Some of the barriers described were teachers' lack of trust in the coaching relationship, teachers' resistance to change, lack of time, and a lack of clarity with regard to the coaching role.

Group coaching. A second sub-category of studies focused on coaching interactions that involved group coaching situations. Gibbons, Garrison, and Cobb (2010) conducted a cross-case comparative analysis in a large urban district involving seven middle school coaches, seven principals, and 32 teachers. Coaching had been instituted in the district to support teachers' implementation of an NSF-funded curriculum. The purpose of the study was to investigate how coaches interacted with teachers (both oneon-one and in group settings) and how school structures influenced the practice of coaches. In contrast to Ai and Rivera's description of barriers to coaching, Gibbons, Garrison and Cobb identified those school structures that positively influenced coaching interactions and that affected the coach's "centrality" in a school.

Gibbons, Garrison and Cobb (2010) asked teachers (a) who they went to for help (the coach vs. other faculty), (b) what they got help with, (c) how frequently they went, and (d) how it impacted them. From these data, they created a measure of "coach centrality" defined as "the ratio of the number of ties directed toward that individual to 
the total ties that could be directed toward that individual" (p. 1389). In other words, they attempted to place each coach in the context of that school's social network by quantifying how often teachers who could approach their coach for help actually did. They categorized each coach as 'central' if the ratio was between $2 / 3$ and 1 , 'somewhat central' if the ratio was between $1 / 3$ and $2 / 3$, and 'not central' if the ratio was between 0 and $1 / 3$. Then they made comparisons across these categories to see what school structures were in place to explain the differences in the coach's centrality. The researchers reported that teachers were more likely to approach a coach who taught at their same grade level; otherwise the teacher would go to another colleague teaching the same grade level for instructional advice and collaboration. This finding seems important given that coaches may be assigned to a grade band that is not necessarily the same grade level from their own teaching experience. It is not clear whether this finding can be generalized to other grade levels or is specific only to middle grades.

Group coaching (weekly department meetings) was one of several structures the researchers identified that influenced the coach's centrality. They found that the coach was "more central" in schools in which the coach led the meeting and placed the emphasis on instruction. When other teachers in the department led the meeting, they were more apt to focus on non-instructional issues. Gibbons, Garrison, and Cobb (2010) recognized the importance of coaching training and recommended that coaches needed professional development on how to facilitate weekly meetings and select appropriate instructional activities for teachers.

A second study focusing on group coaching verified the value of coaches using weekly meetings through common planning time and described the "coaching moves" 
that facilitated interactions with a group of high school teachers (Alloway \& Jilk, 2010). In this study researchers described one coach and four teachers working at a high school in a large urban district. In particular, the study examined weekly planning sessions for the teachers facilitated by the coach. Their analysis of the coach's work was based on interviews with the teachers and videotapes of these common planning sessions.

In a study similar to that of Gibbons, Garrison, and Cobb (2010), Alloway and Jilk (2010) described how the coach consistently kept group conversations focused on student learning and highlighted specific teaching moves by members of the group that provided evidence of student learning. By highlighting the contributions of specific teachers in the group, Alloway and Jilk reported that this strategy facilitated "shared understandings" and "assigned competence" to various members of the planning group.

Summary. The findings from these five studies of mathematics coaching identified important features of the interactions between teachers and coaches in both group and one-on-one settings. The studies described how coaches' interactions dictated the type of activities in which coaches and teachers engaged and the level of that engagement. Ultimately, some relationships were more conducive to improving teachers' practice because of the rapport between teachers and coaches and the teachers' openness to change. Some disagreement amongst researchers was evident regarding whether modeling lessons was an effective coaching strategy and whether coaches should be more or less direct if their goal is to help teachers become more reflective about their practice. Such findings indicate the complexity of the customizing that occurs in the coaching process. It is not at all "scientific"-it involves making split-second decisions on how to best proceed with a teacher given their current needs and goals. 
Studies on coaching interactions also reported both the barriers and supportive structures found in schools implementing coaching. Several barriers to coaching mentioned included: lack of time, lack of trust, and lack of clarity associated with the role. Improved clarity in the coach's role was found in schools where the principal and district leadership agreed on the purpose of the coach and scheduled their activities and school day to support that purpose. School structures that supported the work of a coach included weekly meetings or common planning time facilitated by the coach, where the coach could focus teachers' conversations on student learning.

\section{Coaching as a Follow-up to Professional Development}

The largest category of the research literature examined coaching as a way to support teachers' implementation of ideas learned in professional development settings. Cornett and Knight (2009) reviewed models of coaching including peer coaching, cognitive coaching, literacy coaching, and instructional coaching. All models showed evidence that coaching in tandem with professional development was more effective in supporting change in teacher practice than professional development alone. Findings in this category are organized according to the impact on teachers and the impact on coaches.

Impact on teachers. Seven studies in which coaching served as follow-up to professional development reported on the impact of coaching on teachers' practice. While each study focused on different aspects of teacher practice, in general, all studies found that coaching had positive impacts. In the study by Race, Ho and Bower (2002), coaches conducted classroom visits with 265 elementary teachers from high-risk schools in the Chicago area and collected data on teacher practice. The researchers reported that as a 
result of coaching, teachers increased their use of best practices in instructional strategies learned in a series of workshops. Teachers' grew in their content knowledge and gained confidence in their competence to teach mathematics and science. Furthermore, as the coaches became less directive, the teachers' growth increased. However, the researchers were not confident in claiming that one event caused the other.

Rudd, Lambert, Satterwhite, and Smith (2009) found that 12 preschool teachers used more mathematics mediated language (MML) when they paired coaching episodes with professional development. Participants completed background surveys and were observed by researchers in their classroom use of MML. After the professional development sessions, all participants' MML increased by 56 percent; after the coaching occurred, their MML increased another 39 percent. Overall, 10 out of 12 teachers significantly increased their use of MML.

In a study focusing on kindergarten teachers' fidelity in implementing direct instruction strategies with exceptional children, Kretlow, Wood, and Cooke (2011) compared teachers' perceptions of the impact of professional development versus the impact of coaching. After teachers participated in three hours of professional development, the researchers conducted coaching sessions with the teachers in order to support each teacher's individual implementation efforts. The teachers audio-taped their lessons so the researchers could listen to the tapes and record teachers' use of the strategies after the professional development and then again after the coaching sessions. Teachers said the professional development was "somewhat helpful" in teaching them the strategies and the coaching was "very helpful" because it provided specific feedback on use of the strategies and improved their facility with them. 
A second study that specifically contrasted teachers' perceptions of the impact of professional development versus the impact of coaching was conducted by Becker and Pence (1999). The authors conducted 210 observations and conducted coaching sessions with teachers over the course of six months. The coaches provided feedback on student teacher interactions and promoted reflective thinking. Becker and Pence reported that the coaching sessions had a positive impact on teachers because the feedback on their instruction and interactions with students supported teachers in changing their practice. In addition, the teachers viewed coaching as a "critical extension of the professional development."

In another high school study, two coaches worked with 12 high school teachers across seven schools implementing the Core Plus Mathematics curriculum (Krupa \& Confrey, 2010). The data in this study included teachers' scores on a test of content knowledge, classroom observations, interviews with both teachers and coaches, and coaches' logs. Krupa and Confrey reported two significant impacts of coaching on teacher practice. First, teachers improved their use of class time the longer they participated in the project. For example, one common problem noted in the first year of the project was teachers' difficulty in finishing the curriculum; they either did not get to the final units of the book or they skipped essential units in the middle. To eradicate this problem, teachers received additional professional development the following summer to support them in pacing the course and managing class time more effectively. On their observational tool, coaches tracked teachers' progress on management of class time following the professional development using a measure called "effective time index." The average effective time index increased the longer the teachers were involved in the 
project. A second impact on teachers was improvement in their content knowledge. In fact, both coaches agreed that this was teachers' most consistent need. As a result of increased focus on content, coaches also tracked the percentage of accuracy in the content of the lessons. The teachers' improved both their accuracy with the content over time and their ability to identify student misconceptions.

Two studies were different from other coaching studies in this category because coaching was one component of a comprehensive school reform effort. Balfanz, MacIver, and Byrnes (2006) studied coaching in three high-poverty schools in Pennsylvania. The comprehensive school reform included a new curriculum, 36 hours of professional development for teachers, coaching, creation of materials to supplement the curriculum, and preparation for an on-site trainer to provide sustainability beyond funding of the reform initiative. After teachers attended summer professional development and Saturday workshops, coaching was provided 1-2 days per week to help support teachers in implementing the new curriculum. The researchers conducted interviews and focus groups with 12 teachers, surveyed students about their teachers' instructional practices, and asked the coaches to evaluate how often and to what extent the teachers used the identified instructional practices. A positive impact on teachers was their ability to implement the new curriculum with moderate fidelity. Furthermore, teachers expressed satisfaction with the curriculum, the professional development, and the intensive coaching.

A second study of whole-school reform that included coaching was a longitudinal study conducted in six urban schools initially with kindergarten to grade 3 teachers and later included grades 4 and 5 (Campbell \& White, 1997). Teachers had grade-level 
summer professional development, an on-site coach during the school year, and common planning time. The combination of these three elements had a generally positive impact on teachers' instructional practice resulting in increased levels of student engagement, use of cooperative learning groups, and teacher questioning. However, Campbell and White reported that 10 to 15 percent of teachers made no change in their practice.

An additional impact on teachers reported in this study was an increased level of confidence with the mathematics content. The coach helped teachers learn to look at student work, interpret its meaning, and plan for future instruction to move students ahead. The coach played a critical role in helping teachers value and understand the mathematics in students' strategies. Observational data showed evidence of teachers shifting from simply taking correct answers to requiring students' explanation of their thinking and then making on-the-spot adjustments in instruction from their interpretation of students' thinking. Additional findings from both of these studies of whole-school reform will be revisited later in the section on student achievement.

Impact on coaches. One study in which coaching was used as follow-up to professional development reported on the impact on the coach (Barrett et al., 2002; Olson \& Barrett, 2004). In particular this study focused on what coaches learned about coaching novice or veteran teachers relative to their beliefs about mathematics instruction.

Two of the researchers coached three first-grade teachers following professional development for implementing a standards-based curriculum. Barrett coached two novice teachers (Barrett et al., 2002) and Olson coached an experienced first-grade teacher with a Masters' degree (Olson \& Barrett, 2004). One coach's reflection suggested that, despite the similarity in the experience level of the two novice teachers, he should have given 
more individualized support for each teacher. They had different systems of beliefs about teaching mathematics, and yet the coach assumed they had similar needs because they were new to the profession. The other coach questioned her use of modeling lessons as an effective strategy for the veteran teacher and chose to attempt a different coaching strategy_-"evoking pedagogical curiosity" (Olson, 2005). This strategy involved asking the teacher "what if" questions during a coaching session to support the teacher in predicting what students might say in response to such a prompt. The coach's goal was to pique the teacher's curiosity about what students might do if they were simply asked. This strategy turned out to be productive as the teacher generated higher order questions and got into deeper discussions focused on mathematics from just "wondering" and decided to pursue those wonderings with students. This kind of reflection and curiosity about students' understanding is a desired outcome of coaching interactions.

Summary. The research on coaching used in conjunction with professional development is not surprising as it supports the research on effective professional development (Darling-Hammond, Wei, Andree, Richardson, \& Orphanos, 2009). Coaching can be effective in implementing new ideas because it provides teachers with long-term support and the sustainability needed to make real changes in the classroom. This outcome was observed in research across grade levels. What may not be as obvious is whether the changes reported in teachers came as a result of the professional development, the coaching support, or a combination of the two. From the teachers' standpoint, this finding was clear in the research. Teachers said coaching made the difference in helping them not only to implement new instructional practices but also to better understand the mathematics. This finding occurred at both the elementary and 
secondary levels and enabled teachers to facilitate instruction more effectively because they could make sense of students' strategies and build on students' thinking. Campbell and White (1997) summarized this phenomena:

If any pattern seems evident it is this. Teachers who are ultimately committed to the learning and understanding of their students will work incredibly hard to understand mathematical content and pedagogy, making every effort to effectively apply these understandings within their instructional decisions...the role of the mathematics specialist in this transformation was critical. Teachers need a means to advocate change, to nurture performance, to advance thinking, to increase mathematical understanding, to salute attempts, and to provoke further development. (p. 348)

The research also indicated that coaches are learning from the process as well. Some of these strategies included using a level of coaching interaction customized to the teacher's experience level, beliefs, and needs.

\section{Coaching and Student Achievement}

Student achievement has been a third focus of the coaching research. All of these studies are connected to five different projects that use coaching as the focus of their professional development.

Project findings. Three studies examined the effect of the Mathematics Coaching Program (MCP) at The Ohio State University on student achievement levels in grades three through eight (Brosnan \& Erchick, 2010; Conaim, 2010; Zollinger et al., 2010). The MCP included coursework and professional development to support coaches' knowledge of mathematics content, research on effective teaching and learning, and leadership skills. 
The MCP coaches interacted daily with four teachers in low-performing urban and rural schools. At six weeks, coaches picked up a new group of four teachers and phased out their interaction with the previous group. The results of all three MCP studies were generally consistent with each other with regard to outcomes and varied only slightly in their focus. Each study is described briefly below.

Brosnan and Erchick (2010) reported significant differences in student means on the Ohio Assessment Test (OAT) at every grade level for teachers supported by MCP coaches when compared with teachers who were not. Furthermore, the percent of students who scored proficient or better on the OAT was higher with MCP coached teachers than students whose teachers were not coached at all. The data reported in this study of MCP coaches were collected after coaches completed four years in the program.

In a second study, Zollinger, Brosnan, Erchick, and Bao (2010) examined scores of students at grades four, five, six, and eight across 18 different schools. In contrast to the previous study, MCP coaches supported the students' teachers after only one year in the program. They reported higher student achievement scores for students of MCP coached teachers on the OAT when compared with teachers not supported by MCP coaches. A third study conducted by Conaim (2010), also reported findings after one year in the program, but from only one grade level. This focused specifically on students' understanding of mathematics across different strands. Researchers from the study examined how $4^{\text {th }}$-grade students of teachers coached by second-year MCP coaches performed in number, algebra, geometry, data, and measurement. His study included 110 students across 11 low-performing urban schools with MCP coaches. He reported that a greater number of students performed "above standard" and fewer students "below 
standard" on all five strands, if their teacher had a MCP coach. The evidence from all three of these MCP studies suggests a link between student achievement and preparation of coaches.

A second project that studied coaching and student achievement was conducted in the state of Virginia. Campbell and Malkus (2011) reported the effects of a large project funded and approved by the Virginia General Assembly and implemented by several universities across the state. The program sought to prepare K-5 mathematics coaches and document their impact not only on student achievement but also on coaches' beliefs and content knowledge. Twenty-four coaches were grouped in two cohorts across five school districts and completed five mathematics content courses and two leadership courses. Thirty-six schools were randomly placed into triplets and randomly assigned either a coach with one year of experience, a coach with two years of experience, or no coach at all.

In schools with a coach, student achievement scores at grade levels three, four, and five were initially not significantly higher on Virginia's Standards of Learning (SOL) Tests. However, they were significantly higher at grades three and five as the coach's years of experience increased. The scores were also significantly higher at grade four when teachers classified their engagement with the coach as 'high' (Campbell \& Malkus, 2009). Within three years, these gains were maintained at grades three, four, and five with schools having a coach (Campbell \& Malkus, 2011). Findings from this study indicated that, in order to impact student achievement, coaches needed experience and sufficient time to interact with teachers. 
Research on a third project, Project IMPACT, conducted a decade earlier by Campbell (1996) obtained a similar finding about the importance of a coach's experience - significant increases in achievement were not realized until the middle of the second year. Campbell's (1996) study of whole school reform was conducted in eight urban elementary schools and reported earlier in this chapter. Similar to the previous whole-school reform project, the project included a new curriculum, coaching, training and new materials for teachers; however, the activities were mandated for all teachers.. After tracking achievement in grades K-3, she found student achievement in the treatment schools' differed significantly by the middle of the second grade. Furthermore, significance was maintained into the third grade. In addition, first-grade students in the treatment schools had higher means on geometry items when compared to students in the control schools.

The fourth project that reported student achievement data is the previously described study by Balfanz, MacIver, and Byrnes (2006). This study examined highpoverty middle schools in Pennsylvania over the course of four years. Not only did they find "moderate to medium level of implementation" of the new curriculum, but they also increased student achievement at every level "in educationally significant ways." The researchers reported "significant and substantial achievement gains across multiple classrooms in multiple schools over multiple years...All types of students benefited from a richer and more demanding curriculum, better trained and supported teachers, and an improved teaching and learning environment" (p. 57). This particular study is important to the coaching literature because comprehensive school reform involves many factors 
that contribute to a school's improvement plan; yet, the authors' data attributed teachers and students' success specifically to the coaching component.

The final study on coaching and student achievement involved a large multidistrict initiative based in California (Foster \& Noyce, 2004). California's Silicon Valley Mathematics Initiative (SVMI) brought 44 coaches and teachers from 30 school districts together to participate in a week of professional development. They developed and scored performance-based assessments to give additional evidence of student learning beyond California's high-stakes testing. They also attended an additional five days of follow-up professional development during the school year. After attending the professional development together, the SVMI coaches provided follow-up support to teachers in their classroom.

Foster and Noyce reported that students in grades 2-7 of teachers who participated in SVMI had higher mean scores on the performance-based assessments than students whose teachers had not participated. Various districts also conducted case studies that confirmed that the students of teachers participating in SVMI's professional development and coaching had better scores on both performance-based tests and highstakes tests when compared with teachers who participated in either the professional development or the coaching. Findings obtained from the research in the SVMI districts were critical because they provided a strong rationale for the SVMI to continue funding their coaching initiative. These studies provided additional evidence that securing funding and garnering support of policy stakeholders is critical to the success of coaching programs (Campbell, 2011) as described earlier in the Virginia project (Campbell \& Malkus, 2009, 2011). 
Summary. The news is encouraging regarding preliminary studies of mathematics coaching and its impact on student achievement in grades $3-8$. However, currently no published coaching studies on student achievement exist at the high school level. Some coaching studies related to student achievement explored students' performance across strands of mathematics or on performance-based assessments. The results were positive as students of teachers who were coached showed gains over students whose teachers were not coached on both high-stakes tests and performancebased assessments. In a few cases, the positive student achievement results were cited as critical to a school district's rationale for continued funding of their coaching program.

Campbell's findings send a clear message about the importance of a coach's mathematical background and beliefs as well as prior coursework and coaching experience if coaching is to impact student achievement. The presence of a coach with no experience did not translate into gains in student achievement; instead a combination of courses in mathematics content, effective forms of instruction, and leadership, ongoing professional development as well as the on-the-job training gained after at least a year of experience and at times a higher level of engagement with the teacher were related to student achievement. Campbell recommended that the findings in her research should not be generalized to all coaches. Furthermore, she suggested that future qualitative research on mathematics coaching should describe what coaches do and how their backgrounds affect their choices in coaching.

\section{Concluding Remarks}

A further discussion on the work of coaches and credentials and knowledge needed to serve in the role of a coach is warranted. The Campbell study (2007) described 
earlier examined the impact on coaches after completing a regimen of courses in mathematics content, leadership, and learning of mathematics. After the coaches' first year, Campbell reported their mathematical content knowledge significantly increased from pre-test to post-test over the span of five courses while measures of pedagogical content knowledge took two years to reach significance. Furthermore, coaches' beliefs in reform practices increased significantly, but not within the first year of coaching. These findings suggest that the intentional preparation of coaches can make a big difference in their impact on teacher performance and effectiveness.

The recently released Standards for Elementary Mathematics Specialists (Association of Mathematics Teacher Educators, 2010) suggest that the mathematics education community provide guidance regarding the preparation and skills needed for coaches and build some consistency in the coaching field (Obara, 2010). The standards describe expectations for states and institutions of higher education interested in creating a specialist license or degree program for mathematics coaches. Hopefully, this document will generate more interest in conducting research on mathematics coaching as it is desperately needed to enhance understanding of coaching and its effectiveness.

Coaching has been widely implemented across the United States. Unfortunately, research on the effectiveness of mathematics coaching is just beginning to guide districts, but many questions remain. The studies reported in this chapter offer a positive picture of the effectiveness of mathematics coaching. However, much more research is needed (National Mathematics Advisory Panel, 2008). Gibbons, Garrison, and Cobb (2010) point out that it is critical to understand the coaching interactions that actually support teachers 
in changing their practice. The proposed study will enhance the knowledge that we have on coach and teacher interactions and their impact on teacher practice. 


\section{CHAPTER III}

The purpose of this study was to describe the interactions between a coach, university faculty, and high school mathematics teachers and the impact of those interactions on their practice. This study extended the data collected from a three-year mathematics project in which teachers received extensive professional development on mathematics content and pedagogy in addition to coaching.

\section{Chapter Organization}

The chapter is organized into five sections: (1) an overview of the project that generated the majority of the data collected and analyzed for this study, (2) a description of the participants from the project, (3) an overview of the data collection describing the secondary data as well as the primary data collected as it aligns with the research questions, (4) each of these data sources is described in more detail for both the secondary and primary data, and (5) the plan for data analysis is presented for both the quantitative data and qualitative data.

As a former mathematics coach, my interests led me to study coaching at the high school level in North Carolina. I discovered an opportunity to extend the research efforts of a mathematics-science partnership involving a high school mathematics coach and a local university in a neighboring district. The project was well under way with approximately eighteen months of data already collected for the three-year project. The goals, evaluation plan, and recruitment of teachers for the project had taken place long before I learned of its existence. I had worked with the district and some of the project 
personnel in previous grants and hoped I might have opportunity to work with them. When I proposed the study to the school district leadership, they were interested in my research, which would examine more closely the role of the project's coach and subsequent impact on teachers because this was not an initial focus of the project. The next section provides context for what became the focus of my study.

\section{Overview of MAST}

Math Achievement Success Today (MAST) was a three-year high school mathematics partnership between a local school district and nearby university and funded by the US Department of Education. The goals of MAST were: (a) to increase teacher content knowledge in mathematics, (b) to increase student achievement in mathematics, (c) to improve classroom instruction, and (d) to create a sustainable partnership between the institution of higher education and the participating school district. A number of people worked together to accomplish the goals of MAST including three university faculty, a mathematics coach, a project director, an external evaluation team, and the classroom teacher participants.

Similar to other whole school reform studies, many activities in MAST involved different people giving support to each other. Teachers attended content courses that university faculty developed and taught. The university faculty responsible for codeveloping and co-teaching the content courses included two mathematics educators and one mathematician. The coach had a secondary role facilitating instruction for the content courses. The coach's primary responsibilities were leading the follow-up professional development during the year, facilitating lesson study groups, and providing classroom coaching during the school year. The university faculty did not participate in any of these 
project activities during the school year. The coach in this study had served as the district's high school mathematics coach since January 2008. The school system agreed to allow her to commit to the goals of MAST while continuing her role as high school mathematics coach across the district. The project director worked for the school district, coordinated the project activities with all its stakeholders, managed the budget, and prepared reports for state and federal agencies. Finally the external evaluation team was responsible for managing the project's data collection, conducting the data analysis, and submitting data summaries to the project director for the annual reports.

\section{Participants}

The participants of the study were the high school mathematics coach, the three university faculty, and mathematics teachers participating in MAST. Thirty-five teachers and two administrators volunteered to participate in the first summer content course of MAST. Some of the participants from the first year chose not to continue with the project; additional teachers joined the project for the second year for a total of twentyfour teachers and three administrators. The third year of the project also saw some change in participants with 34 teachers. Teacher attrition in MAST was the result of retirement, moving out of the district, or leaving the profession. Over the course of the project, nine teachers participated all three years. The majority of participants were high school teachers, but eighth grade teachers were also invited to participate. Approximately onethird of the high school mathematics teachers in the district were new to their school or new to teaching.

All teacher participants were employed in a single school district in southeastern North Carolina across 14 different schools. The district included five public high schools, 
five public middle schools, two private middle schools, one private alternative high school, and one charter middle school. The project paid teachers a stipend each year for their participation in the summer content course and two lesson studies during the school year.

\section{Summary of Data Collection}

Two timelines for data collection were implemented. Staff in the existing MAST project had been collected data since June 2009 and continued their planned evaluation of the project through July 2012. I received approval from the district in January 2012 to collect additional data (beyond the original project proposal). Once I received permission from the university Institutional Review Board, the timeline for my data collection was October 2012 through December 2012.

I chose a mixed methods design because of the variety of existing longitudinal data available from the project. The external evaluation team collected three years of quantitative and qualitative data from the MAST teacher participants and interview data from university faculty and the coach. The timeline of this study occurred at the project's end, suggesting additional qualitative data had the potential to enhance and support the existing data measures collected.

The data already collected for the MAST project were intended to evaluate the effectiveness of the entire project. These data included the content course evaluation led by university faculty and supported by the coach, as well as the lesson study groups and classroom coaching facilitated by the coach. The focus of the study was to examine the coach's work with teachers and university faculty and her impact as reflected in the 
research questions. I used eight sources from the MAST project deemed pertinent to addressing the research questions in this study (see Table 1):

1. What was the nature of the coach's interactions with secondary teachers and university faculty during the MAST project?

2. What was the impact of the coach's interactions during the MAST project?

a. To what extent did secondary teacher practice change?

b. To what extent did university faculty practice change?

\section{Table 1}

Alignment of Data Sources to Research Questions

\begin{tabular}{l|c|c}
\hline \multicolumn{3}{c}{ MAST Secondary Data Collection } \\
\hline Data Source & $\begin{array}{l}\text { How does the } \\
\text { coach interact with } \\
\text { teachers? (RQ1) }\end{array}$ & $\begin{array}{l}\text { What is the impact } \\
\text { of the coach's } \\
\text { interactions? (RQ2) }\end{array}$ \\
\hline Coach's Log & $\bullet$ & $\bullet$ \\
\hline End-of-Year Survey & $\bullet$ & $\bullet$ \\
\hline Coach Interview & $\bullet$ & $\bullet$ \\
\hline University Faculty Interviews & $\bullet$ & $\bullet$ \\
\hline Lesson Study Post Conference & $\bullet$ & $\bullet$ \\
\hline Document Review of Duties & \multicolumn{1}{|c}{} \\
\hline RTOP & \multicolumn{1}{c}{$\bullet$} & $\begin{array}{l}\text { What is the impact } \\
\text { of the coach's } \\
\text { interactions? (RQ2) }\end{array}$ \\
\hline Focus Group & $\begin{array}{l}\text { How does the } \\
\text { coach interact with } \\
\text { teachers? (RQ1) }\end{array}$ \\
\hline Drimary & Data Collection & $\bullet$ \\
\hline Coach Interview & \multicolumn{1}{c}{$\bullet$} \\
\hline Faculty Interviews & \multicolumn{1}{c}{$\bullet$}
\end{tabular}

Six sources of secondary data from MAST contributed to answering the first research question about the coach's interactions with teachers. One of these was a log of the coach's school year activities. A second source of secondary data was an end-of-year 
survey completed by the teacher participants to evaluate the coaching and lesson study components of the project. Third and fourth sources of secondary data were interviews conducted with university faculty and the coach. A fifth source of secondary data that answered the first research question was audiotapes of teachers and the coach participating in lesson study post conferences. A sixth and final source of data was a document review with a list of the coach's responsibilities within the MAST project. Except for the coach's log and the document review, all of these secondary data sources also contributed to answering the second research question.

Two additional sources of secondary data from MAST answered the second research question about the coach's impact. One of these was classroom observations of teachers in the project using the Reformed Teaching Observation Protocol (Piburn et al., 2000). Finally a second source of secondary data for the second research question was focus group interviews conducted with teacher participants.

Finally I collected primary data to supplement these eight existing data sources already collected by the project. These data included follow-up interviews with the coach and the university faculty to further probe the information gleaned during their first interviews.

\section{Data Sources}

This section provides more detail about each of the eight data sources. The detail includes: (a) who took the instrument, (b) what purpose it served, (c) when and how often it was administered, and (d) which research question it addressed. To remind the reader of which research question was aligned with each data source, it is indicated by the 
parenthetical reference in each subheading. RQ1 refers to research question 1 and RQ2 refers to research question 2 .

\section{Coach's Log (RQ1)}

The instructional coach logged her activities for the MAST Project during the three years in the North Carolina Math-Science Partnership (NCMSP) database, made available by the state department. In the database, the coach recorded the type of activity (i.e. individual coaching, workshop, etc.), the duration of the activity, and the number of participants involved in the activity. The database is hosted by the NCMSP site and was accessible by project personnel to help with annual and interim reports. The information in the log addressed the first research question by providing a list of the coach's key activities, the number of teachers involved in that activity, and its duration.

\section{End-of-Year Survey (RQ1, RQ2)}

All MAST teachers completed an end-of-year survey in the spring of each school year. The survey included both Likert-scale items and open-ended items primarily rating the effectiveness of the coaching and the lesson study components of the project. The items on the end-of-year surveys addressed both research questions (See Appendix A). For instance, on the 2012 survey, items 12 and 13 described ways in which the coach interacted with the teacher and the focus of those interactions. On the other hand, items $10,11,14,15$ and 16 provided information about the coach and her impact in working with teachers.

\section{University Faculty Interviews (RQ1, RQ2)}

A member of the project's external evaluation team interviewed the university faculty responsible for developing and leading the summer content courses. Both 
interviews occurred within six months of completing the content courses (December 2009 and November 2010). Both of these interviews were transcribed for analysis. A number of questions were contained in both interviews but only a few addressed the research questions of this study. Some of the questions pertinent to this study included a description of the university faculty members' relationship with the coach and the role she played during the content courses.

I conducted follow-up interviews with the university faculty to probe more about the role of the coach (see Appendix C). In the transcripts, the university faculty spoke highly of the coach's comments and interjections during the content course in "leading class to the right kinds of questions." My intent in the interviews was to explore the university faculty's perspective on the coach's contributions to the content courses (how it was different from their own) and its subsequent impact on the teachers. The interviews took less than an hour and were audio taped. These data provided information for the first and second research questions.

\section{Coach Interview (RQ1, RQ2)}

A member of the project evaluation team interviewed the coach in December 2009, which was six months after the first content course and midway through the first academic year of the project. The focus of questions included descriptions of the coach's role, philosophy of coaching, relationship with teachers in the project, frequency of interaction with them, experience in conducting the RTOP observations, description of the lesson study meetings and perception of their progress, description of the relationship between the teachers and university faculty, descriptions of major areas of success for MAST, and descriptions of areas of improvement for MAST. The coach's responses to 
the interview prompts addressed both the way in which she interacted with teachers as well her perception of her impact on teachers.

I conducted a follow up interview with the coach (see Appendix D) at the conclusion of the MAST project in summer 2012. Some questions from the previous interview were included in the follow-up interview to see what changes, if any, occurred. Other prompts were intended to corroborate (or refute) data already collected from the teachers. For example, item 15 of the end-of-year teacher survey (Appendix B) asked teachers what benefits they received from coaching; therefore, interview prompt 14 from the coach's interview (Appendix D) asked for the coach's perspective on teacher benefits. Item 16 on the end-of-year teacher survey asked what changes teachers have implemented in the classroom as a result of coaching, and interview prompt 13 from the coach's interview asks the coach the same question. This prompt may also provide additional evidence related to the RTOP scores on teachers' instructional changes. The interview lasted approximately one hour and was audio taped. The data from the pre- and post-interviews addressed both research questions in the study.

\section{Lesson Study Post Conferences (RQ1)}

In the spring of the final year of MAST, the coach audiotaped some of the post conferences between herself and the lesson study groups. She did this with approximately five different groups. The conferences took place after one person had taught the lesson, the group revised the lesson, and then a second person taught the revised lesson. The coach facilitated conversations with the teachers about what they learned about their students' learning from the lesson study process. I transcribed and used these data to see 
how the coach and teachers interacted with one another during coaching sessions (first research question).

\section{RTOP (RQ2)}

The coach conducted classroom observations of the participants using the Reformed Teaching Observation Protocol (RTOP) (Piburn et al., 2000). The RTOP is an observation tool for documenting evidence during a mathematics lesson to assess the teacher on five main categories (see Appendix E). The five categories were: (a) lesson design and implementation, (b) propositional content knowledge, (c) procedural content knowledge, (d) classroom culture via communicative interactions, and (e) student/teacher relationships. Five statements under each of the five headings were rated from 0 (never

occurred) to 4 (very descriptive). The ratings were combined to give the teachers a total score out of 100 possible points. An increase in the total score indicated a change in teachers' instruction toward more reform-based teaching practices.

The coach observed all teacher participants during the fall of each year of the project. The change in scores of the nine participants who participated in all three years of the project addressed the second research question of impact on teachers, particularly their instructional practice.

\section{Document Review (RQ2)}

A document titled Some MAST Project Coach Responsibilities (see Appendix F) delineated a list of duties the coach carried out for the project. Some interview prompts for the coach are provided to give context to this document (see items 6 and 7 of Appendix D). Data from this document answered the first research question. 


\section{Focus Group with Teachers (RQ2)}

A member of the project evaluation team conducted a short focus group with all teachers that attended the final year-end lesson study celebration. In the focus group, the evaluator asked teachers in what ways they had benefited from their interactions with the coach. The evaluation team audiotaped and transcribed this session, which provided evidence for the second research question on the coach's impact.

\section{Data Analysis}

A triangulation mixed-methods design (Creswell, 2008b) was employed given the combination of quantitative and qualitative data available for analysis. In a triangulation mixed-methods design, both types of measures are collected at the same time with no particular priority given to the timeline under which each occurs. Then the data in each type are analyzed individually and compared with each other for verification or contradiction of the findings. This choice was appropriate for this study because the data sources: (a) spanned a three-year time period, and (b) were both secondary and primary. By using both quantitative and qualitative data, the weaknesses of one type of data type can be minimized by the strength of the other type of data, providing a more complete examination of the outcomes and process in the study.

\section{Quantitative Data}

In this section, I described the analysis of all data sources, organized according to its type - quantitative first, then qualitative. The quantitative data for this study included the coach's log, the Likert-scale items on the end-of-year surveys, and the RTOP scores.

Coach's log (RQ1). The coach's log provided information about the various activities in which the coach engaged with the teachers. The log required a description of 
the meeting or activity, the number of teachers involved, and the contact hours for each activity. The log revealed that the coach interacted with teachers in fairly predictable ways that summarized the bulk of her daily work (Campbell, 2007). The coding of these categories is described in the next section under analysis of the qualitative data.

Descriptive statistics are appropriate to give the total number of contact hours for each activity by year and the relative frequency of each category. There was little variability among the number of teachers and number of hours, as limited by daily school schedules and times the coach was able to meet with teachers (and vice versa). Excel was used to compute the descriptive statistics and all subsequent quantitative data described in this section.

End-of-year survey (RQ1, RQ2). The survey completed by teachers in the late spring of each year contained Likert- scale items with statements about the coaching and lesson study aspects of the project (see Appendix A and B). Teachers rated their agreement with the given statements on a scale from 1 (strongly disagree) to 6 (strongly agree). Means, standard deviations, and relative frequency of teachers' ratings on the items that were particularly relevant to answering the second research question of the coach's impact were computed.

RTOP (RQ2). As a means of determining the project's impact on teachers' instruction, the coach observed teachers using the Reformed Teaching Observation Protocol (or RTOP). The RTOP was selected because it measures the extent to which reform-based teaching is present in a mathematics class. The RTOP total score is deemed reliable according to Cronbach's alpha measured at $\alpha=0.97$ (Sawada et al., 2002). It is 
also reasonably high for each of the five subscales ranging from $\alpha=0.80$ on propositional content knowledge to $\alpha=0.93$ on procedural content knowledge.

Teachers can score a maximum of 4 points (very descriptive) and a minimum of 0 points (never occurred) on each of 25 items for a total possible score of 100. Descriptive statistics with each teacher's total score, then an overall mean score and standard deviation, and finally subscale means and standard deviations were computed.

The baseline RTOP score from fall 2009 was compared to the score from spring 2012. A one-tailed t-test was conducted to see if the overall mean in 2012 was significantly greater than the overall baseline mean at an alpha level of 0.05 .

Additionally, it was feasible to consider the five individual subscales within the 25 items to see which, if any, of these means were significantly higher at the 0.05 significance level. Recall the five subscales are: lesson design and implementation, propositional content knowledge, procedural content knowledge, classroom culture via communicative interactions, and classroom culture on student-teacher relationships.

\section{Qualitative Data}

In this section, I outline the analysis of the qualitative data in this study. There four qualitative data sources in this study were: (a) interviews and focus groups with university faculty, coach, and teachers; (b) observation of coach and teachers, (c) document review of Some MAST Project Coach Responsibilities, and (d) open-ended items from the end-of-year survey. Each of these data sources went through a similar process of data analysis as outlined in the next section.

In a triangulation mixed methods design, one strategy for analyzing the data is to look for comparisons between the quantitative and qualitative data to see if the outcomes 
of one support or contradict the other (Creswell, 2008b). This strategy was particularly appropriate with this study since both types of data were available to answer both research questions. I described apparent themes from the qualitative data and how they aligned (or misaligned) with the statistics (and vice versa). The qualitative data provided further insights into the findings.

Analyzing qualitative data is an iterative process that generally includes collecting the data, transcribing the data, reading through the data multiple times, and developing codes that emerge from the data (Creswell, 2008a). In this study, I began with an initial read-through, making notes particularly where the data seemed to address the research questions. In the second read-through, I used initial notes and new notes to begin identifying patterns across data sources for coding, possibly low-level coding at a minimum to provide a starting point. The process of coding is "segmenting and labeling text to form descriptions and broad themes in the data" (p. 251). Subsequent readthroughs refined the codes at each iteration, identified the emerging themes and noted discrepancies or glaring omissions from the data. After grouping related or redundant codes, I reduced all the codes down to seven themes, making it possible to give the reader more detail on the most important themes as opposed to less detail on many themes. This strategy is an important strength of qualitative research not possible with quantitative research. On the other hand, some limitations inherent with qualitative research must be addressed directly.

When conducting qualitative research, the researcher becomes the instrument, creating concerns of researcher bias. Therefore particular attention must be given to: (a) verifying the data through methods of triangulation, (b) convincing the reader that the 
data are reliable, and (c) establishing the credibility of the researcher. The final section of the chapter addresses these methods for verification and trustworthiness of qualitative data.

Triangulation. Triangulation employs systematic procedures to validate research data rather than relying on the researcher's best intentions (Stake, 1995). Triangulation is critical for verifying the data collection techniques, credibility, and generalizability of the data. It provides assurance that the researcher has followed accepted procedures to guard against bias in reporting and interpreting the data. This guard occurred in three distinct ways during the study.

First, I used multiple data sources including surveys, observations, interviews, and document review (Table 1). Second, I included three different voices (faculty, coach, and teacher) from the data to give their perspectives on coaching and its impact. Finally, the use of different data types and multiple data collection points for the end-of-year surveys (two times) and the interviews (two times) support the reliability of the data.

Reliability. The ability to compare participants' responses over time increased my chances of recognizing inconsistencies between and among the data sources. Each method of data collection had the potential for bringing bias into the research process. Observations provided a visual snapshot into participants' lives. Interviews and surveys gave participants a chance to tell their story, as shaped by the researcher's questions and manner in which they are posed. Each of these data sources gave both the participant and the researcher opportunity to introduce bias.

The participants could introduce bias in how they choose to portray themselves in three different ways: visually through observation; verbally through interviews; and in 
writing through their presentations. The researcher can introduce bias in developing and implementing the methodology protocol. Expectation bias is also possible if the researcher views the participants' response according to how he or she expects them to respond (Black, Little, McCoach, Purcell, \& Siegle, 2008)

I used multiple data sources and various data collection points for the end of year surveys (two times) and the interviews (two times) to control for and recognize inconsistencies within and across methods. Additionally, the use of two data sources (coach and teacher) for each type of data collection provided differing perspectives on the coaching relationship to prevent the voice of one source from overpowering the voice of the other source.

Researcher credibility and reflexivity. Patton (2002) described the importance of researcher credibility as it determines how others view our research. He said:

...Because the researcher is the instrument in qualitative inquiry, a qualitative report should include some information about the researcher. What experience, training, and perspectives does the researcher bring to the field...what prior knowledge did the researcher bring to the research topic and study site? (p. 566) I engaged in personal and epistemological reflexivity by answering Patton's questions.

I bring a broad range of experiences and personal values to my work as a researcher. I am a specialist of mathematics, a teacher, a professional developer, and a coach. With those experiences I have formed opinions and values about mathematics education. I have specialized in mathematics and leaned toward certain branches of mathematics (like geometry) more than others in my previous research. The participants in my study were secondary mathematics teachers and likely specialists too; yet I still 
remained aware of the contextual differences in their interests and background and how those factors shaped their choices and responses. Also, I have strong opinions about teaching mathematics and coaching that could possibly influence me as I interview my participants and analyze their responses. My own experience in coaching motivated this study so it has certainly shaped my research agenda. These experiences color my view of coaching and its impact on teachers. I am predisposed to using particular strategies from my prior experiences in coaching.

According to Patton (2002), the best strategy to keep these biases and assumptions in check is to engage in reflexivity throughout the research process-while collecting the data, conducting the analysis, writing up the results, and offering implications. Reflexivity is not just reflection but more "deliberate self-scrutiny" (Hellawell, 2006). Therefore, during the data collection process I remained highly conscious of how I presented myself to others and how this affected my participants' responses (Patton, 2002). Understanding my participants' context and background was part of the research. I attempted to see this and represent it accurately to others. During analysis and reporting, I was cognizant that my interpretation of the data was only one interpretation, and it is no more significant than another's interpretation (Creswell, 2008a). My results included descriptions of my experiences and biases so the reader might understand my interpretations in the research. Also, I identified my conclusions as a beginning point subject to others' viewpoints and consideration. Finally, in offering implications, I generated more questions for consideration, and invited others to give their perspective. 
Triangulation, reliability, and researcher credibility as methods of verification are critical to validating the trustworthiness of qualitative research. Paying attention to these methods was essential, not only throughout the data collection, but also throughout the data analysis and interpretation of my results. These results are the focus of the next chapter. 


\section{CHAPTER IV}

This chapter presents findings from a study whose purpose was to describe how high school mathematics teachers interacted with a mathematics coach during the MAST project and the subsequent impact of those interactions. MAST was a three-year partnership between a school district and an institution of higher education. The participants included some middle school but mostly high school mathematics teachers who took three content courses in the summer led by university faculty and the coach. During the school year, the teachers participated in lesson study groups and classroom coaching facilitated by the high school mathematics coach.

I conducted a mixed-methods study utilizing data collected by MAST's external evaluation team as well as data that I collected myself to answer two research questions:

1. What was the nature of the coach's interactions with secondary teachers and university faculty during the MAST project?

2. What was the impact of the coach's interactions during the MAST project?

a. To what extent did secondary teacher practice change?

b. To what extent did university faculty practice change?

I organized my findings by research question first then from the three different voices in the data: (a) the university faculty, (b) the teachers, and (c) the coach. Then within each of those voices I presented each of their data sources, if there was more than one. 


\section{Research Question 1}

For the first research question, I present data from the three university faculty interviews. Second, I share the teachers' responses to two years of survey data. Third, I report the bulk of data provided by the coach from three different data sources. These came from the coach's log, a document she drafted listing her responsibilities, and finally a pre- and post -interview. Finally, I share the analysis of the post conference audio data that involved both the coach and the teachers.

\section{University Faculty}

Two university faculty, Thomas and Donna, were interviewed after each of the content courses by the external evaluators for the project. These two university faculty co-developed and co-taught the first two content courses, Algebraic Reasoning and Geometry/Data \& Measurement with the coach. They split up the five-day course, one teaching two days and the other teaching three days, while the coach taught all five days. One new university faculty member, Meg, was brought in the last year to help co-develop and co-teach the final course, Math Applications. Teaching responsibilities were again split between her and another university faculty member, in which Donna taught the first three days, Meg taught the last two days, and the coach taught all five of the days. All three faculty members were employed at the same university. Thomas is a mathematics professor and Donna and Meg are mathematics education professors teaching within a mathematics department.

I conducted a focus group interview (see Appendix C) after the last course offering in December 2012 with all three university faculty who participated in the content course development and delivery with the coach. My goal in interviewing the 
university faculty was to gain their perspective on how the coach interacted with them and with the teachers during the content course work. In general, the university faculty responded that they had limited knowledge of the coach's interactions with teachers unless that interaction took place in a whole group setting.

Two of the university faculty, Donna and Thomas, indicated why their knowledge of the coach's one-on-one interaction with teachers was limited. Donna explained, "It's hard for me to know how she interacted with some of the groups because I was interacting with the groups simultaneously." Thomas corroborated this statement but also suggested that their interaction with teachers was somewhat isolated. Since they were the content course instructors, this initially seemed like a peculiar statement to me. However he explained it in this way:

Our workshops were designed for the teachers to resolve things on their own. And so we left them alone quite a bit. And most of the interaction that took place was isolated here and a little bit there. Actually we interacted more with each other in trying to figure out what was going on at each table and sharing information about what have you heard. 'Look at what the people did at that table. Those had a really good idea.' So we were really more interacting with each other than we were actually interacting with the teachers.

And so it is understandable why the university faculty felt they could not speak to direct interactions between the coach and teachers when they were interacting in small groups. However, they were able to provide some insight into (a) interactions between themselves, the teachers and the coach during whole-group settings of the course; and (b) their personal interactions with the coach during the course planning and course delivery.

\section{Whole Group Interactions}

Two ideas permeated their descriptions of the coach's interactions with teachers during the content course work. First they described the coach's rapport and strong 
connection to the classroom as an important contribution. Secondly, this rapport allowed the coach to "chime in" during the group discussions during the course. I describe both of these in more detail below using data collected in the initial and final interviews with the university faculty.

Personal rapport and classroom connection. The coach's personal rapport with the teachers provided an important context to understand the relationship among the university faculty, the coach, and the teachers in the course settings. In general, the university faculty indicated their work with the teachers was brief, not allowing time for them to build rapport with the teachers; however, they did talk about having a relationship with the coach beyond teaching the course together.

In the first interview with evaluators in December 2009, Thomas and Donna were asked about their relationship with the teachers and the coach and if it extended beyond the course. Thomas said:

I have not had contact with the teachers beyond the instruction of the course. I have had lots of contact with the [coach]... in fact she is one of my students and she is in one of my courses because she is getting a Masters' degree. I talk with her quite a bit, not only within...the MAST grant, but also outside in the context of the curriculum at the college level.

Donna said:

I worked with teachers for 2 days so there wasn't a lot of time to build a collaborative relationship with the teachers...my relationship with the coach has extended beyond the course... about the project and about her goals...beyond what we were doing to plan for the workshop. In particular, we have talked about some of the teachers' lesson study experiences. We are making a strong effort to bridge the content the teachers are learning in the workshop with the lesson study activities the teachers are doing in the classrooms.

In the final interview, a third faculty member Meg also brought out the coach's rapport and its significance to the course. Meg said the coach: 
...definitely had that personal rapport with the individual teachers and I think she could talk; she could say what each teacher taught. And that was something that I worked with them for two days. I was lucky when I got half the group's name before the end. And that was I felt like a strong asset in the room...she came in and provided that bridge that I didn't have and wasn't going to have the opportunity to build.

Looking across these statements it appears that all three university faculty members were dependent on the coach's personal rapport and her connection to the classroom because they were unable to establish this in the short time they spent with teachers. This context is important to note in lieu of the second theme observed in the faculty's comments about the coach's interactions with teachers. They repeatedly described her "chiming in" during whole group discussions with the teachers.

"Chiming in." All three of the university faculty cited the coach's "chiming in" to bring out the pedagogical discussion or recall the strategies that teachers were using at their tables. Thomas explained that the coach "would take a definite lead in bringing out the discussion, deciding how to best get teachers to collaborate... asking the leading questions to find out what they had learned." He had previously made statements in his initial interview describing how the coach would chime in and lead the class to the "right kinds of questions." I asked him in the final interview what he meant by that. He said:

The right kinds of questions to me are the questions that reflect or lead to a conceptual understanding of the material rather than a procedural aspect of the material. And so, the questions that show that a particular problem can be viewed, for example, from different perspectives and yield solutions from different perspectives is a good kind of question. A question that says, that just pertains to a procedural thing is a good question but it is not as important a question for me. 'How do you factor this?' Okay that is a question but not as important as a question, 'Why am I factoring this?' or 'If I'm factoring this, what relevance does it have to the problem?' or 'How do I represent this factorization in terms of a conceptual idea?'... So things that read through the conceptual understanding of the problem rather than procedural things. 
Donna described the coach chiming in: "When she made pedagogy statements or when she made math statements, they were always connected to what the teachers were doing actually in their classroom." In response to how the coach interacted with teachers directly, two of the faculty had this exchange describing an important contribution from the coach's interjections:

Donna: ... whenever we did have a bigger group discussions, say if I was leading it and a particular group of teachers were sharing out their solutions [the coach] might chime in and say 'I noticed this group in the back did it this way. Do you guys want to share?'

Meg: She was really good about that.

Donna: Because she may have had access to knowing what that group was doing when maybe that's not an idea I had or maybe I didn't even notice it.

Meg: Yeah she was really good at pulling, at remembering what was going on in the different places in the room. I do, now that you say that, I do remember her doing that a couple of times and being like, 'Excellent'.

This exchange of dialogue indicated that the coach's interjections brought in additional participant strategies and helped to generate more group discussion and engagement in the course. One other idea that came up related to the coach's "chiming in" was the timing of that interjection and whether it was appropriate or not.

Timing. The university faculty had some differences of opinion when they talked about the timing of the coach's interjections. Donna said:

Some of the interjections came too early in a discussion or it was almost like an antsy feeling of, you know, not letting the teachers struggle enough before the interjection. Because you could see her getting nervous that something wasn't going to happen...but that's what happens when you collaborate with somebody. You always have that, like you don't always know exactly where that person's going or how much that person is going to allow a struggle...

Meg followed up to say, "Fortunately I didn't have any of that because she wasn't as familiar with the stuff I was doing...I didn't get as much of the...interjecting too soon 
because she just really wasn't as familiar with the stuff I was doing." Finally Thomas concluded:

My experience in that regard was fairly seamless. I don't know how it happened but we had a really good chemistry. And she felt absolutely comfortable to say something when it was appropriate. And I have no feeling that anything was done out of line...we did have good teaching moments. I thought it worked really well.

So there was some disagreement about whether the coach's "chiming in" was always timed appropriately. One said her timing was too early while the other two never observed any problems with the coach's timing. I postpone my own thoughts about this difference in opinion for chapter five. I now shift to describing how the coach and university faculty members interacted with each other in both the delivery of the course and the planning stages.

\section{One-on-One Interactions}

Course delivery. Donna provided a summary of what the coach and university

faculty were doing while teachers were working on problems. She said:

Both her and I would walk around from different groups. I didn't have access to some of her conversations with groups, but in the end, we would come back and share sort of what we figured out they were doing and if we were surprised by something. 'Oh this group solved it this way. We didn't expect them to solve it this way.' Or 'This one's struggling' or 'The $6^{\text {th }}$-grade teacher is struggling' or 'The calculus teacher is bored.' Those kinds of conversations that you would have.

Thomas agreed with her summary and gave some additional insight into his previous comment about interacting more with the coach than with the teachers. In response to

Donna he said:

Yeah, and that was actually useful because then when we wanted to share information then we could actually select across the sequence that made sense. 'These teachers did this problem this way.' 'These teachers did a different way, but they piggybacked on the same kind of idea.'... and so we shared that 
information before while the teachers were working and used that as a way to bring up the discussion.

So their interaction was focused on understanding what the teachers were doing in their individual groups. And in the case of Thomas, he and the coach utilized that knowledge to prepare for the whole group discussions that were about to take place. Finally, I was able to learn from the university faculty how they interacted with the coach during the planning stages of the course.

Course planning. In the second interview with evaluators in November 2010, Thomas and Donna described their work with the coach in planning for the geometry course. This interaction did not involve teachers directly but what the coach contributed in the planning process involved the teachers indirectly. Donna explained that the coach "plays a big part in deciding what we do because she has a lot of knowledge of the experience the teachers have in the classroom, some of the struggles they have, she's observing lessons and talking to them regularly."

Thomas echoed this idea in the final interview saying, "the assumption was that since [the coach] was more connected with the teachers, she had a better idea of what were the actual needs with regards to the new curriculum. And so she identified a number of topics that would be of importance." Once they had identified specific topics of need, this led them to identify or suggest a task or activity focused on that topic.

Meg followed up to explain that the final course, which she helped teach, was developed from scratch whereas the other two courses were developed and used in a previous project in which [the coach] participated. So on the last course, what the coach "provided was probably more on the topic level and not specifically as much on the 
activity level." This distinction is important to know in understanding a comment made by Donna about the kind of input the coach provided. Donna stated:

While we still planned the nitty gritty of it as far as the content, the earlier courses she would say things such as 'this was a really important problem that I worked on. I think this would be good.' And she would identify things that she did....and that she remembered and thought were really good tasks to use. Whereas that didn't happen in the last course.

Based on data gathered from the university faculty, the coach's primary role and contribution in planning the course was helping determine the topics and focus of the course based on the teachers' needs. But she also used her prior knowledge of doing the tasks as a participant in previous offerings of the course and was able to recommend particularly good tasks that helped her as a teacher and that she had been able to use in her own classroom. This additional evidence supports their earlier statements regarding the value of the coach's personal rapport with teachers and strong connection to the classroom.

\section{Teachers}

The teachers provided a second voice in answering the first research question. This data came from surveys that the MAST staff posed at the end of each school year.

Teachers provided three years of survey data; however, the first year's data were erroneously exported by MAST staff without the names. Therefore, I was not able to get the appropriate consent to use that year's data. I analyzed the data the teachers provided after the second and third year of the project (see Appendix A and B). I found three items from the surveys that related directly to teachers' interactions with the coach. One item came from the 2011 survey where 12 participants responded. The other two items came 
from the 2012 survey where eight participants responded. I obtained 100\% consent from those participants that responded in 2011 and 2012.

The Likert scale items were scored on a 6-point scale: strongly disagree, disagree, mildly disagree, mildly agree, agree, and strongly agree. Responses of strongly disagree received a score of 1 and responses of strongly agree received a score of 6 . I computed the means and standard deviations of those scores in addition to the relative frequency of responses among the participants. The survey year, survey item, number of respondents, means and standard deviations are shown in Table 2.

\section{Table 2}

MAST Survey Likert Items (Interactions)

\begin{tabular}{llccc} 
Year & Survey Item & $n$ & $M$ & $S D$ \\
\hline 2011 & $\begin{array}{l}\text { The coaching focuses on how to effectively } \\
\text { teach math concepts. }\end{array}$ & 12 & 5.42 & 0.51 \\
2012 & $\begin{array}{l}\text { The dialogue focused on teaching and } \\
\text { mathematical concepts. }\end{array}$ & 8 & 5.88 & 0.35 \\
2012 & I had regular dialogue with the coach. & 8 & 5.63 & 0.74 \\
\hline
\end{tabular}

The only survey item from 2011 that related to the first research question indicated that 100 percent of teachers agreed or strongly agreed that the focus of their interaction with the coach was on effective teaching of mathematics concepts. There was a slight change in teachers' perceptions of the focus of their dialogue with the coach in the third year. The score on this item increased from a mean of 5.42 in 2011 to a mean of 5.88 in 2012 because 88 percent of teachers strongly agreed with this statement compared to 42 percent in the previous year. 
One hundred percent of teachers agreed or strongly agreed that the dialogue focused on teaching and mathematical concepts. One final item from the 2012 survey was more about the frequency of interaction than its focus. From that item, 87.5 percent of teachers agreed or strongly agreed that they had regular dialogue with the coach. Note four fewer participants responded to the survey in the final year compared to the previous year.

One difficulty with the survey items is that they were used to evaluate the project as a whole and measure growth towards its four goals. Those goals had a larger focus on the project as a whole where the focus of this study was on the coach and her work. So it was harder to find items that addressed the coach directly. A few more items related to her impact were in their analysis, but discussion is postponed to a later section where I address the second research question.

\section{Coach}

The coach, Toni, provided a third voice in the data to answer the first research question. These sources included: (a) a pre-interview, (b) activities recorded in the coach's $\log$, (c) a document with a list of the coach's responsibilities, and (d) postinterview in December 2012. I begin by presenting information that provides background for the MAST project coach.

\section{Pre-Interview Context}

Toni provided some context for her role in the initial interview with external evaluators, describing how she had operated before MAST began. "My role was coach before the project started...I go in each week, observe teachers, plan with teachers, models lessons, mentor teachers...I'm in their classroom every week." Teachers 
confirmed this claim on the final MAST end-of-year survey where 88 percent of teachers agreed or strongly agreed with the statement that they had regular dialogue with the coach. Toni described her relationship with the teachers:

As far as 9-12 teachers, the relationship was already there because I had already been in their classrooms for the last 2.5 years or the last year and a half when we started the project...so they already knew me, I was already coming into their classrooms, and I'd already been developing professional development with them.

When asked to describe a typical session with a teacher, Toni responded:

When I go in and observe, I will go in observe a couple of times, two or three times usually, and then sit down with teachers and we'll have a good discussion about what's going on in the classrooms...sometimes I kind of get a feel for the classes so I go in at different times, different periods to see if they're teaching that way all day or its just one particular class.

Toni described collecting evidence in her observations sometimes visiting a class 2-3

times before sitting down to talk with the teacher. This particular finding is consistent with a category generated from both the coach's log and the coach's list of duties. I called this category data collection and record keeping. It will be described more in a later section.

The external evaluator also asked Toni to describe what gets logged in the North Carolina MSP database. She responded:

The coaching I've been putting in there has just been directly towards MAST, but it is so integrated with what I do every day...but there are so many times that you sit down and plan with a teacher or they talk to you about what went right and what went wrong and some of the suggestions are coming from the staff development that we've done through the MAST program. So it's very integrated with what I was already doing, so it's kind of hard to separate the two. So far I've pretty much logged in when teachers have asked me specifically to meet with them to plan a MAST lesson, or if in our conversation we've gotten around to talking about the MAST ideas and how they can incorporate that into their classroom now, even if it's not a lesson study lesson. 
There were two important points from Toni's response here. One key point was that she provided an overall summary of what happened in her one-on-one sessions with teachers. Their interactions included planning, identifying both successes and challenges, and making suggestions for improvement. This same finding was also observed in the themes from the post conference transcripts and the coach's log. These themes will be described more in a later section.

The second point from Toni's response was in describing how she decided what to record in the coach's log. Toni expressed difficulty in separating work that qualified as MAST vs. non-MAST. I made the decision in this study to focus on the coaching that occurred within the context of MAST because all of the existing data collected centered on that project and the participants in that project. However, in the final interview Toni made some distinctions between coaching MAST teachers and non-MAST teachers and the subsequent impact on both groups. I report those results in the post-interview section on interactions. She clearly specifies the type of activities that she was required to document in the coach's log. In the next section, I provide a listing of these activities and my analysis.

\section{Coach's Log}

In the database, I was able to generate different kinds of reports for the MAST project. The first report used was called P.D. Provider Contact Hour Summary and I compiled this summary for each of the three years of the project. This report included the activity name, number of days, contact hours provided, and number of participants. I also generated a second report called Activity Summary Report for each of the three years. This report was more detailed including activity name, start date, end date, number of 
days, number of contact hours, number of sessions, number of participants, comments, location, facilitator, activity type, activity emphasis, and subject focus. I worked back and forth between these two reports to generate all the different activity titles Toni facilitated with teachers and began keeping track of the number of hours for each. The complete list of activities and their respective hours for each year of the project are found in Table 3.

\section{Table 3}

Various Activity Titles from NC MSP Database Coach's Log

\begin{tabular}{lcccc}
\hline & $2009-$ & $2010-$ & $2011-$ & TOTAL \\
Activity Title & 2010 & 2011 & 2012 & HRS \\
\hline Algebraic Reasoning Course & 30 & & & 30 \\
Geometry Course & & 30 & & 30 \\
Content Area Reading in & & & \\
Science/Mathematics PD & 6 & & 1 & 30 \\
Lesson Study PD & & & 30 & 7 \\
Math Applications Course & 11 & 4 & 8.5 & 30 \\
Lesson Study Team Meetings & 1 & 9 & 2 & 23.5 \\
RTOP Observations & 52 & & & 12 \\
Coaching & & 2.5 & & 52 \\
Coaching, observation, pre, post & 1.5 & & 0.5 & 2.5 \\
Coach middle school coach & 28 & & & 2 \\
Lesson Study & 4.5 & 8 & 4 & 28 \\
Lesson Study Planning & 24.5 & 19 & 17 & 60.5 \\
Lesson Study Lesson & 1 & 7.5 & 4.5 & 13 \\
Lesson Study Post Conference & & 49 & 62 & 111 \\
Lesson Study, post conference & 2.5 & 6 & 3.5 & 12 \\
Lesson Study Celebration & & & & $460 \mathrm{hrs}$ \\
\hline
\end{tabular}

Then I looked across the titles for common words or activity types and was able to fit all 16 titles into five general categories. To start with, for one category I grouped the three content courses together (Algebraic Reasoning, Geometry, Math Applications). For a second category I grouped the district-level professional development together. For a third category I grouped all the titles with "coaching" in them. For a fourth category I 
grouped all the titles involving some aspect of lesson study. The final category was used for the RTOP observations.

During Toni's post-interview, I used member checking of these five categories that I created from the titles in the coach's log. Toni provided clarification that adjusted my original set of categories from five down to three. These final three categories are shown in Table 4 with the activity titles bulleted underneath. The total number of hours logged did not change but she described some fine-tuning that shifted some hours into

\section{Table 4}

Summary of Activities from Coach's Log

\begin{tabular}{|c|c|c|}
\hline Category & Time Logged & Percent \\
\hline Data Collection \& Record Keeping (RTOPs) & $12 \mathrm{hrs}$ & $2.6 \%$ \\
\hline $\begin{array}{l}\text { Content Courses (co-taught with university faculty) } \\
\text { - Algebraic Reasoning Course } \\
\text { - Geometry Course } \\
\text { - Math Applications Course } \\
\text { - Content Area Reading in } \\
\text { - Science/Mathematics } \\
\text { - Lesson Study PD }\end{array}$ & $\begin{array}{l}127 \mathrm{hrs} \\
\text { - } 30 \mathrm{hrs} \\
\text { - } 30 \mathrm{hrs} \\
\text { - } 30 \mathrm{hrs} \\
\text { - } 30 \mathrm{hrs} \\
\text { - } 7 \mathrm{hrs}\end{array}$ & $27.6 \%$ \\
\hline $\begin{array}{l}\text { Lesson Study } \\
\text { - } 1^{\text {st }} \text { year: Coaching } \\
\text { - } 1^{\text {st }} \text { year: Lesson Study } \\
\text { - } 2^{\text {nd }} \text { year: Coaching, Pre, Observation, Post } \\
\text { - } 1^{\text {st }}, 3^{\text {rd }} \text { year: Coach Middle School Coach } \\
\text { - Team Meetings } \\
\text { - Planning } \\
\text { - Lesson } \\
\text { - Post conference } \\
\text { - } \text { Both lesson and post conference } \\
\text { - Lesson Study Celebration }\end{array}$ & $\begin{array}{l}321 \mathrm{hrs} \\
\text { - } 52 \mathrm{hrs} \\
\text { - } 28 \mathrm{hrs} \\
\text { - } 2.5 \mathrm{hrs} \\
\text { - } 2 \mathrm{hrs} \\
\text { - } 23.5 \mathrm{hrs} \\
\text { - } 16.5 \mathrm{hrs} \\
\text { - } 60.5 \mathrm{hrs} \\
\text { - } 13 \mathrm{hrs} \\
\text { - } 111 \mathrm{hrs} \\
\text { - } 12 \mathrm{hrs}\end{array}$ & $69.8 \%$ \\
\hline & $460 \mathrm{hrs}$ & $100 \%$ \\
\hline
\end{tabular}


other categories while making some previous categories unnecessary. One change she suggested was that the three content courses and two district-level professional development sessions (lesson study and reading strategies) also included content and were facilitated by university faculty. So I dropped the district-level professional development category and categorized it all as content courses. She also explained that the 56.5 hours of activities titled as "Coaching" involved either lesson study or the initial RTOP observations required in the first year. These changes were made in the recording process at the request of the external evaluator for the purpose of the annual reports. That is why this title only appeared in the first year. She did not have a breakdown of those 52 hours between Lesson Study time and RTOP Observations but I was comfortable with dropping the "Coaching" category since it was not really a different kind of activity that the coach engaged in with teachers.

The adjusted categories provided a clearer picture of how Toni's time was divided across the project. The essential piece that came from this adjustment was that the coach spent a little more than $2 / 3$ of her time working on some aspect of lesson study with the teachers. This time included preliminary planning with the individual teams at each school, the actual teaching of the lesson, the post reflective conferences, or the final celebration at the end of each year to showcase each team's lesson and development process. Clearly lesson study was a big part of MAST, and Toni was heavily involved in all activities throughout the process. More will be said about lesson study in a later section. The next data source provides more details on each of the three categories from her log in addition to some other duties that were not recorded in the log. 


\section{Document Review}

The coach had shared a document entitled Some MAST Project Coach

Responsibilities (See Appendix F). I used this document to add to my understanding of her interactions with the teachers in the MAST project, particularly beyond what I already learned from the coach's log. In order to understand the context of this document, I asked Toni some questions about it in the final interview. Some of my questions included when it came into place, who generated the list of duties, and why. This information seemed important to understand given that lack of clarity in a coach's role was an issue raised in the coaching literature (Ai \& Rivera, 2005; Gibbons et al., 2010)

First I asked Toni if the document was in place before the MAST project began or developed later on. She said "that's what I developed as I went through coaching the grant. Some of it was stated ahead of time...but a lot of things just came out of the need for the grant." Second, I asked her what prompted the document and where it came from. Toni said:

A comment was made that it wasn't taking very much of my time to do this...I do a summary every so often and sent that out...this is what we're doing in the grant and this is where we are and what's going on. But yeah a comment was kind of made that it really wasn't that much time. And I felt like well it's not when you're looking at one small piece, but when you pull everything together from all the sources it's quite a bit more...

I questioned if the document was a response to administration and others needing clarity about her work - she agreed that it was.

For my analysis, I used the three categories from the coach's log to attempt categorizing all the duties listed in this document. I discovered that many duties fit nicely under those three categories and other duties had never been mentioned before. I sorted the categories into two separate lists and utilized member checking in Toni's final 
interview to have her review them. The list of responsibilities that I saw evidence of in the coach's log is shown in Table 5. The bulleted items under each category were the descriptions taken directly from the document. Those responsibilities that were not described in the coach's log are shown in Table 6.

\section{Table 5}

\section{MAST Project Coach Responsibilities Aligned with Coach's Log Activities}

Data Collection \& Record Keeping

- Conduct RTOP observations

Content Courses (with faculty)

- Help deliver content courses (including face-to-face, online via Blackboard, led make-up sessions)

Lesson Study

- Meet with school lesson study teams to discuss expectations, lesson study lesson plans, team logs for documentation, using the Moodle, enter participant information into NCMSP database, due dates, and MAST Celebration of Learning

- Observe lesson study teams, provide appropriate coaching, and facilitate post reflective conferences

- Meet with teams when needed or requested to plan/coach on their lesson

- Participate on 2 lesson study teams. Meet with each team member to plan and create lesson study lesson, teach lesson or segment of lesson, prepare PowerPoint for presentation, and help present at the Celebration

- Plan and coordinate MAST Celebration of Learning. Create brochure and communicate expectations to participants.

One new category included the coach's personal preparation for many of the activities documented in the coach's log. In those cases, I adjusted the category names slightly to show they were related. Then I generated new categories for everything else in the list that did not fit the original three categories. When I shared with her my list that fit the categories and those that did not, I got further clarification from her that "in the log are only direct contact with teachers. And it's only contact recorded for lesson study since my position is funded from other sources. Not all my coaching time is recorded in 
those logs." Other responsibilities that did not involve teachers were managing and attending project meetings with various partners, attending personal professional development, and disseminating project outcomes at conferences and for print distribution.

\section{Table 6}

MAST Project Coach Responsibilities Not Recorded in Coach's Log

Preparation for Content course Work

- Plan with UNCW professors

- Search for materials or activities

- Purchase materials for PD

- Work through activities (personal prep)

- Secure locations \& refreshments

Scheduling Lesson study, giving electronic feedback

Data Collection \& Record Keeping

- Participant logs in MSP database

- CEUs and sign-in sheets

- Annual Reports

- Report to external evaluators

- Document teacher meetings for MSP database

Dissemination

- Present at state mathematics teacher conference

- Distribute/compile books for lesson study celebration

Internal Project Management

- Meet with project director

- Meet with external evaluators

- Meet with UNCW and SMEC

- Meet with MSP database coordinator

Coach Professional Development

- Attend state mathematics teacher conference

- Attend North Carolina School of Science \& Math workshop

- Attend national mathematics teacher conference

- Attend national supervisors of mathematics conference 
To summarize, this document provided two new types of information: (a) some details of activities recorded in coach's log, and (b) additional responsibilities of the coach that did not involve teachers directly. The coach's log only included her face-toface contact with the teachers per se. The preparation and planning she did on her own was obviously an important part of her job but was not required to be logged. I decided these were important results to include in order to give a broader picture of what the coach's day-to-day activities entailed, even though there was no record of how much time she spent on them nor did they include direct teacher interaction.

\section{Post-Interview}

The final piece of data that the coach provided was the post-interview. I gained clarification, engaged in member checking, and followed up on some unknowns that proved to be very helpful in "connecting the dots" across the coach's work with teachers.

Numerous activities focused on coaching interactions were validated by showing up across multiple data sources. The evidence that the coach collected data was in the coach's log, the document review of her duties, and the initial pre-interview. Evidence of the coach planning with teachers, identifying successes and challenges in the lesson and making suggestions was also present. These activities showed up in the coach's log, the initial interview, and the post conference sessions. However some ideas about their interactions only came out in the final coach interview.

"Remember when..." One idea was how the coach provided emotional support for teachers and would often remind them of things they had learned in their content courses sessions. Toni suggested that they were more willing to try things that "they were 
hesitant to try before." I asked her how she knew that was because of her coaching and

not the course work they had taken. Her response was:

The coaching helps remind them of the things they have and reflects back on 'Well you remember when we did this' when they are saying 'I just can't get through to the students...' and I ask them 'What have you tried?' and they don't mention something we've done through the workshops then I bring those up...because it's easy once you've been to a workshop to put your materials on your shelf and not look back at it just because you don't have time to do that, but having a coach, a coach can help remind you and get you to reflect...coaching is professional development differentiated for teachers on a one-on-one basis.

So reminding was an important way that the coach interacted with teachers.

Engaging with the content. Another type of interaction that occurred in the preinterview was how the teachers and coach interacted with the mathematics content. I followed up on a statement Toni made that "teachers were connecting". When I asked her to elaborate, she said "you work with people every day but you don't get to sit down and work math problems... and I have seen some teachers where they share their methods and they are teaching each other different methods of doing things..." So she said that the teachers' interaction with the content and each other was important. Furthermore, I learned that Toni pushed them to think flexibly and look for multiple paths to a solution. She stated:

I remember that first summer we started posting up their groups work...we had about 7 or 8 different ways and I'd ask them if they finished one way to try to work it as many ways as they could so we could get a variety. They had some of the neatest ways to work things and you could hear them, 'Wow I never thought about working it that way'...I think it was just a way for teachers to shine and work math and you know something that they love doing.

The coach engaged the teachers in authentic learning experiences around the content.

Finally, I explored how Toni's interactions with MAST teachers differed from non-MAST teachers. I questioned whether to report this portion of my interview with the 
coach since this study was focused on the teachers in the MAST project. However, the comparison between coaching MAST and non-MAST teachers helped give more definition to the nature of coach-teacher interactions in MAST. It is also relevant to the implications of this study to inform future coaching practice that will be shared in chapter five.

MAST vs. non-MAST teachers. I was curious what differences Toni would describe when she sat down with non-MAST teachers, and I asked her if her one-on-one coaching sessions with non-MAST teachers differed considerably from MAST teacher sessions. She responded:

I think they do because I think we have that protocol in place and they have that commonality of that lesson that we just go into much greater depth with the lesson study conferences than probably with the other teachers. Sometimes with the other teachers we get into that, but a lot of times it depends, because we just have so much turnover each year it's like you're starting over and building a relationship over and over. And these folks have been in it for that time period so that relationship is already established so you're going deeper and deeper I think each time. And I think they're more open to bringing out things that they thought worked or didn't work before you ever even as a coach have to bring it up or talk about it. Whereas other teachers when you go in, 'Everything's fine', 'Everything's great.' So you really have to work at that conversation to bring it up. And that's a big difference.

To Toni, lesson study was an essential component of MAST because it provided context for the post conference and the expectation that the discussion would focus on the lesson and whether it worked for students. The focus on student learning was a distinguishing feature of the coach's interactions with MAST teachers.

I was still skeptical that lesson study could make that much difference in the post conference interactions with a non-MAST teacher. I followed up to ask her if having lesson study as a backdrop in MAST had enabled her to get to the heart of the lesson more quickly. In other words, Toni was accustomed to doing one-on-one coaching before 
MAST and continued during MAST with non-MAST teachers. But lesson study was a new idea when MAST began. Her answer was:

I think it changes the teacher's attitude towards that post conference in that the teacher is much more open to having that conversation about whether the lesson was successful or not because it's not their lesson, it's a group lesson. And when it's your lesson, it's much more personal. And so teachers have that defense up immediately, whereas this is our lesson, and we are trying new things, and we are thinking about 'Well what if we do this?' and 'What if we do that?' and I think we get a much richer and deeper reflective conference on it, whereas that may take a lot more time to get to with the non-MAST teachers.

Lesson study made the MAST coaching sessions less personal and so teachers did not need to be defensive. It also did not require as much time for them to reach those rich discussions in the lesson study sessions with MAST teachers as compared to the one-onone coaching sessions with non-MAST teachers.

I questioned whether there were non-MAST teachers with whom she had interacted longer and had a stronger relationship than those participating in MAST. Given the long-standing relationship with non-MAST teachers, I thought it was possible that the coach could still achieve thoughtful and reflective sessions interacting one-on-one. Toni indicated that another key difference was having the other lesson study members there in the close-knit relationship.

These are teachers you know that have been in all the different staff developments where the other teachers have not, so they have a different relationship with each other in sitting down and having these conversations in front of the other teachers that are there. It's not just with me, but also with their peers.

Since multiple teachers were in the lesson study groups, the coaching sessions with MAST teachers became group coaching sessions. Furthermore, the relationships within the lesson study team were established and teachers could also identify critical elements of the lesson instead of the coach being solely responsible. 
Another valuable part of group coaching was teachers having the opportunity to observe one another. Toni pointed out why this was important:

And I think in MAST they get to see each other teach, which I think is very valuable, and that's been a comment that they have made...because even talking about it, it's very different when you see it implemented for that observation piece. And the other teachers are just missing out on some of those kinds of things.

This quote shows evidence of the lesson study cycle at work. The focus is on students doing their work and teachers observing their peers, reflecting on ways to improve the lesson, testing those improvements and seeing the results of those choices.

Toni's comments provide solid support for group coaching via lesson study as a necessary and critical part of MAST. She summarized some of the key differences of one-on-one coaching with non-MAST teachers vs. group coaching with MAST teachers:

We've really tried to... through the lesson studies we're always looking at students and the student work and 'Is it working for the students?' And we're not really looking at the teacher and critiquing the teacher...It's really concentrating on student learning and 'Is the student learning?' and if they're not, 'What are we going to do about it?'...We actually change what we think needs to be changed, put it in place, and see if it actually works. And I think the other teachers that are not in MAST don't have that luxury of being able to do that.

The differences that exist when coaching teachers in the context of lesson study suggest the importance of the lesson study protocol and the focus it places on students and student learning. It provides parameters that give the coach and teachers clear direction for working together towards a common goal.

I learned more in the post-interview but it centered on the coach's perception of her impact. I will say much more about the coach's impact in the discussion of the data for the second research questions. 


\section{Teachers and Coach}

The final piece of data related to the first research question came from the voices of the coach and teachers as they conducted post-reflective conferences together after a lesson study observation of a team member. The configuration of the lesson study teams varied from one teacher pairing with the coach to small groups of two or three teachers. My analysis and results of those post conference sessions follow.

\section{Post Conferences}

What is lesson study? Since lesson study consumed about $2 / 3$ of the coach's time, the post conference sessions were where the "magic" happened. In the preinterview, the evaluators asked Toni to describe a lesson study meeting. Her response gave a summary of the lesson study cycle they followed throughout the MAST project. I provide the coach's description for the reader who may not have been as familiar with what lesson study entails. She stated:

I met with all of the teams at each school and went over a guideline as to the lesson plan format...So I met with them all to start as a group and then we had them meet themselves to start planning their first lesson, to decide what lesson they might do and where it would fit in their curriculum. Then they contacted me or if they were having difficulty with that or if they had a lot of questions. I would meet with them and we all met for the lesson itself, and then we all met back and did a conference together after the first lesson was taught and talked about how it went, what they wanted to change...And then we went back in to the other teacher's class as they taught it and then we came back and we met a second time on that same lesson. That's one complete lesson study cycle for the teachers.

Finding the themes. The audiotapes from five different lesson study groups were captured in the final year and final semester of the project. Three groups met once, one group met twice, and the fifth group met three times for a total of eight post conference sessions. I transcribed each of the eight sessions and began my analysis by listing key words or phrases in the margins of the transcript that captured how the teacher or coach 
interacted at that stage of the conference. Then I typed or wrote out those phrases in chronological order for each session. I then looked for similar or related phrases that might fall together or indicate essentially the same thing, and I used different colors to mark those phrases. I repeated this coding process again until I had fewer new phrases and colors and could note relationships between and among them. I also decided that it was not necessary to separate teacher actions from coach actions, and instead to look at them overall as verbs that could apply to either group. In the end, I identified seven themes to describe the type of interactions between the teachers and coach. These themes are listed in Table 7.

Describing the themes. Six of the seven themes have bullets underneath indicating who said or initiated the action, if appropriate, and the actual phrase used in the coding. For instance, whenever the coach probed, the teacher posed a question, or the teacher asked specifically for feedback, I coded this interaction as "Questioning or Probing." A second theme that arose in response to questioning or probing was team members agreeing or disagreeing, or the coach offering a recommendation. I coded this as "Recommending or Providing Feedback." I questioned whether theme \#5 and \#7 were really different. In the end, I decided that a recommendation was stronger and carried more authority than someone offering an idea or strategy to the group. And, the majority of the time, such recommendations came from the coach. Offering an idea or strategy is better described as brainstorming or generating ideas to improve the lesson, handling a challenge, or providing scaffolding for students or groups having difficulty in the lesson. Therefore, the two themes are different enough from each other to be separate. 


\section{Table 7}

Themes Across Lesson Study Post Conference Sessions

1. Questioning or Probing

- Coach Probes

- Teacher poses question

- Teacher asks for feedback

2. Hypothesizing or Recognizing Challenge

- Student Difficulty

- Teacher Challenge or error

- Lesson weakness

3. Identifying or Recognizing Success

- Student Success

- Teacher Success

- Lesson Strength

4. Summarizing or Justifying

- Paraphrasing or active listening

- Offering evidence from the lesson

- Providing rationale for instructional choices

5. Offering Idea or Strategy

6. Teaching or Explaining

- Mathematics content

- Technology

- Standards, particularly Common Core

- Vertical Alignment of content or cross-curricular alignment

7. Recommending or Providing Feedback

- Agrees or disagrees

- Makes recommendation (typically the coach)

- Sets goal(s) or reminds of goal already set

- Gives feedback

The sixth theme in Table 6 is titled "Teaching or Explaining." This theme

typically originated from the coach. She directly explained mathematics content, standards, curriculum alignment, or technology. However, sometimes a teacher took on this role to explain something (e.g. new calculator operating system). This theme was not as regular as the others but it happened on more than one occasion and in more than one session. 
The second and third themes, "Hypothesizing or Recognizing Challenge" and "Identifying or Recognizing Success," were not surprising since the lessons were lesson study sessions. The stages of lesson study are: (1) develop the lesson, (2) teach the lesson (or observe the lesson), and (3) meet with others to reflect and improve the lesson. The lesson study protocol dictates the reflection process by facilitating talk that recognizes challenges for the student, the teacher, or the lesson itself and hypothesizing possible sources of those challenges. On the other hand, teachers also reflect on what went well for students or teachers, or what was a strength of the lesson. This type of reflection and analysis by teachers focused them on student learning and understanding how the lesson facilitated that learning. Identification of both challenges and successes was prevalent throughout single sessions and across every session.

The fourth theme, "Summarizing or Justifying," appeared at first to be mostly initiated by the coach. However, as the sessions continued and as teachers became more settled in the process, they engaged in those actions also. For instance, it was not surprising to see a coach engage in active listening or offering evidence from the lesson, since these are typical coaching behaviors (Alloway \& Jilk, 2010; Becker \& Pence, 1999). However, the more the coach modeled this behavior and followed the lesson study protocols, the more teachers followed suit. In fact, teachers might, in turn, offer a justification for an instructional choice they made.

I again used member checking in the final post-interview with the coach. I shared the themes in Table 7 and asked if these were representative of any of her post conference sessions and not just the eight audiotaped sessions that I analyzed. She validated the themes I found; however she said that they always followed a protocol in the conference 
where the person teaching the lesson reflected first, and then the other team members followed. She was concerned that this protocol might not have come through in the sessions that I heard. This was the third year of the project and she and the teachers were very comfortable with each other. They might not have followed the protocol as closely in terms of who spoke or reflected first. I assured her that I was not really concerned with lesson study protocols as much as what was happened between the teachers and her during the sessions.

\section{Research Question 2}

The second research question was a follow-up to the first, analyzing the impact of interactions among teachers, university faculty, and the coach. I organized the data again according to the three voices in this study. First I present the teachers' voice from the survey data, focus group, and the RTOP scores. Second, I present the coach's voice from the pre- and post-interview. Finally, I present the university faculty's voice from their first and last interview.

\section{Teachers}

\section{Surveys}

The end-of-year surveys (see Appendix A and B) contained nine items, both Likert and open-ended, pertaining to the second research question. Four items (two of each) were used in 2011, and five items were used in 2012 (three Likert and two openended). First, I share the results of the first few items that reported teachers' satisfaction with the coach.

For item 8 on the 2011 survey, 91 percent of teachers agreed or strongly agreed with the statement "I am satisfied with the coach provided by the program." On item 6, 
83 percent agreed or strongly agreed, "The coaching provided by the MAST program meets my current needs." The following year teachers' agreement with this statement increased to 100 percent. For item 11 in 2012, 100 percent of teachers agreed or strongly agreed with "The coach employed sound coaching practices." The results of these items provided important context for the rest of the teachers' responses. If the teachers were not satisfied with the coaching or the coaching practices were ineffective, then it is unlikely that it would have much impact on them or cause them to change. These items did not reveal the impact of coaching but added validity to the other survey items that did.

Recall that the Likert items for both years' surveys used a 6-point scale and responses of strongly disagree received a score of 1 while responses of strongly agree received a score of 6 . I computed the means and standard deviations of the scores in addition to the relative frequency of responses among the participants. The survey year, survey item, number of respondents, means and standard deviations are shown in Table 8 .

\section{Table 8}

MAST Survey Likert Items (Impact)

\begin{tabular}{llccc}
\hline Year & Survey Item & $n$ & $M$ & $S D$ \\
\hline 2011 & $\begin{array}{l}\text { I am satisfied with the coach provided by the } \\
\text { program. }\end{array}$ & 12 & 5.25 & 0.62 \\
2011 & $\begin{array}{l}\text { The coaching provided by the MAST program } \\
\text { meets my current needs. }\end{array}$ & 12 & 5.08 & 0.67 \\
2012 & The coaching provided met my needs. & 8 & 5.5 & 0.53 \\
2012 & The coach employed sound coaching practices. & 8 & 5.75 & 0.46 \\
2012 & $\begin{array}{l}\text { I implemented methods from the coaching } \\
\text { received into my classroom. }\end{array}$ & 8 & 5.625 & 0.52 \\
\hline
\end{tabular}

For item 14, 100 percent of teachers agreed or strongly agreed that "I implemented methods from coaching received into my classroom.” Item 16 asked them to "describe the methods you implemented into your classroom due to the coaching you 
received." Only five of the eight teachers answered this item, so I listed all of their responses in Table 9. Item 15 asked teachers to describe the benefits they received from their coach. All five of their responses are also in Table 9.

\section{Table 9}

MAST 2012 Survey Open-Ended Items (Impact)

Open-Ended Item \& Teacher Responses $(n=5)$

Item 16: Describe the methods you implemented into your classroom due to the coaching you received.

a. I have introduced more student-centered lessons. My questioning has become better.

b. I implemented a new notebook organization as a suggestion from my coach to better organize my freshmen.

c. 2 lessons in geometry. Both involving right triangles and one can follow the other. They can be used again and again.

d. More student self-discovery.

e. Question prediction and answers, hands-on for concept understanding, reading strategies, and greater rigor.

Item 15: Describe any benefits you received from having access to your coach.

a. [Toni] was invaluable to me. She helped me most by being supportive and keeping my morale up. However, she was always introducing new ideas and suggestions, too.

b. I was able to implement new teaching methods successfully. I implemented new assessment strategies as suggested by my coach.

c. Showed ample knowledge, saw my weaknesses and strived to help me develop better practices.

d. [Toni] pushed me out of my comfort zone and I really enjoy doing hands-on activities in the classroom now.

e. Better teaching practice and concept understanding

On the benefits of coaching, teachers' responses $a, c$, and $d$ from Item 15

described how the coach provided moral support and helped teachers want to change, and responses $b$ and $e$ described a change in teachers' behavior. This same question about benefits was posed to teachers in the focus group. All five responses from this item 
corroborated with at least one of the four themes identified in the focus group analysis. These themes will be shared in the next section.

A similar open-ended item about benefits was asked in the previous year; it did not target the coach, but rather the project in general. Item 10 on the 2011 survey said "List the main benefits to you as a result of participating in the MAST program." None of the teachers' responses credited the coach directly, so I have not included those in the table. However, they mentioned topics consistent with other data sources. Four teachers' indicated an increase in teacher content knowledge, and three mentioned working collaboratively as main benefits. Also, two teachers mentioned the reading strategies, and two mentioned a greater focus on student thinking and engagement. The coach referenced all four of these ideas in her final interview.

One final open-ended survey item focused on the project in general. Item 14 on 2011 survey asked "What parts of MAST should be sustained after grant funds are expended?" One teacher said "Lesson study portion. I think there would be a greater impact on student learning if it would be possible to at least keep [Toni] visiting the classrooms to oversee Lesson Study lessons." The next section of teacher data includes the results from the focus group conducted by the MAST external evaluator.

\section{Focus Group}

MAST teachers $(n=22)$ participated in an informal focus group at the conclusion of the MAST Celebration of Learning in April 2012. Four general questions were posed. The first two were not specific to the coach but to the project in general. The majority of their responses to these two questions related, in some way, back to the lesson study. Since the coach was involved in all the lesson studies, I share a few of these responses. 
The first question asked teachers "How has your teaching been impacted?" Some examples of what they said included "keep using the lessons," "observing is better than talking, discovering is better than giving," "too large of a group does not work well," "keep notes to share more effectively, helps organize the discussion part," and "using a gallery walk to share student work." These kinds of discussions were common in the interactions between the teachers and coach during the lesson study post conferences.

The second general question was "What will you miss most after MAST?" Two participants cited the coach specifically in response to this. One teacher responded, "[Toni] to guide her and provide positive feedback" while another said he would "miss the coach because he is the only teacher teaching that course at this school. It's nice to have someone to talk to." Both of these responses are related to themes that were identified in the teachers' responses to the third question, which targeted the coach. The third question was "What benefits did you gain from having an instructional coach?" with a final follow-up question "Additional thoughts?" Most of the teachers gave short responses to both questions which are categorized them into four themes.

The first three themes describe the coach providing: (a) a second set of eyes and ears in the room, (b) a specific lesson idea or strategy, or (c) modeling of teaching behaviors. The fourth theme described evidence of student impact in the classroom. All four themes are presented in Table 10 with the teachers' direct quotes underneath to show consistency and detail for that theme. The quotes are labeled with lowercase letters so I can reference some that were different or noteworthy. The lowercase letters do not represent the same teacher across the four themes. For example, 1a and 2a do not necessarily represent the same teacher's response. 


\section{Table 10}

\section{Focus Groups Themes on Teacher Impact}

3. What benefit did you gain from having an instructional coach? 4. Additional thoughts?

1. Second Set of Eyes and Ears

a. She sees things from a different perspective.

b. Nice to have the feedback (positive and negative).

c. Dialogue with the coach.

d. Amazing how she can hear the student conversations in the classroom.

e. Another person to collaborate with, part of the team.

f. See things in the teacher that they do not see in themselves.

g. Offering suggestions that teachers had not thought of yet.

h. [Toni] is awesome, makes me think of things I would never think about.

2. Specific Lesson Idea
a. She suggested the topic.
b. Guiding questions.
c. Reading activity.
d. Sorting activity.
e. Open-ended assignment.
f. She has so many ideas.
g. Gaining strategies for teaching content to the students.

3. Teaching Behavior

a. Learned to stand back and let the students explore. [The coach] taught her how to do that.

b. She encourages teachers to hold back, don't give answers.

c. Answer a question with a question.

d. Modeling lessons.

e. [Toni] is really good with transitions.

f. Would like to create more moments of focus.

g. Needs to be more of a coach, less controlling.

h. MAST is a lot of work. It makes you reflect on what you are doing.

4. Student Impact

a. Students were more engaged.

b. Was interesting to watch students.

c. Could see the understanding come across the kids face.

d. Hands-on makes students focus more. They develop concrete memories.

The first theme, "Second set of eyes and ears," described how teachers valued having someone to talk to and provide a perspective different from their own. Teaching 
can be a lonely business, and it is evident from their answers that the coach diminished that feeling. Response 1d described his/her amazement at how the coach could hear student conversations. Responses $1 \mathrm{f}$ and $1 \mathrm{~h}$ stated how the coach helped them see things in themselves they might have missed otherwise. Note that the final quote of the first theme actually came in response to the "Additional thoughts?" prompt. So, even though they were not asked specifically about the coach, response $1 \mathrm{~h}$ credited Toni specifically.

The second theme centered on specific lesson ideas that they had recieved from the coach. Teachers were able to recall specific lessons, even after all the lessons and activities they had completed over the three years (two lesson study cycles and at least one content course each year). Response $2 \mathrm{c}$ mentioned a reading activity and response $2 \mathrm{~d}$ a sorting activity. Teachers' implementation of reading strategies was confirmed with teachers' responses on the open-ended items from both years of survey data as well as the post-interview with the coach.

The third theme teachers described as a benefit of having a coach was teaching behaviors they either learned from the coach or the coach modeled for them. One particularly popular teaching behavior was allowing students to explore and not giving them answers but responding with another question. The last four responses (3e, $3 \mathrm{f}, 3 \mathrm{~g}$, and 3h) were "additional thoughts" responses to the fourth focus group question. Response 3e referred to the coach's transitions and response $3 g$ extended beyond the idea of letting students explore to say, "Be more of a coach, less controlling."

The final theme described in the focus group related directly to students and their actions. Teachers said students were more engaged and focused. Only the first teacher's response alluded to the benefits she gained from having a coach. Teacher's "additional 
thoughts" described the looks on students' faces, suggesting they were making sense of things.

In summary, the focus group themes described two kinds of impact. The first two themes described specific actions provided by the coach —emotional support and feedback as well as specific ideas for teaching. The last two themes were more descriptive of teacher or student behaviors as echoed in the open-ended survey item described in the previous section. The next section describes the results from the RTOP, rating teachers' movement toward reform-based teaching.

\section{RTOP}

As described in Chapter 3, the Reformed Teaching Observation Protocol or RTOP (see Appendix E) is:

An observational instrument that can be used to assess the degree to which mathematics or science instruction is reformed. It embodies the recommendations and standards for the teaching of mathematics and science that have been promulgated by professional societies of mathematicians, scientists, and educators (Piburn and Sawada, 2009, p. 32)

In this instrument, the teacher is assessed on five categories including: lesson design and implementation; propositional content knowledge; procedural content knowledge; communicative interactions; and student/teacher relationship. Five statements under each of the five headings are rated from 0 (never occurred) to 4 (very descriptive). The ratings can be combined to give the teachers a total score out of 100 possible points. An increase in the total score indicates a change in teachers' instruction towards more reform-based teaching practices.

The coach observed MAST teachers once a year for three years using the RTOP. Twenty-six teachers were observed in 2010. However, only 15 of those teachers were 
still participating in 2011. Therefore, I computed the mean RTOP score for those 15 to compare the first year to the second year. In 2012, only nine of those 15 teachers with valid data for all three years remained. The overall means and subscale means for each year are reported in Table 11.

I shared these results with the coach in the final interview. She gave the following caution:

You have to be careful with the RTOP...if you don't see where teachers start and you just walk in you may not think they have reformed at all...we are really looking at growth from that first one and through that last one. That's the important piece, just that growth that they are showing...but I think we are headed in the right direction.

I also tested for statistical significance using a one-tailed paired t-test to compare overall means from year 1 to year 2 and from year 1 to year 3. From 2010 to $2011(n=15)$, teachers' overall RTOP mean was significantly higher with $p=0.00003$. From 2011 to $2012(n=9)$, teachers' overall RTOP mean was significantly higher with $p=0.00048$.

I followed up by asking the coach what changes, if any, might not be sensitive to the RTOP instrument but still worth mentioning. Recall that the survey data reported the extent to which teachers implemented new methods as a result of coaching and the coach corroborated this in the both the pre- and post-interviews. She added, "not only their willingness to try things mathematically but to try things with the literacy strategies." Literacy is not something explicitly addressed in the RTOP statements, so this action was a valid addition to include in a discussion of changes to teachers' instruction. 


\section{Table 11}

$\underline{\text { RTOP Overall and Subscale Means }}$

\begin{tabular}{|c|c|c|}
\hline Year & Category & $M$ \\
\hline $\begin{array}{c}2010 \\
n=15\end{array}$ & $\begin{array}{l}\text { OVERALL SCORE } \\
\text { Lesson Design \& Implementation } \\
\text { Propositional Content Knowledge } \\
\text { Procedural Content Knowledge } \\
\text { Communicative Interactions } \\
\text { Student-Teacher Relationships }\end{array}$ & $\begin{array}{c}34.06 \\
5.1 \\
10.9 \\
2.5 \\
7.4 \\
8.3\end{array}$ \\
\hline $\begin{array}{c}2011 \\
n=15\end{array}$ & $\begin{array}{l}\qquad \text { OVERALL SCORE } \\
\text { Lesson Design \& Implementation } \\
\text { Propositional Content Knowledge } \\
\text { Procedural Content Knowledge } \\
\text { Communicative Interactions } \\
\text { Student-Teacher Relationships }\end{array}$ & $\begin{array}{l}53.93 * * * \\
9.3 * * \\
15.2 * * * \\
5.7 * * \\
11.87 * * * \\
12 * * *\end{array}$ \\
\hline $\begin{array}{l}2012 \\
n=9\end{array}$ & $\begin{array}{l}\text { OVERALL SCORE } \\
\text { Lesson Design \& Implementation } \\
\text { Propositional Content Knowledge } \\
\text { Procedural Content Knowledge } \\
\text { Communicative Interactions } \\
\text { Student-Teacher Relationships }\end{array}$ & $\begin{array}{l}61.78 * * * \\
12 * * * \\
15.1 * * \\
7.7 * \\
13.33 * * * \\
13 * * *\end{array}$ \\
\hline $\begin{array}{l}* p<.05 \\
* * p<.01 \\
* * * p<.001\end{array}$ & & \\
\hline
\end{tabular}

\section{Coach}

In this section, I present the data that the coach provided in the pre- and postinterview concerning impact on the teachers and then on herself.

\section{Impact on Teachers}

In the pre-interview conducted in December 2009 by the external evaluator, the coach made a couple statements indicating how teachers' relationships and view of the 
content were already changing within the first six months. The evaluator asked Toni if the teachers were more connected with each other. She replied:

I think they've really enjoyed, and this is what they've shared with me. They really enjoy getting together and working the problems, and seeing their colleagues in a different way with the project. They love working the problems, they love having the discussions about the math, and that's really important to them, and I think it's helped them look at math in a different way.

This statement was corroborated in my follow-up interview in 2012.

Toni was also asked in the pre-interview if there were any things that stood out as big successes of MAST. She said, "I've been really excited about the lessons that they're doing. It's been nice to watch them try new things that they hadn't tried in the past, and to hear their reflections of how all the students were engaged and participating." I used member checking in the follow-up interview to determine if what the teachers said they were implementing and the coach saw them implementing was consistent. She confirmed this original statement and was able to elaborate on why she thought the change had occurred.

"Willingness to try." I shared with Toni that 100 percent of teachers agreed or strongly agreed that they had implemented methods from coaching that they had received. I asked her what methods she had observed MAST teachers implementing. Her response was:

I've observed them turn more of their teaching back to the students and allow their students to have an opportunity to answer the questions rather than the teacher just to tell them the answer or how to do a problem... asking them questions, 'How did you get that? Why did you think that?' Having the students talk to each other to find out how they're thinking about the math...I've seen a lot of teachers implement the reading strategies...from CARSAM. I think their questioning has been more higher-order than it was before... and I've seen a willingness to try tasks and activities that they were hesitant to try before. 
Since this willingness to try had appeared in multiple data sources (teachers' survey, university faculty interviews, and coach pre-interview), I followed up by asking if she attributed their willingness to try new things to coaching. She gave two reasons, citing the use of accessible tasks with different entry levels as well as the support of the coach and lesson study team. She said, “I think they've seen that it will work in their classroom whereas before I don't think they thought that it would work. It allowed for entry level for all their students and it allowed for differentiation." I asked if she thought teachers were more willing to try because she was in the room to help. Toni explained:

Probably so... because they kind of worry about if it's going to fall apart. I told them, 'Look we're teachers. We know what it means when it falls apart and not every lesson is perfect, but this is the perfect day to try something you haven't tried before because you've got all of us in here to help you'. And then also any day that I'm in here coaching, just me, I'm there I can come in and help them. So I do think that that does make a difference.

So not only did the teachers have the support of their coach but also their lesson study team members as they tried implementing new ideas or lesson strategies.

Another reason for teachers' willingness to try was due to the lesson study. This came out when I was asking Toni the difference between coaching a MAST teacher and non-MAST teacher and whether the lesson study context affected their interactions. She explained that in lesson study, it was not a specific teacher's lesson but the entire group's lesson. So it would not be as personal if the lesson flopped. Furthermore, she explained that the teachers "have been in all the different staff developments whereas the other teachers have not. So they have a different relationship with each other in sitting down and having these conversations in front of the other teachers."

Lesson study made MAST teachers potentially less defensive, particularly if a lesson went poorly, because the focus was on students and student learning. Also, unlike 
non-MAST teachers, they had established relationships with the other members of their team through lesson study, and participation in all the MAST activities made them more comfortable to have those discussions with each other. It seems that coaching was critical to teachers' change, but it would not have happened as easily if not for lesson study and the entire MAST experience that came along with it. Another impact of the interactions between the coach and teachers also focused the teachers on students and students' thinking. This impact came from teachers doing the mathematics.

Doing the mathematics. In the pre-interview, Toni described how the teachers loved working the problems and discussing the mathematics. I asked her why she thought the discussions about the mathematics were so important to them. Her response was:

Well what I heard them say was...they are in those time constraints, and so they start telling the students this is how you work it and it is this way and only this way. And I think it made them step back and take a look at 'Wait a minute. There are other ways to teach. There are other ways to work the problem. And having multiple ways to work it can be important or is important for me to know and for my students to know and to understand how my students are thinking about the mathematics.' And I think that was an eye-opener when we first went in, at all the different ways...So I think that was important in helping them to start thinking about multiple representations and also in thinking about how many...if we think of it that many ways in this room, how many different ways will our students think about it?

Working the problems put the teachers in the role of learners and showed them the need to know many ways to work the problem was ultimately to the benefit of their students. In other words, doing the mathematics was an avenue that helped them focus on the students and their thinking.

In my follow-up, I asked Toni if she thought that by teachers valuing multiple ways, they felt obligated to give their students the same opportunity. She repeated their concern with time constraints, explaining "to try to show them those tasks where we 
could cover a lot of objectives through one task and provide those opportunities for the students, I think was invaluable." Putting the teacher in the learner's role also gave teachers a chance "to work through it and see what it was like... if they didn't get it right off the bat that's how your kids feel sometimes... what it's like to be in a class where you don't know the answer immediately." When I asked her how doing the mathematics "helped them look at math in a different way," she said:

Some of them had only looked at it that one way they would work it and that's it...I actually heard some of them 'Well I never thought to work it that way' or 'Oh that's what so-and-so was trying to do. I didn't get what they were trying to do' and having that discussion about not telling a kid 'That's wrong' because they are not working it the way that you worked it.

I heard three points from Toni's responses about teachers doing the mathematics. The first was that it reminded teachers what it was like to be a student. The second was how proper selection of mathematical tasks could help them with the time constraints in teaching their curriculum. The third was that they should appreciate and encourage the diversity in students' methods for doing the mathematics.

Teachers' interaction with the content helped them understand the mathematics better, but the coach's discussion seemed to indicate the teachers were also learning lessons about better pedagogy. I was curious if the teachers were doing mathematics purely in the course settings or also when they worked with Toni. She said it happened in both, but especially through the course. In the responses that followed the coach described other ways they worked to support teachers in changing their pedagogy through the course and the lesson study.

Pedagogy. According to Toni, she and the university faculty used the course to model "the way that we wanted teachers to teach." At the same time, with the lesson 
study lessons, she "asked them to concentrate on student-centered lessons with some type of exploratory and/or use the literacy strategies" and encouraged the use of pairs or small groups. This statement might explain why we heard from teachers' surveys and focus group that they used reading strategies. Toni explained, "we tried to model that and all of our work was through group work to help them or allow them the opportunity to see the benefit of being able to work as a group on the problems." She also said:

We really talked about choosing the task and how you had to choose the right task at the right time for it to be successful... and setting norms for the classroom so that the students would be ready and prepared to do that group work and to do those activities.

So the content course provided a setting not only for teachers to do the mathematics, but also for the coach to model the kind of pedagogy desired in the lesson study lessons. Then she was able to set the expectations for the lesson studies and used coaching within the lesson studies to hold teachers accountable to those expectations.

I asked Toni if there were any other new impacts on teachers that she had noticed since most of the impacts we had discussed were also mentioned in her first interview only six months into the start of MAST. She shared one final area in which teachers grew-leadership.

Leadership. The coach described how teachers exhibited more leadership in the lesson studies and at the district level as time progressed. She said, "I like the grant because I think it keeps teachers being reflective. I like the collaboration that teachers have to have to work with a team.....and I like that it hasn't always been the same team members working together." Toni mentioned how some groups had mixed an honors algebra 2 teacher with an applied mathematics teacher or "vertically teamed precalculus 
with geometry" and "done some really nice lessons to show the different levels that you can have in the same lesson."

She also took responsibility for one incident with a lesson study group where she felt she did not give enough leadership with a new teacher who had only joined MAST in the last year. However she was able to use this incident to talk to the other team members about their lack of leadership. Toni described to me what happened:

We had a brand new little teacher on their team, and they talked her into doing this lesson. When we talked about it, she thought she would be where it was and she wasn't. And that lesson fell apart like crazy. But she never spoke up to say 'We need to wait to do the lesson.' So I think that kind of taught me a lesson in that I've got to be more careful with my new folks in making sure that they do put the lesson at the right place. Because she missed that whole conversation that we had that first year...she came in last year without ever having any content training with us...so because she didn't...she ended up doing a lesson before the kids had any of the material...So I think it kind of helped them see, 'You got to look out for your team members number 1 , and you got to put the lesson in the right place for everybody.

Despite the lesson not going well for one team member, the coach was able to emphasize again the importance of timing a task and other members needing to step up and take the lead to look out for other members. Their relationships with each other had changed and grown through the lesson study process facilitated by the coach. I was curious if there were other impacts that came about from the teachers working with each other in the course and lesson study settings.

Toni gave examples of some teachers taking on "more leadership and directing their group." She also told me how some had quickly and graciously accepted invitations to share their lesson study lesson at district level staff development sessions. Finally, she reported, "Several of them between schools have shared materials." This practice had not 
happened prior to MAST, and she thought it was because they were more comfortable now because they had gotten a chance to know one another.

Whether the changes in teachers' leadership happened intentionally or as a byproduct of lesson study, coaching, or all of the above is not clear. Either way it is encouraging since the project is over. Sustainability of a project's initiatives is always a concern when funding runs out. Teachers' growth in reflectiveness and collaboration from their participation in MAST provides a good starting point to sustain the positive work that has begun. Toni was around before MAST and will likely be around after MAST, but now she has some leaders across the district to continue fostering the changes that have begun.

One final point of interest to me was whether the coach had experienced change or impact from having interacted with the teachers or university faculty. She had seen multiple impacts on teachers and students but what was she learning? The next section reports the personal impacts.

\section{Impact on the Coach}

I began by asking Toni what impact the course development and delivery had on her as a coach. I knew she had attended many professional development sessions as a participant and led many also, but now she was teaming with university faculty to lead them. Toni said it helped her to plan better. "I got a perspective from five different people on five different styles of planning for something, so I got the benefit of the best of all five with that." The coach was referring to the three university faculty with whom she cotaught the three content courses. The fourth was a university faculty member with whom 
she co-led the lesson study professional development, and the fifth with whom she co-led the CARSAM workshop (reading strategies).

Next I asked the coach what impacts she had experienced personally from serving as the project coach for MAST. My goal was to find out what, if anything, she had learned from interacting with the teachers. Toni answered, "I have had the opportunity to see ALL the lessons and I've gotten to see some 'aha' moments that were just pretty cool to watch. I don't think that you get that through just one-on-one coaching all the time." It struck me for the first time that what Toni was doing with lesson study was actually group coaching. Recall there were a handful of studies in the coaching literature on coaching interactions that were categorized as group coaching (Alloway \& Jilk, 2010; Gibbons et al., 2010). I asked Toni to elaborate and what she described was definitely “group coaching.” She said:

Well I think when you are one teacher in the classroom, you got so many things you are looking at at one time that sometimes you miss some things that can be pretty profound in student learning. And I think with us all being in a room as a team, it allowed the teacher some time to either see the 'aha' moments or through their partner bring out some of the discussion that they weren't able to hear because they were tied up with someone else and they could hear that from us and go 'Wow!'

She went on to give a specific example from the first year that was particularly memorable to her.

I remember that first year when we started talking about lesson study, especially with the younger teachers they had some concern about being able to put their kids in groups and kids doing what they were being asked to do and to go in and see their lessons and the kids were all talking about math and how they were thinking about math. And we did cup stack and somebody, one of the kids said, 'I'm not sure about my answer for 52 cups. Can I stack those cups up and see what the answer is?' in a class where the teacher is just like 'They usually don't work and they won't do anything.' They were all on task, they were all working, and here he was asking for something extra to do, so to see those kind of lessons 
and to let the teachers see the effect of that, I think has been pretty phenomenal for me as a coach.

It is not obvious from the coach's responses about personal impacts whether she was truly changed or acted differently due to her interaction with teachers. However, two key points can be taken away. First, Toni was accustomed to doing one-on-one coaching prior to MAST or when she currently coached non-MAST teachers. Her statements indicate a realization that group coaching through lesson study was much more powerful than one-on-one coaching. Secondly, her memorable example of authentic student engagement was atypical for that particular teachers' classroom. This scenario was likely a common sight for the coach to witness, but now the teachers saw for themselves how the changes they made affected student learning. I imagine Toni's meaning of "pretty phenomenal" was from the enjoyment of experiencing that moment with them.

\section{University Faculty}

I now present the final voice in the data for research question two. The voice of the university faculty described possible impacts on the coach's interaction with teachers but more of what they could speak to was the impact of their own interaction with the coach.

Recall three interviews were conducted with the university faculty who co-taught the content courses with the coach. The external evaluator conducted the first two interviews and I conducted the last interview. All of them took place about six months after the content courses were taught. Not much information was gleaned from the first interview about the coach's impact. What little the university faculty knew they had heard from the coach. Thomas said, "I had some feedback from [Toni], and she tells me that some of the teachers have implemented in their classes and they are very positive 
about it." He went on to say that the lesson plan component provided an important incentive because the teachers knew they would have to incorporate it into their classrooms. Donna said she was surprised at teachers' willingness to try the activities because they were intended for the adult learner, not necessarily for students, and yet some teachers used the exact same task from the content course while others modified the task.

That was the extent of what I learned from the initial interview and the subject of impact did not come up at all in the second interview. However, since it was the focus of my second research question, I pursued it intentionally in the final interview (see Appendix C). Interestingly, even when I pursued the subject, I still was not able to glean much more from them about the coach's impact unless it was personal impact.

\section{Impacts on Teachers}

I asked the university faculty what contributions the coach made after or outside of the course setting. In general, the university faculty could not say with certainty that the changes they saw in the teachers came from their interactions with the coach. All three reported that they were not privy to that information. They did not have follow-up with teachers or visit their classrooms. The university faculty simply taught the content courses. Donna did say that despite that, "I think she had an enormous amount of contributions outside of what took place within that week of content because she was in the in teachers' classroom, she was the one working with them on the lesson plans so I don't know how much information I could provide on that." Thomas reminded me that this was not their role. "We were contracted on a short-term basis to help provide content in the summer...and then it was her job to follow-up afterward." 
I followed up asking if they had heard anything from the teachers the next

summer about their success or failure with trying any of those lessons out. Donna responded:

I don't know that I know it was from her contributions, but the teachers definitely came back and said things such as trying a problem because...in the following year we would start the session saying 'Okay tell us what you've done since we saw you last summer,' and some of them would share out ideas they used from the weeklong course that they used in the classroom. Whether that was from some conversation with [Toni] or not, I have no idea.

Thomas described a change that occurred but was also unable to be certain of its origin.

This led to the following exchange between the three of them.

Thomas: There is a change taking place; that certainly is clear. And it's clear at least to me, from year to year, because the reluctance of students to go beyond their comfort zone certainly was diminished very highly as we went through the years. In the first year there was a reluctance to do things that are not in my course. 'So why should I do things in geometry when I'm teaching algebra 1?' or 'Why should I teach these algebra 1 topics differently than I already do?'

Donna: ... when you're speaking, that's exactly what I remember from the first year to the second year, that there was a significant change in the teachers' willingness to work on problems that were challenging.

Thomas: ... so that openness to try new things was certainly an effect that took place...I don't know how it took place, but it did take place. And I assume that part of it had to do with whatever was going on during the year, with interacting with [Toni] and the teachers in their own classrooms.

Donna: It's hard for me to distinguish impact...I don't feel very comfortable answering that question. I do agree with [Thomas] that over the course of time there was definitely change in the teachers....little things that were noticeable but overall, I think, and this is just my impression of what took place and I don't have evidence for it. I think the stuff that [Toni] did with them pertaining to the lessons had a huge impact. It's just I don't have evidence to show that...

Meg: Yeah, something happened there that we're not privy to, probably multiple things influencing that. The rapport that she has with the teachers, the work that she does, them becoming more comfortable with the process of the program and trusting in the program and there's probably tons of factors and a lot of them probably have to do with Toni. 
Donna: I think you'll get more information from teachers on that one, if you interview them.

Despite the university faculty feeling like they did not know much, their statements confirmed changes that emerged in other data sources. I did not personally interview the teachers, but I have already reported data from both the coach and teachers indicating they were willing to try new things. And Donna's statement about the lesson study being "huge" does not seem unusual either. The only thing certain in the university faculty's responses was that they could not be certain what precipitated the changes they observed.

On the other hand, they obviously had first-hand knowledge of how their work with the coach had impacted them personally. I organized their responses in the next section with the responses of the two mathematics education faculty first and the mathematician last.

\section{Impacts on University Faculty}

Meg. I asked what impact, if any, the course development and delivery with the coach had on each of them. Meg taught the fewest number of days and had interacted with Toni the least of the three. She responded first by saying:

I found it invaluable because I was coming in $7^{\text {th }}$ inning for the last class of the last year for the last two days of the week. So I found [Toni], and [Donna] too, of course, I looked to both of them for a lot of guidance as to like what the norms were, what the expectations were. And so like [Toni] provided a lot of topic input and answered most of my questions... she would bring in documents of standards and unpacking standards documents and I found all of that really helpful simply because I had very little information coming into it.

Meg's response about Toni's contributions centered on how she had helped prepare her for teaching her first MAST course.

Donna. Donna gave a different response about how Toni helped her stay connected to classrooms. She said: 
I think for me, personally and professionally, it has helped me because I was a classroom teacher. And I know once you go to a university, you don't stay, it's hard to stay connected to the day-to-day lives of teachers. I mean I go, I supervise interns and I see some things that are happening but that interaction with [Toni] has really helped keep me on top of what is taking place within classrooms and what's happening specifically in her county and for me that has been one of the biggest contributions to me and something that professionally I really want. Like for me it's hard not to be in a classroom so she's kind of my link of helping me see what's happening, the challenges teachers are facing and things maybe I need to address in a methods course...so it helps me, I think it helps me keep, stay connected.

Later on toward the end of the interview, Donna returned and concluded:

I think just like for me a final note would be that it's really nice having that person who has the rapport with the teachers who has seen them in the classroom knows what's happening in the classroom and can contribute to the planning and the execution of the workshops, having that knowledge. Because that's not something, the way we designed this, that's not something I can develop with teachers. I mean the two days I worked with them, there's just no way that I can develop that kind of rapport to know what's going on in their classroom. And her knowing that and being there and being able to help teachers make the connection between what's happening with the content and what they are doing in the classroom I think was a huge part of this project, and that piece came from her.

I thought this final statement was significant because it brought back a theme from the first research question that the university faculty mentioned regarding the importance of the coach's rapport and how they relied on her to fill that role. Secondly, Donna acknowledged Toni's contribution from her knowledge of the teachers and their work. Finally, she made a big deal about Toni being her "link" to the classroom and keeping her fresh with the current challenges, particularly to inform teaching of her methods course. I got no other information from Meg or Donna about the coach's impact. The final piece of data I present is what Thomas, the mathematician, had to say about his work with the coach. 
Thomas. Thomas had much more to say on the impact of his work with Toni.

Four things in particular were: (a) "bringing in toys," (b) dealing with gaps, (c) managing groups, and (d) understanding the levels. The first three he explained as follows:

Well for me, I guess there's made a big difference. I sort of feel that what little I know about teaching I have learned from working with the teachers. I teach at the college level very high-level content courses where it is typically very unlikely that students can discover the ideas on their own working in small groups, but whenever it is possible I do take the opportunities to do so. I have found myself bringing toys to class for graduate courses. I have used some of the same sort of activities that I used for the $6^{\text {th }}$ graders to show graduate students how to prove theorems that they should have known but they've forgotten. Theorems in trigonometry, theorems in calculus, so I mean just in proofs without words, little handouts and activities with students at lower levels and whenever there's a little gap, whenever I can see a little clearing in the forest in every classroom then I do little group sessions. I've always been doing that but I have gotten better at how to, how to...manage! That's the word I was looking for...I have learned more how to manage the group sessions by working with the teachers and with [Toni].

Thomas used some of the same concrete materials from the teachers' content course with his own graduate classes. He also described using some of the same activities to deal with gaps in his graduate students' knowledge. He said more about these gaps and talked about dealing with different levels in his follow-up response to my 'anything else?' prompt. He stated:

I'm not sure that this is, it's just a sensitivity. I have gotten more sensitive to having classes with students at different levels of understanding. Typically I always made the assumption that you come to Calculus 2 then your background is Calculus 1 and everybody is at the same level and if you are not at that level, it is not my fault. But I have become more sensitive to the fact that yes, I have to work with extra, some of the students to bring them up to the level, whatever it takes. Because in classes like the ones we taught the difference between the people in the levels was absolutely enormous and yet we were able to work with all of them in one way or the other. And so I think I have become better at teaching the students who are at a more beginning level and have more gaps in their understanding.

Working with Toni and the teachers to facilitate the content courses helped Thomas differentiate better and not ignore the gaps his own students brought to his class. Instead 
of being frustrated with what his students did not know, he decided he could and should work with them all, regardless of the level they were working at.

I gave all three university faculty one last opportunity to say anything they had not had a chance to share yet. Again, Thomas replied, "For me an important revelation is that it is no longer, we can longer teach mathematics in isolation." If he had stopped there, I would have thought he was talking about the content and making connections among mathematical concepts. Instead he continued by explaining something much deeper:

We need to understand what the students bring in to the classroom to be able to determine where we can take them from there and unless, without this working with the teachers, I would not know the different modes of learning that the students are bringing into the classroom, the different techniques with which they have been taught so that I try not to shock them as much by doing the traditional type of university teaching...

His statement here was about pedagogy not content. The point I heard him making was that as the teacher our role is to know the students' backgrounds and to do whatever it takes to prepare for teaching all learners, even the ones with gaps. He reiterated how he becomes less frustrated when "I find a student in my vector calculus class who still doesn't know how to simplify... or doing a wrong cancellation law" and instead viewed it as something to deal with swiftly and move on.

In his final statement, Thomas made one more point about teaching mathematics. He said, "I think it's working with students at all the different levels makes you more sensitive to the different kinds of difficulties that students have learning mathematics." The sensitivity point was not new but he acknowledged that mathematics is not easy to learn and it is understandable if they have difficulty. 
There was one final thing I needed to clarify with Thomas before ending the interview. In his initial response about the coach's impact, he began saying “...I have learned from working with the teachers" but later said "by working with the teachers and with [Toni]." I wanted to know if he was attributing his statements about what he had learned and changed to his work with the teachers, the coach, or both. He answered:

Some combination of the two... Yeah the combination of the two because without the managing skills of working with teachers that I observe her doing I would not be able to improve my own ability to manage my own group sessions. And plus one thing that you're increasing to learn is when a group session is working and when it's not working. And that takes experience. And you don't have enough time at the college level to try it out but here it's something that's happening every day, six hours a day for three years. You know when things are working and you know when it's time to 'Ah, okay, here's a time when I need to interject and bring things, bring people together' or 'Here's a place where everyone is doing something slightly different but they are all connected. Let me say something here and try to connect things.'... So I'm a better manager of my group sessions.

Not only did he answer my question about who was responsible for helping him to change his own practice. He also acknowledged another aspect of managing group sessions is knowing when things are going well and when they are not and having more than one way to interject to facilitate the current state of the groups.

\section{Triangulation of Data}

A key finding on interactions (RQ1) was the importance of the coach's rapport with teachers. Three data sources served as triangulation of this finding. The university faculty emphasized in their interviews the importance of the coach's rapport with the teachers because they did not have time to achieve that level with the teachers in a weeklong course, even over multiple summers. However, the university faculty interacted with the coach much more than the teachers and had worked with her outside of MAST. The coach described in her interview the dynamics of her relationships with the teachers, 
as she had coached them at least a year prior to MAST. Through the surveys and focus group, the teachers described how they valued the relationship with each other and having access to the coach.

Another key finding (RQ1) was that the coach and teachers' interactions focused on student learning. Triangulation across six data sources contributed to this finding. In the coach's first interview (year one), she described her interactions with teachers that included planning lessons, analyzing and reflecting on lessons, and taking steps to improve. Analysis of her coach's log indicated she spent two-thirds of her time with teachers doing some aspect of lesson study, one-quarter of her time delivering content courses with the university faculty, and the rest documenting or collecting data. The document outlining the coach duties was consistent with the student-focused activities reported in the coach's log. In her final interview, the coach also described engaging teachers in authentic learning experiences with the content as an important part of their interactions. The teachers' voice came through over two years of survey data. They agreed or strongly agreed that they had regular dialogue with the coach and that the dialogue was focused on teaching and mathematical concepts. All seven of the themes from the lesson study post conferences between the teachers and the coach also showed evidence of focus on student learning. Recall the themes were: (a) questioning or probing, (b) hypothesizing or recognizing challenge, (c) identifying or recognizing success, (d) summarizing or justifying, (e) offering idea or strategy, (f) teaching or explaining, and (g) recommending or providing feedback.

A final key finding reported by the university faculty related to coaching interactions (RQ1) in whole-group settings was the coach "chiming in" to bring out 
discussion, highlight teachers' strategies, and make important connections to their classroom work. While this finding is unique to the university faculty interviews, it is triangulated across all three faculty members. One university faculty member highlighted her leading the class to the 'right kinds of questions,' which he described as having a conceptual focus instead of a procedural focus.

Regarding the impact of coaching interactions (RQ2), a key finding was teachers changed their practice. Triangulation was accomplished through four data sources. On the surveys, teachers agreed or strongly agreed they were satisfied with the coaching, the coaching met their needs, and they implemented methods from the coaching they received. The methods mentioned were specific lessons or teacher behaviors like questioning. The benefits of coaching cited by teachers were having the moral support to change their practice and try something new like reading strategies.

The teachers' focus group confirmed these benefits, with additional teaching behaviors they learned or the coach modeled for them. Some of these behaviors were standing back to let the students explore, giving fewer answers and asking more questions. Results from the RTOP confirmed statistically significant increases in the mean overall score $(\alpha=.001)$ indicating teachers were exhibiting more reform-based teaching practices.

In the final interview, the coach provided her perspective on the changes she had observed teachers making in their practice. First and foremost was a "willingness to try" implementing new strategies that they had previously been hesitant to try. In particular, teachers were implementing literacy strategies although the RTOP would not detect that particular type of change. She attributed this change to teachers not only having the 
support of a coach but also their lesson study team and tasks that were easy to differentiate. She also cited lesson study as critical to their change because it allowed them to develop relationships with each other and put the focus on students. "Doing the mathematics" was also critical to their development because it focused them on students' thinking and put them in the role of the learner. They valued the power in understanding a problem in multiple ways for themselves and for their students. It helped them gain flexibility with the mathematics and prepared them for a variety of student responses. They recognized how rich mathematical tasks could cover multiple standards to deal with time constraints in meeting all their course objectives. 


\section{CHAPTER V}

In this final chapter, I present a summary of the study, the major findings and how they are related to the research literature. In addition, I report surprises in the findings, and implications of those findings. Finally I present limitations of the study, recommendations for future research, and some concluding thoughts.

\section{Summary of the Study}

Coaching has been widely implemented in mathematics education as a form of customized professional development, yet research to support it lags behind its implementation (McGatha, 2009a; National Mathematics Advisory Panel, 2008).

Evidence is needed to establish the effectiveness of coaching in supporting change in teacher practice and the type of interactions between coaches and teachers that precipitate that change. One category of the mathematics coaching research described coach interactions but these were all conducted at the elementary level (Barrett et al., 2002; Becker, 2001; McGatha, 2008; Olson, 2005; Olson \& Barrett, 2004; Race et al., 2002). Of all the studies published on mathematics coaching, only three were conducted at the secondary level (Alloway \& Jilk, 2010; Becker \& Pence, 1999; Krupa \& Confrey, 2010).

\section{Study Purpose and Research Questions}

The purpose of this study was to examine a high school mathematics coach in the context of a three-year project called MAST (Mathematics Achievement Success Today) that provided summer content courses, lesson study, and mathematics coaching for high school teachers. The goals of MAST were to improve student achievement, increase 
teachers' mathematical content knowledge, support teachers in changing their instructional practice, and create a partnership between a local school district and a neighboring university. This study focused in particular on the work of the MAST project coach as she interacted with classroom teachers and university faculty, and the subsequent impact of those interactions on both groups. The purpose of the study led to these questions:

1. What was the nature of the coach's interactions with secondary teachers and university faculty during the MAST project?

2. What was the impact of the coach's interactions during the MAST project?

a. To what extent did secondary teacher practice change?

b. To what extent did university faculty practice change?

\section{Review of the Methodology}

This was a mixed-methods study that used a combination of primary and secondary data. The secondary data were from the three-year MAST project and included coach and university faculty interviews, teacher surveys, teacher observations with the Reformed Teaching Observation Protocol (Piburn et al., 2000) or RTOP, a teacher focus group, audiotaped post conferences between the teachers and the coach, a coach's log, and document review of the coach's project duties. I collected the primary data after the project had ended in the form of post interviews with the coach and three university faculty. Given the quantity of data in this study, I remind the reader of Table 1 presented in chapter three that summarized the data sources and indicates the research question addressed by each source. 
The data included both quantitative and qualitative sources and were analyzed accordingly. I analyzed the quantitative data from the surveys and coach's activity log computing means, standard deviations, and relative frequencies. The RTOP observational data had overall scores and subscale scores with means and standard deviations as well but I also tested for significance to see if teachers' mean score increased significantly over time to indicate movement towards reform-based instruction in mathematics.

\section{Table 1}

\section{Alignment of Data Sources to Research Questions}

\begin{tabular}{|c|c|c|}
\hline \multicolumn{3}{|c|}{ MAST Secondary Data Collection } \\
\hline Data Source & $\begin{array}{l}\text { How does the } \\
\text { coach interact with } \\
\text { teachers? (RQ1) }\end{array}$ & $\begin{array}{l}\text { What is the impact } \\
\text { of the coach's } \\
\text { interactions? (RQ2) }\end{array}$ \\
\hline Coach's Log & $\bullet$ & \\
\hline End-of-Year Survey & $\bullet$ & $\bullet$ \\
\hline Coach Interview & $\bullet$ & $\bullet$ \\
\hline University Faculty Interviews & $\bullet$ & $\bullet$ \\
\hline Lesson Study Post-conferences & $\bullet$ & \\
\hline Document Review of Duties & $\bullet$ & \\
\hline RTOP & & $\bullet$ \\
\hline Focus Group & & $\bullet$ \\
\hline \multicolumn{3}{|c|}{ Primary Data Collection } \\
\hline Data Source & $\begin{array}{l}\text { How does the } \\
\text { coach interact with } \\
\text { teachers? (RQ1) }\end{array}$ & $\begin{array}{l}\text { What is the impact } \\
\text { of the coach's } \\
\text { interactions? (RQ2) }\end{array}$ \\
\hline Coach Interview & $\bullet$ & $\bullet$ \\
\hline Faculty Interviews & $\bullet$ & $\bullet$ \\
\hline
\end{tabular}

I analyzed all the qualitative data using general coding strategies (Creswell, 2008a). This included collecting the data, transcribing the data, reading through the data multiple times, and developing codes that emerged from the data. Coding was an iterative process that I repeated to group related codes, eliminate redundancy, and identify key themes that were evident. These analyses were used on the initial list of activities pulled 
from the coach's log, document review of the coach's responsibilities, the post conferences, the teachers' focus group, the coach interviews, and the university faculty interviews. Additional details on the analysis and ways in which researcher bias was managed are described in chapter four.

\section{Major Findings Related to the Literature}

The findings in this study align with many reported in the mathematics coaching research literature. In this section, I report the major findings for each research question and their connections to the research literature.

\section{Research Question 1: Nature of Coaching Interactions}

In this study, interactions among project participants provided important context for understanding the subsequent impact. Three major findings that align with the research literature were: (a) the coach's rapport, (b) the clarity of the coach's role, and (c) levels of engagement.

\section{Coach's Rapport}

A key contribution to coaching interactions was the coach's strong rapport and connection to teachers and their classrooms. This strong rapport in a coaching relationship stands in contrast to the research literature where a lack of trust and rapport is cited as a barrier in coaching relationships (Ai \& Rivera, 2005). From the university faculty's perspective, the coach's rapport with teachers significantly impacted the interactions between the coach, university faculty and MAST teachers in three ways: (a) providing follow-up for teachers' classroom implementation, (b) providing a bridge between university faculty and the teachers, and (c) providing input to the planning and delivery of the content course. 
First, the coach followed up the courses by supporting teachers' implementation throughout the school year. This follow-up correlates with multiple studies in the coaching literature which used coaching as a follow-up to professional development to support teachers' implementation in the classroom (Balfanz et al., 2006; Becker \& Pence, 1999; Campbell \& White, 1997; Kretlow et al., 2011; Krupa \& Confrey, 2010; Race et al., 2002; Rudd et al., 2009).

Second, since the university faculty did not have time to develop rapport with the high school teachers, the coach played a critical role in providing a bridge between the university faculty and teachers. The university faculty relied on the coach's rapport in the content courses because their interaction with the teachers was limited. Within each course, two faculty members split the responsibility for teaching to two or three days for the week while the coach taught the entire week. Because of this teaching schedule, the university faculty actually claimed to interact more with the coach than the teachers. Clearly the coach's rapport with teachers provided an important link between the university faculty and the teachers.

Third, the coach's rapport had an impact on the planning and delivery of the course. In the content courses, the university faculty and coach collaborated and negotiated how to best deliver the content and model the pedagogy they wanted teachers to emulate. The coach's rapport with teachers gave her a better sense of their content needs. The coach had recently come out of a teaching position and participated in a previous offering of these courses. This gave her a unique lens to contribute when planning the course with university faculty. One faculty member cited this knowledge 
that the coach had for "planning and execution of the workshops" as a "huge part of this project."

\section{Clarity of the Role}

A second major finding on the nature of the coach's interactions focused on the clarity and consistency of her role. There were three primary activities in which the coach interacted with teachers: (a) teaching the content courses and other professional development, (b) gathering data, and (c) facilitating lesson study. Almost 70 percent of the coach's time logged with teachers was spent on lesson study. Recall the document the MAST coach drafted for her administration to help clarify her role in MAST (see Appendix F). This is in contrast to several studies in the research literature describing how coaches are often pulled away from their coaching responsibilities to fulfill noninstructional duties (Campbell, 2007; Campbell \& Malkus, 2009; Gibbons et al., 2010; Poglinco \& Bach, 2004).

Furthermore, it was clear from the teachers' survey data that MAST teachers had a common understanding of the coach's role. Teachers agreed they had regular dialogue with the coach on how to effectively teach mathematical concepts. The themes in the post conference discussions with teachers corroborated this focus on teaching. Recall some of the post conference themes regarding coach and teacher interactions were "hypothesizing or recognizing challenge," "identifying or recognizing success," and "summarizing and justifying" related to teaching as described in Chapter 4. Clearly the MAST teachers and MAST coach had a common view of the coach's role that focused their interactions on teaching. In contrast, the research literature cites a lack of clarity in the coach's role as a barrier to coaching relationships (Ai \& Rivera, 2005; McGatha, 2008). This barrier was 
overcome in the MAST project by a very explicit attention to student learning. This was accomplished by the use of the lesson study protocol, which constantly focused conversations on student thinking. A student learning focus was identified as an important structure in several studies in the mathematics coaching research (Alloway \& Jilk, 2010; Campbell, 1996; Campbell \& White, 1997; Gibbons et al., 2010).

\section{Levels of Engagement}

A final area related to the coach's interactions with teachers focused on the level of engagement. Recall that McGatha (2008) categorized teachers' levels of engagement as "consulting," "collaborating," and "coaching" as described in Cognitive Coaching SM (Costa \& Garmston, 2002). "Coaching" is the most effective level of engagement for coach and teacher interactions because at this level the teacher is the most thoughtful and autonomous while the coach probes and questions. A very notable change in the MAST project over time was that teachers took on more leadership as they became more reflective. For example, during their post conference sessions, teachers questioned and provided feedback and strategies to their peers, taking on the coach's role as they became comfortable with the lesson study protocol and each other. The coach also cited that some teachers presented their transformed lessons to other mathematics teachers during district-wide staff development sessions. The mathematics coaching research literature supports teachers becoming as reflective and self-directed as possible to reach the optimum level of engagement for coaching interactions (Becker \& Pence, 1999; Costa \& Garmston, 2002; McGatha, 2008; Race et al., 2002). 


\section{Research Question 2: Impact of Coaching Interactions}

In this section, I report the major findings related to the literature from the second research question on the impact of the coaching interactions to teachers' practice, and university faculty practice.

\section{Changes in Secondary Teachers' Practice}

The majority of mathematics coaching research studies focused on coaching as a follow up to professional development and found teachers changed their practice as a result of these coaching interactions (Becker \& Pence, 1999; Kretlow et al., 2011; Krupa \& Confrey, 2010; Race et al., 2002; Rudd et al., 2009). The findings from this study regarding change in teachers' practice align with the mathematics coaching research. MAST teachers and the coach reported evidence of change in teachers' practice.

Teachers reported implementing a variety of new instructional strategies or specific lessons with success. These included strategies for literacy, assessment, organization, and displaying student work. The coach reported some teachers were sharing materials and lessons between schools on their own initiative. She also claimed that teachers asked higher-order questions, directed students to talk with each other, encouraged group work, and used hands-on activities with student self-discovery. In general, teachers put greater focus on student thinking and engagement, proper selection of mathematical tasks, and setting classroom norms.

The RTOP data corroborated teachers' changes in instructional practice showing significant increases in their overall scores between the first and second year and between the first and third year. All five subscales in lesson design and implementation, propositional content knowledge, procedural content knowledge, communicative 
interactions, and student-teacher relationships were significantly higher in the second year, third year, or both. Teachers also reported increases in content knowledge on the end-of-year surveys as well.

The university faculty noted changes in the way teachers interacted with the mathematics in the course. They saw teachers more willing to try new and challenging tasks or tasks outside their course or grade level that they would previously have been hesitant to try. The university faculty had no knowledge of whether that willingness translated back to teachers' instructional practice. However, the coach corroborated this willingness in the teachers. In contrast, the mathematics coaching literature cited teachers' resistance to change as another barrier to coaching interactions (Ai \& Rivera, 2005). From interacting with the mathematics as learners, teachers increased their content knowledge, looked at mathematics differently, valued knowing multiple ways to work a problem, and increased their ability to use one task to teach many objectives in their curriculum.

Two large whole-school reform studies from the mathematics coaching literature also reported on positive changes to teachers' practice. These studies differ from the studies previously discussed because the coaching was part of a larger reform effort very similar to MAST that included course work for the teachers, coaching follow-up, gradelevel meetings, and in some cases a new mathematics curriculum (Balfanz et al., 2006; Campbell \& White, 1997). While all of these studies, and the findings from this study report positive changes to teachers' practice, there were a number of factors at work making it difficult to claim the changes resulted specifically from the coaching. 


\section{Changes in University Faculty Practice}

Only three studies in the mathematics coaching literature included course work for teachers led by university faculty (Barrett et al., 2002; Becker \& Pence, 1999; Campbell \& White, 1997; Olson \& Barrett, 2004). None of these mathematics coaching studies examined how university faculty practice changed as a result of interactions with a coach. This study is the first to examine the impact of coaching interactions on university faculty and thus, fills a gap in the literature.

There was evidence of impact on the university faculty however it differed from one individual to the next. This makes sense considering there was some variation in the amount of time each of them spent co-teaching or co-planning with the coach. Recall that two of the university faculty were mathematics educators and one was a mathematician.

One of the mathematics educators taught only two days of one course in the final year of the project. She expressed appreciation for the coach's contribution to helping with the MAST course development and delivery but there was no indication of change in her instructional practice at the university level. Another mathematics educator faculty member taught at least three days of each of the three courses. She appreciated the interactions because the coach provided a link to the MAST teachers' content needs and classroom needs. This proved to be not just useful information in working with MAST teachers but also in working with pre-service teachers in general. She cited these interactions with the coach as informing her work in teaching methods courses.

The mathematician taught at least two days with the coach in the first two courses. He spoke of dramatic impacts on his instructional practice from interacting with the coach. In terms of his practice, he described using some of the same concrete 
materials ("toys") with his graduate level mathematics courses that he observed the coach using with teachers in the content courses. He spoke about gaining a sensitivity to gaps he discovered in his students' knowledge that typically he would have ignored, citing the students at fault for not coming in with the prerequisite knowledge they should have had. Instead, he embraced the notion that his students' backgrounds were quite varied and it was his obligation as the instructor to be aware of the differences in their levels and differentiate accordingly. As a result of these changes in beliefs, his pedagogy changed to reflect an increased attention to these levels. For instance, he conducted more group sessions to help students with gaps in their knowledge. He claimed to know better how to manage these group sessions as a result of his interactions with the coach during the content course.

\section{Surprises}

There were a few surprises that emerged as I collected and analyzed the data for this study. One was the group coaching, and the other was the different degrees of impact on university faculty from interacting with the coach.

The lesson study component of MAST transformed this from a study about oneon-one coaching to one about group coaching. Recall only two studies in the mathematics coaching literature were identified as group coaching (Alloway \& Jilk, 2010; Gibbons et al., 2010). A common finding in the group coaching literature was the coach's use of meetings focused on student learning. Lesson study helped accomplish the same focus on student learning in the MAST project. When I formulated the research questions and plan for data analysis I did not fully understand how lesson study was going to be a driving force in this project. 
I was also surprised at the impact on the university faculty and the differences in impact among the three of them. There were definitely differences in the amount of time each of them interacted with the coach, which would likely create differences in what they learned from each other. I was especially struck by the insights expressed by the mathematics faculty member, Thomas. I was surprised by Thomas' comments and how working with the coach and MAST teachers impacted his teaching at the graduate level. Not only did he implement some lessons and materials from the summer courses but he also changed his beliefs and pedagogy accordingly. He articulated the need to understand students' varying levels of knowledge, the need to differentiate accordingly, and his role and responsibility in that process (versus blaming on the students).

Furthermore, I was surprised at the chemistry between Thomas and the coach in the content course that he described as "seamless." All three university faculty members were very explicit in the interview about their expertise, whether it was content or content and pedagogy. Thomas claimed that he was the "content person" so when he worked with the coach she would need to take the lead on pedagogy. In contrast, Donna said her interaction with the coach was different because as a mathematics educator she had expertise in both content and pedagogy. It appeared that the coach's role in the content course was not as well defined with Donna as it was with Thomas. I think these differences give some indication why Thomas had a more "seamless" chemistry in the course delivery with the coach because each person knew what they needed to contribute. In addition, perhaps he was less certain about managing the group discussions in the course because he knew pedagogy was not his area of expertise and so he knew he had to take greater measures to prepare for those discussions. 
Recall Thomas was the one who indicated that they actually "interacted more with each other in trying to figure out what was going on at each table and sharing information about what have you heard." Donna agreed with this description but then Thomas extended his response explaining these interchanges were essential because "then when we wanted to share information then we could actually select across the sequence that made sense...so we shared that information before while the teachers were working and used that as a way to bring up the discussion." If this same interaction was not as common between Donna and the coach, it would explain her comment that the coach sometimes intervened too early in a discussion because they had not talked with each other or planned ahead about how they were going to lead that whole group discussion.

This idea is also validated in Thomas' description of the coach's impact on him where he said working with the teachers and the coach had helped him learn how to manage group sessions better in his own college classes. He recognized the coach's experience with pedagogy and was able to learn from it in a substantial way. I would argue that their 'seamless' chemistry and his personal revelations about managing groups resulted from more intentional planning than was evident when the coach interacted with Donna or Meg.

After Thomas' comments about working with the coach, I was surprised that the coach did not have more to say about what she learned from working with the faculty. I actually expected to hear more planning and thoughtful pedagogical practice initiated from the leadership of the mathematics educators. I recognize that the focus of MAST was to improve teachers' practice but this seemed like a missed opportunity to not only improve the content course discussions with the teachers but also for the faculty to 
provide leadership and professional growth to the coach (or vice versa) in facilitating effective discourse.

\section{Implications}

Many factors in the MAST project contributed to its success and the changes that occurred in teachers and university faculty's practice. It is reasonable to question whether the same results would have been achieved without the three critical components of MAST: (a) the coach, (b) lesson study, and (c) content courses. I argue that it was the combination of these three components that led to the positive outcomes in the MAST project. Removing any one of those would likely have resulted in different findings. I reflect below on each of these and whether each of them was necessary to the success of this project.

\section{Was the coach necessary?}

After examining the existing data, I had learned of many positive things that were happening with teachers from their involvement in MAST. What I did not know was what parts of MAST were responsible for the impacts that teachers described. I posed questions to the coach in the final interview to try and uncover some understanding of what led to or caused the changes.

Recall some of the coach's descriptions of changes in teachers' practice. Teachers focused more on students' thinking, probed students to describe their thinking, asked more higher-order questions, gave fewer answers, and were more willing to attempt tasks they would not have tried previously. This "willingness to try" also came out in the teachers' survey and university faculty interviews. I asked the coach if she thought these changes in teacher practice were a result of the content course and if teachers would 
implement the methods she observed without a coach. She responded that coaching "helped remind them" (referring to actual tasks or pedagogical ideas modeled in the content courses) and explained how easy it can be to forget things learned in a course or workshop.

The coach was central to the MAST project. Recall in the survey data, teachers reported that the coach was "invaluable," "pushed me out of my comfort zone," and was one part of MAST that should be sustained beyond the funding. In the focus group, some teachers cited the coach as the thing they would miss most after MAST was over, while others valued the additional perspective she brought to their classrooms in seeing "things I would never think about." The value of coaching is cited in the mathematics coaching literature as critical and more effective than professional development in isolation because teachers needed individualized support to implement the changes they desired (Becker \& Pence, 1999; Cornett \& Knight, 2009; Kretlow et al., 2011).

\section{Were the content courses necessary?}

To play the devil's advocate, I asked the coach if she thought the same could be achieved without the content courses because I knew she had experience coaching prior to MAST that did not engage teachers in content courses. She said, "You have to have both...coaching is professional development differentiated for teachers... at the same time I think you do that intense professional development... you're just following up on that throughout the year with that coaching... it's both working together."

Recall "doing the mathematics" and the follow-up discussions were an important part of teachers' content development throughout MAST but also played a part in transforming their thinking about pedagogy. I asked the coach if the math discussions 
only occurred in the content courses or in coaching sessions as well. She said they happened in both and reiterated how they used the content course to model the pedagogy they expected in the lesson studies. So the content course played a critical part in the MAST project in giving teachers opportunities to work on mathematical tasks, to see the kind of pedagogy needed to enact those tasks, and to give the coach and teachers a common set of tasks to access and refer back to in their sessions together. The coaching provided the follow-up or reminder that the coach suggested but the content courses gave them the shared set of instructional tasks.

\section{Was the lesson study necessary?}

If the coaching and the content courses were critical, what about the lesson study? The role of lesson study in MAST was to hold teachers accountable to implementing lessons at a standard set in the content course and teachers knew the coach and their peers would be holding them to those standards. I questioned the coach in our final interview to find out if the lesson study backdrop made that much difference in coaching MAST teachers compared to non-MAST teachers.

First and foremost, she stated that the post conferences with MAST teachers were much deeper and did not take as much time to get to the rich discussions about student learning. I think this can be attributed to the focus on student learning created by the lesson study protocol and the relationships that are established within the teams. Teachers were quickly able to get to the heart of the lesson, its strengths and weaknesses, and how to improve it for the next team member teaching.

Second, participating in lesson study increased MAST teachers' leadership and reflectiveness. The coach described how teachers were "more open to bringing out things 
that they thought worked or didn't work before you ever even as a coach have to bring it up or talk about it." The mathematics coaching literature recommended this as the ideal level of engagement for coaching interactions (Becker \& Pence, 1999; McGatha, 2008). In contrast, the non-MAST teachers were more likely to report "Everything's fine" and so the coach had to work much harder to facilitate productive conversations about student learning.

Third, lesson study made the post conferences less personal. The coach suggested this was because the lessons did not belong to an individual but to the group. If the lesson did not go well or needed work, then the group analyzed what happened and figured out a way to make it better, whereas the non-MAST teachers might, as described by the coach, "have that defense up immediately."

Finally, I would argue the lesson study was necessary because it provided teachers an opportunity to observe their peers. The teachers found this experience in lesson study very valuable "because even talking about it, it's very different when you see it implemented." I contend this contributed to their willingness to try new things because they had the chance to test a lesson, adjust as necessary, and see the results of those choices almost immediately instead of having to wait another year or semester to try a lesson again. Unfortunately, the non-MAST teachers missed out on this kind of experience by not participating in the lesson study.

\section{Limitations}

After analysis of the data and further reflection, there were some limitations that emerged in this study. First and foremost, the teachers in MAST were not just engaged in coaching but were also content courses and lesson study. It is difficult to be certain which 
of these factors caused the subsequent changes in teachers' practice. As indicated earlier, I argue that it was a combination of factors as opposed to any single factor.

Second, the use of secondary data from an existing project provided advantages and disadvantages for this study. The advantages were having access to multiple sources of data as well as longitudinal data. The disadvantages were not having access to the project in its inception and planning stages. If I had been engaged with the project early on, I could have had more input into the data collection so it had a closer alignment with the research questions of this study.

Third, the sample of MAST teachers was constantly changing from year to year and from one data source to the next. Teacher attrition in MAST was the result of retirement, moving out of the district, or leaving the profession. Even the teachers who did participate with MAST over the three years and had RTOP data for all three years did not consistently respond to surveys or may not have participated in the post conference sessions that were audiotaped. Therefore there is a lack of consistency from participants across the data sources.

Finally, MAST is only one project involving a limited number of teachers from one district in a small geographic area. The findings from this project might not transfer to other projects in other districts or other areas of the country. Following consideration of this study's limitations, I reflected on possible directions for future research that emanate from the findings of this study.

\section{Future Research}

In terms of mathematics coaching research, there are no studies that include a focus on lesson study. Future studies could examine mathematics coaching in which 
lesson study is used. It would be instructive to determine if coaching used in conjunction with lesson study supports teachers in becoming more reflective as is recommended in the coaching literature (Costa \& Garmston, 2002; Garmston, Linder, \& Whitaker, 1993; McGatha, 2008).

Even though this was not a focus of this study, there were small evidences of impact on students from the post-interview with the coach (cup stack story) and the focus group responses from teachers (students' faces, increased engagement, etc.). I would recommend a more intentional examination of impact on students in the context of group coaching.

\section{Final Thoughts}

Coaching allows for customized professional development for teachers and the coach made a closing statement in her final interview with me that summarized this well. She said, "We shouldn't have one-size-fits-all PD for teachers. And a lesson study allows them to, wherever they are...they can be at two totally different places with their team member and still grow through the process." The coach went on to describe the isolation teachers feel but I would argue the same isolation exists for coaches. Recall her words in the post interview, "When you are one teacher in the classroom, you got so many things you are looking at, at one time that sometimes you miss some things that can be pretty profound in student learning." The coach said that getting to participate in this process was "pretty phenomenal" and I wondered if this feeling was heightened because it happened in a group coaching situation instead of a one-on-one coaching situation. Did having other teachers present and identifying 'aha' s for one another increase the impact 
of those insights? I would argue that it helped not only the teacher affected but also the others watching it unfold.

It also made me think about how lonely teaching can be when you see students have 'aha' moments and often no one is around to witness it except the teacher. It is a special thing to witness, but as a former coach it was just as special (possibly even more so) to see teaching professionals having one of those moments. I can see why she described these group coaching experiences as "pretty phenomenal" in her final statements to me. Having these kind of experiences on a regular basis are possible with group coaching. 


\section{REFERENCES}

Ai, X., \& Rivera, N. (2005). Linking ideas to practice: Effectiveness of coaching upon teacher practice. In J. R. Dangel \& E. Guyton (Eds.), Research on alternative and non-traditional education: Teacher education yearbook XIII (pp. 191-204). Lanham, MD: Association of Teacher Educators with Scarecrow Education.

Alloway, M., \& Jilk, L. M. (2010). Supporting students by supporting teachers: Coaching moves that impact learning. In P. Brosnan, D. B. Erchick \& L. Flevares (Eds.), Proceedings of the 32nd annual meeting of the North American Chapter of the International Group for the Psychology of Mathematics Education (Vol. VI, pp. 1420-1427). Columbus, OH: The Ohio State University.

Association of Mathematics Teacher Educators. (2010) Standards for elementary mathematics specialists: A reference for teacher credentialing and degree programs. San Diego, CA: AMTE.

Association of Mathematics Teacher Educators (Producer). (June 2010). The role of elementary mathematics specialists in the teaching and learning of mathematics. AMTE Connections Newsletter. [Joint position statement] Retrieved from http://www.amte.net/sites/all/themes/amte/resources/newsletters/AMTENewslette r_Vol19-4_Summer2010.pdf

Balfanz, R., MacIver, D. J., \& Byrnes, V. (2006). The implementation and impact of evidence-based reforms in high-poverty middle schools: A multi-site, multi-year study. Journal for Research in Mathematics Education, 37(1), 33-64.

Barrett, J., Jones, G., Mooney, E., Thornton, C., Cady, J., Guinee, P., \& Olson, J. (2002). Working with novice teachers: Challenges for professional development. Mathematics Teacher Education and Development, 4, 15-27.

Becker, J. R. (2001). Classroom coaching: An emerging method of professional development. In R. Speiser, C. Maher \& C. Walter (Eds.), Proceedings of the Twenty-third Annual Meeting of the North American Chapter of the International Group for the Psychology of Mathematics Education (Vol. 2, pp. 751-760). Snowbird, UT.

Becker, J. R., \& Pence, B. J. (1999). Classroom coaching: A critical component of professional development. In F. Hitt \& M. Santos (Eds.), Proceedings of the Twenty-first Annual Meeting of the North American Chapter of the International Group for the Psychology of Mathematics Education (Vol. 2, pp. 771-777).

Columbus, OH: ERIC Clearinghouse for Science, Mathematics, and Environmental Education. 
Black, A. C., Little, C. A., McCoach, D. B., Purcell, J. H., \& Siegle, D. (2008). Advancement via individual determination: Method selection in conclusions about program effectiveness. The Journal of Educational Research, 102(2), 111123.

Brosnan, P., \& Erchick, D. (2010). Mathematics coaching and its impact on student achievement. In P. Brosnan, D. B. Erchick \& L. Flevares (Eds.), Proceedings of the 32nd annual meeting of the North American Chapter of the International Group for the Psychology of Mathematics Education (Vol. VI, pp. 1362-1370). Columbus, OH: The Ohio State University.

Campbell, P. F. (1996). Empowering children and teachers in the elementary mathematics classrooms of urban schools. Urban Education, 30(4), 449-475.

Campbell, P. F. (2007). A quantitative investigation of the activity and impact of elementary mathematics coaches. Paper presented at the Annual Meeting of the American Educational Research Association, Chicago, IL.

Campbell, P. F. (2011). Elementary mathematics specialists: A merger of policy, practice, and research. In W. F. Tate, K. King \& C. R. Anderson (Eds.), Disrupting tradition: Research and practice in mathematics education (pp. 93103). Reston, VA: National Council of Teachers of Mathematics.

Campbell, P. F., \& Malkus, N. N. (2009). School improvement through elementary coaches: Impact on teacher beliefs and student achievement. Paper presented at the Annual Meeting of the American Educational Research Association, San Diego, CA.

Campbell, P. F., \& Malkus, N. N. (2011). The impact of elementary mathematics coaches on student achievement. The Elementary School Journal, 111(3), 430-454.

Campbell, P. F., \& White, D. Y. (1997). Project IMPACT: Influencing and supporting teacher change in predominantly minority schools. In E. Fennema \& B. S. Nelson (Eds.), Mathematics Teachers in Transition (pp. 309-355). Mahwah, New Jersey: Lawrence Erlbaum Associates, Publishers.

Conaim, S. (2010). Mathematics coaching and its impact on urban fourth grade students' mathematics proficiency on high stakes testing. In P. Brosnan, D. B. Erchick \& L. Flevares (Eds.), Proceedings of the 32nd annual meeting of the North American Chapter of the International Group for the Psychology of Mathematics Education (Vol. VI, pp. 1379-1386). Columbus, OH: The Ohio State University.

Cornett, J., \& Knight, J. (2009). Research on coaching. In J. Knight (Ed.), Coaching: Approaches and perspectivves (pp. 192-216). Thousand Oaks, CA: Corwin Press. 
Costa, A. L., \& Garmston, R. J. (2002). Cognitive Coaching: A foundation for renaissance schools (2nd ed.). Norwood, MA: Christopher-Gordon Publishers.

Creswell, J. W. (2008a). Analyzing and interpreting qualitative data. Educational research: Planning, conducting, and evaluating quantitative and qualitative research (3rd ed., pp. 243-270). Upper Saddle River, New Jersey: Pearson Education Inc.

Creswell, J. W. (2008b). Mixed methods designs. Educational Research: Planning, conducting, and evaluating quantitative and qualitative research (3rd ed., pp. 551-595). Upper Saddle River, New Jersey: Pearson Education Inc.

Darling-Hammond, L., \& McLaughlin, M. W. (1995). Policies that support professional development in an era of reform. Phi Delta Kappan, 76(8), 597-604.

Darling-Hammond, L., Wei, R. C., Andree, A., Richardson, N., \& Orphanos, S. (2009). Efffective teacher development: What does the research show? Professional Learning in the Learning Profession: A Status Report on Teacher Development in the United States and Abroad (pp. 9-13). Stanford University: National Staff Development Council.

Dossey, J. (1984). Elementary school mathematics specialists: Where are they? Arithmetic Teacher, 32(3), 3,50.

Evered, R. D., \& Selman, J. C. (1989). Coaching and the Art of Management. Organizational Dynamics, 18(2), 16-32.

Fennell, F. (2006, November). We need elementary school mathematics specialists NOW. NCTM News Bulletin, 43(4), 3.

Foster, D., \& Noyce, P. (2004). The mathematics assessment collaborative: Performance testing to improve instruction. Phi Delta Kappan, 85(5), 367-374.

Garmston, R., Linder, C., \& Whitaker, J. (1993). Reflections on cognitive coaching. Educational Leadership, 51(2), 57-60.

Gibbons, L. K., Garrison, A., \& Cobb, P. (2010). Teacher networks and the role of mathematics coach: How institutional factors influence coach centrality. In P. Brosnan, D. B. Erchick \& L. Flevares (Eds.), Proceedings of he 32nd annual meeting of the North American Chapter of the International Group for the Psychology of Mathematics Education (Vol. VI, pp. 1387-1394). Columbus, OH: The Ohio State University.

Grant, C. M., \& Davenport, L. R. (2009). Principals in partnership with math coaches. Principal, 88(5), 36-41. 
Hellawell, D. (2006). Inside-out: Analysis of the insider-outsider concept as a heuristic device to develop reflexivity in students doing qualitative research. Teaching in Higher Education, 11(4), 483-494.

Jones, G. A., Lubinski, C. A., Swafford, J. O., \& Thornton, C. A. (1994). A framework for the professional development of K-12 mathematics teachers. In D. B. Aichele \& A. F. Coxford (Eds.), Professional development for teachers of mathematics (pp. 23-36). Reston, VA: National Council of Teachers of Mathematics.

Joyce, B., \& Showers, B. (1982). The coaching of teaching. Educational Leadership, $40(1), 4-8,10$.

Knight, J. (2006). Instructional coaching: Eight factors for realizing better classroom teaching through support, feedback and intensive, individualized professional learning. The School Administrator, 63(4), 36-40.

Kretlow, A. G., Wood, C. L., \& Cooke, N. L. (2011). Using in-service and coaching to increase kindergarten teachers' accurate delivery of group instructional units. Journal of Special Education, 44(4), 234-246.

Krupa, E. E., \& Confrey, J. (2010). Teacher change facilitated by instructional coaches: A customized approach to professional development. In P. Brosnan, D. B. Erchick $\&$ L. Flevares (Eds.), Proceedings of the 32nd annual meeting of the North American Chapter of the International Group for the Psychology of Mathematics Education (Vol. VI, pp. 1465-1473). Columbus, OH: The Ohio State University.

McGatha, M. (2008). Levels of engagement in establishing coaching relationships. Teacher Development, 12(2), 139-150.

McGatha, M. (2009a). Mathematics specialists and mathematics coaches: What does the research say? In J. R. Quander (Ed.), Research Brief. Reston, VA: National Council of Teachers of Mathematics.

McGatha, M. (2009b). What does the research say about mathematics specialists and coaches? Paper presented at the Association of Mathematics Teacher Educators Conference, Orlando, FL.

National Mathematics Advisory Panel. (2008) Foundations for success: The final report of the National Mathematics Advisory Panel. Washington, DC: U.S. Department of Education.

National Research Council. (1989) Everybody counts: A report to the nation on the future of mathematics education. Washington, DC: National Academy Press.

Obara, S. (2010). Mathematics coaching: A new kind of professional development. Teacher Development, 14(2), 241-251. 
Olson, J. C. (2005). Evoking pedagogical curiosity: A coaching approach to support teacher's professional growth. The Mathematics Educator, 8(2), 84-94.

Olson, J. C., \& Barrett, J. E. (2004). Coaching teachers to implement mathematics reform recommendations. Mathematics Teacher Education and Development, 6, 63-78.

Patton, M. Q. (2002). Qualitative research and evaluation methods (3rd ed.). Thousand Oaks, CA: Sage Publications.

Piburn, M., Sawada, D., Falconer, K., Turley, J., Benford, R., \& Bloom, I. (2000). Reformed Teaching Observation Protocol (RTOP). ACEPT IN-003.

Piburn, M., \& Sawada, D. (2009). Reformed Teaching Observation Protocol (RTOP) Reference Manual. Technical Report.

Poglinco, S. M., \& Bach, A. J. (2004). The heart of the matter: Coaching as a vehicle for professional development. Phi Delta Kappan, 85(5), 398-400.

Race, K., Ho, E., \& Bower, L. (2002, April 1-5). Documenting in-classroom support and coaching activities of a professional development program directed toward school-wide change: An integral part of an organization's evaluation efforts. Paper presented at the Annual Meeting of the American Educational Research Association, New Orleans, LA.

Reys, B. J., \& Fennell, F. S. (2003). Who should lead mathematics instruction at the elementary school level: A case for mathematics specialists. Teaching Children Mathematics, 9(5), 277-282.

Rudd, L. C., Lambert, M. C., Satterwhite, M., \& Smith, C. H. (2009). Professional development + coaching = enhanced teaching: Increasing usage of math mediated language in preschool classrooms. Early Childhood Education Journal, 37, 6369.

Sawada, D., Piburn, M. D., Judson, E., Turley, J., Falconer, K., Benford, R., \& Bloom, I. (2002). Measuring reform practices in science and mathematics classrooms: The Reformed Teaching Observation Protocol. School Science and Mathematics, 102(6), 245-253.

Shaughnessy, J. M. (2010, June). NCTM's joint position on elementary math specialists-It's about time! NCTM Summing Up Retrieved July 23, 2011, 2011, from http://www.nctm.org/about/content.aspx?id=26072

Stake, R. E. (1995). Triangulation The art of case study research (pp. 107-120). Thousand Oaks, CA: Sage Publications. 
Zollinger, S., Brosnan, P., Erchick, D. B., \& Bao, L. (2010). Mathematics coaching: Impact on student proficiency levels after one year of participation. In P. Brosnan, D. B. Erchick \& L. Flevares (Eds.), Proceedings of the 32nd annual meeting of the North American Chapter of the International Group for the Psychology of Mathematics Education (Vol. VI, pp. 1371-1378). Columbus, OH: The Ohio State University. 
Appendix A

MAST End-of-Year Survey 2011

You are being invited to voluntarily participate in the following survey. The purpose of the survey is to gather information about your experience in the MAST program. You are eligible to participate because you are a MAST participant.

Your participation will involve completing the survey. It will take you about 10 minutes to complete the survey and you may choose not to answer some or all of the questions. There are no known risks from your participation. There is no cost to you except for your time.

The external evaluator and her team will have access to your email address and the information that you provide. In order to maintain your confidentiality, your email will not be revealed in any reports that result from this survey. Survey data will be stored on a secure server.

By participating in the survey, you are giving permission for the investigator to use your information for evaluation and research purposes.

Thank you.

1. Rate your satisfaction level with the MAST program.

$\circ$ Very Dissatisfied

○ Dissatisfied

- Mildly Dissatisfied

- Mildly Satisfied

- Satisfied

- Very Satisfied

- No Opinion

2. Participating in the MAST program has met my professional expectations.

- Strongly Disagree

○ Disagree

○ Mildly Disagree

○ Mildly Agree

- Agree

- Strongly Agree

- No Opinion

3. The professional development offered through MAST meets my current needs.

○ Strongly Disagree

$\circ$ Disagree

○ Mildly Disagree

○ Mildly Agree

- Agree

- Strongly Agree

- No Opinion

4. My knowledge of the mathematics content has increased due to my participation in MAST. 
- Strongly Disagree

- Disagree

- Mildly Disagree

- Mildly Agree

- Agree

- Strongly Agree

- No Opinion

5. I have developed relationships with the other teachers as a result of my participation in MAST.

- Strongly Disagree

- Disagree

- Mildly Disagree

- Mildly Agree

- Agree

- Strongly Agree

- No Opinion

6. The coaching provided by the MAST program meets my current needs.

- Strongly Disagree

$\circ$ Disagree

○ Mildly Disagree

- Mildly Agree

○ Agree

- Strongly Agree

○ No Opinion

7. The coaching focused on how to effectively teach mathematical concepts.

○ Strongly Disagree

○ Disagree

○ Mildly Disagree

- Mildly Agree

○ Agree

- Strongly Agree

○ No Opinion

8. I am satisfied with the coach provided by the program.

- Strongly Disagree

- Disagree

- Mildly Disagree

- Mildly Agree

- Agree

- Strongly Agree

- No Opinion 
9. My experiences during the MAST program have increased my ability to deliver appropriate math lessons.

○ Strongly Disagree

- Disagree

○ Mildly Disagree

○ Mildly Agree

- Agree

- Strongly Agree

- No Opinion

10. List the main benefits to you as a result of participating in the MAST program.

11. Describe the impact of Lesson Study on your teaching practice.

12. Describe what you have learned about student learning as a result of your participation in the MAST program.

13. Do you have any suggestions on improving the MAST program?

14. What parts of MAST should be sustained after grant funds are expended?

15. Additional Comments: 
Appendix B

MAST End-of-Year Survey 2012

You are being invited to voluntarily participate in the following survey. The purpose of the survey is to gather information about your experience in the MAST program. You are eligible to participate because you are a MAST participant.

Your participation will involve completing the survey. It will take you about 10 minutes to complete the survey and you may choose not to answer some or all of the questions. There are no known risks from your participation. There is no cost to you except for your time.

The external evaluator and her team will have access to your email address and the information that you provide. In order to maintain your confidentiality, your email will not be revealed in any reports that result from this survey. Survey data will be stored on a secure server.

By participating in the survey, you are giving permission for the investigator to use your information for evaluation and research purposes.

Thank you.

1. The course helped meet my content knowledge needs for:

a. Data Analysis

- Strongly Disagree

- Disagree

- Mildly Disagree

- Mildly Agree

- Agree

- Strongly Agree

- No Opinion

b. Probability

- Strongly Disagree

- Disagree

○ Mildly Disagree

○ Mildly Agree

- Agree

- Strongly Agree

- No Opinion

c. Geometric Constructions

○ Strongly Disagree

$\circ$ Disagree

○ Mildly Disagree

- Mildly Agree

- Agree

- Strongly Agree

- No Opinion 
2. The course met my professional expectations.

- Strongly Disagree

- Disagree

- Mildly Disagree

- Mildly Agree

- Agree

- Strongly Agree

- No Opinion

3. The course stimulated my thinking.
- Strongly Disagree
- Disagree
○ Mildly Disagree
○ Mildly Agree
- Agree
- Strongly Agree
○ No Opinion

4. I have a better understanding of the following concepts as a result of the course:

a. Data Analysis

- Strongly Disagree

- Disagree

- Mildly Disagree

- Mildly Agree

- Agree

- Strongly Agree

- No Opinion

b. Probability

- Strongly Disagree

- Disagree

- Mildly Disagree

- Mildly Agree

- Agree

- Strongly Agree

- No Opinion

c. Constructions

- Strongly Disagree

- Disagree

- Mildly Disagree

- Mildly Agree

- Agree

- Strongly Agree

- No Opinion 
5. I am confident in my ability to explain the following concepts to my students as a result of the course:

a. Data Analysis

- Strongly Disagree

- Disagree

○ Mildly Disagree

- Mildly Agree

- Agree

- Strongly Agree

- No Opinion

b. Probability

- Strongly Disagree

$\circ$ Disagree

- Mildly Disagree

- Mildly Agree

- Agree

- Strongly Agree

○ No Opinion

c. Geometric Constructions

- Strongly Disagree

- Disagree

- Mildly Disagree

- Mildly Agree

- Agree

- Strongly Agree

- No Opinion

6. The course material was presented at an appropriate level.
○ Strongly Disagree
- Disagree
○ Mildly Disagree
○ Mildly Agree
- Agree
- Strongly Agree
- No Opinion

7. Rate your satisfaction level with the course:

○ Very Dissatisfied

- Dissatisfied

- Mildly Dissatisfied

○ Mildly Satisfied

○ Satisfied

- Very Satisfied 
- No Opinion

8. Additional comments about the course:

9. Who was your instructional coach during the 2011-2012 school year?

10. The coaching provided met my needs.
○ Strongly Disagree
- Disagree
○ Mildly Disagree
○ Mildly Agree
- Agree
- Strongly Agree
○ No Opinion

11. The coach employed sound coaching practices.
○ Strongly Disagree
- Disagree
- Mildly Disagree
○ Mildly Agree
- Agree
- Strongly Agree
- No Opinion

12. I had regular dialogue with the coach.
- Strongly Disagree
- Disagree
○ Mildly Disagree
- Mildly Agree
- Agree
- Strongly Agree
- No Opinion

13. The dialogue focused on teaching and mathematical concepts.
- Strongly Disagree
○ Disagree
○ Mildly Disagree
○ Mildly Agree
- Agree
- Strongly Agree
○ No Opinion

14. I implemented methods from the coaching received into my classroom.

○ Strongly Disagree 
○ Disagree

○ Mildly Disagree

- Mildly Agree

- Agree

- Strongly Agree

- No Opinion

15. Describe any benefits you received from having access to your coach:

16. Describe the methods you implemented into your classroom due to the coaching you received:

17. Lesson Study increased my mathematical content knowledge.

○ Strongly Disagree

○ Disagree

○ Mildly Disagree

- Mildly Agree

- Agree

- Strongly Agree

- No Opinion

18. Lesson Study increased my knowledge about instruction.

- Strongly Disagree

- Disagree

- Mildly Disagree

- Mildly Agree

- Agree

- Strongly Agree

- No Opinion

19. I am better able to understand my students' learning as a result of lesson study.
- Strongly Disagree
- Disagree
- Mildly Disagree
- Mildly Agree
- Agree
- Strongly Agree
- No Opinion 
20. Lesson Study enhanced my relationship with other teachers.

- Strongly Disagree

○ Disagree

○ Mildly Disagree

○ Mildly Agree

- Agree

- Strongly Agree

- No Opinion

21. Lesson Study helped me develop better lessons.

○ Strongly Disagree

○ Disagree

- Mildly Disagree

- Mildly Agree

○ Agree

○ Strongly Agree

- No Opinion

22. Additional comments about Lesson Study:

23. General comments regarding your overall experience during MAST: 
Appendix C

Faculty Interview Protocol

Thank you for agreeing to participate in this research study that is an extension of the MAST project evaluation. I am interested in understanding the role that the MAST coach has played throughout the project with you and with the teachers. Please answer as honestly as possible. Let me know if at any point you are not comfortable answering a question or continuing with the interview. There is no right or wrong answer. Your identity will remain completely anonymous in the reporting process.

1. In previous interviews, you mentioned the important role played by the coach in determining the content of the summer professional development. Say more about how you interact at this stage.

a. Describe the contributions that the coach provided DURING the summer content courses (i.e., beyond the course development). What was her role?

b. Describe the contributions she made (if you are aware of any) AFTER the summer content courses.

2. How were these contributions different or unique from your own?

3. In a previous interview, you stated that the coach led the class to the "right kinds of questions." Tell me more about that.

4. In a previous interview, Miss Rhodes stated you were "surprised by the teachers' willingness to try activities in their classrooms..." Tell me more about that.

a. How do you know they actually tried the activities?

5. How would you characterize the coach's interactions with teachers during PD? What was the focus, if any? (i.e. content, pedagogy, etc.)

6. Did the teachers talk about working with the coach? If so, explain their interactions with her.

7. a. What impact do you perceive the coach is having on the teachers?

b. And are the teachers also having an impact on her? If so, how?

c. What impact, if any, did the course development and delivery with the coach have on each of you?

8. Is there anything else you think I should know about your work with the coach? 
Appendix D

Coach Interview Protocol

Thank you for agreeing to participate in this research study that is an extension of the MAST project evaluation. I am interested in understanding your role as the MAST coach in interacting with teachers and the subsequent impact of your coaching that you have observed. Please answer as honestly as possible. Let me know if at any point you are not comfortable answering a question or continuing with the interview. There is no right or wrong answer. Your identity will remain completely anonymous in the reporting process.

\section{Coach's Log}

1. I have reviewed the data logged in the NC MSP database of your coaching activities. Here is a list. Would you mind reviewing them for accuracy? What would you add or change?

2. Were you given certain direction about logging things in the database? (i.e., which activities warranted logging and which did not?)

3. You logged 52 hours as "coaching" in the $1^{\text {st }}$ year. Describe what this might include.

4. This was not used again after year 1. Why?

5. You logged 28 hours as "lesson study" but then did not use that title again. Explain.

\section{Document Review}

6. I also reviewed the document Some MAST Coach Project Responsibilities. Was this in place before the grant began or developed later on?

7. Who developed or created that list of duties?

Why?

8. It describes make-up sessions for content PD. Was this the course work?

9. Did you lead these by yourself or did faculty help you?

\section{Post conferences}

I have also reviewed the audio of your post conferences with MAST teachers. Here are some of the themes I have identified to describe the type of interactions that occur during a session. Would you mind reviewing for accuracy? What would you add or take away from this list?

10. Would you say these behaviors are representative of a typical MAST coaching session?

11. In what ways do your coaching sessions with non-MAST teachers differ, if any?

12. Does the lesson study backdrop change the interactions of a typical coaching session? 


\section{Impact}

13. In the end of year surveys, $100 \%$ of teachers agreed or strongly agreed with the statement "I implemented methods from coaching received in my classroom." What methods have you observed MAST teachers implement as a result of coaching?

14. What impacts do you observe from coaching non-MAST teachers? Is there a difference? If so, why?

15. The RTOP results show significant differences in teachers' overall score and subscale scores towards reform-based teaching. Are there other changes or impacts on teachers you observed, not sensitive enough to be detected on the RTOP or that may be less tangible or less obvious?

\section{Coach Interview}

16. During EMEC's initial interview with you, you were asked about teachers connecting with each other. You said "they really enjoy working together and working the problems, and seeing their colleagues in a different way with the project." Say more about this.

17. You went on to say, "They love working the problems, they love having the discussions about the math, and that's really important to them." Say more about this impact.

18. Did working the problems and the math discussions happen solely in the course settings?

19. Or also while you were coaching them?

20. Finally you also said "it's helped them look at math in a different way." Explain.

21. These were all described after only 6 months of the grant. What new impacts, if any, would you identify since then?

22. Has this change in teacher relationships led to greater leadership on their part?

\section{Course Work/PD}

23. MAST teachers have received course work and district PD. You indicated that the course work "did meet their needs" (the teachers'). What impact(s), if any, did the course development and delivery have on the university faculty? What changes did you see in them?

24. What impact(s), if any, did the course development and delivery have on you as a coach?

25. What other impacts have you experienced personally from serving as the project coach for MAST? 
26. Is there anything else of interest about your work in MAST that you think I should know:

a) Interaction with teachers?

b) Its impact on teachers?

c) In general? 


\section{Appendix E}

Piburn, M., Sawada, D., Falconer, K., Turley, J., Benford, R., \& Bloom, I. (2000). Reformed Teaching Observation Protocol (RTOP). ACEPT IN-003.

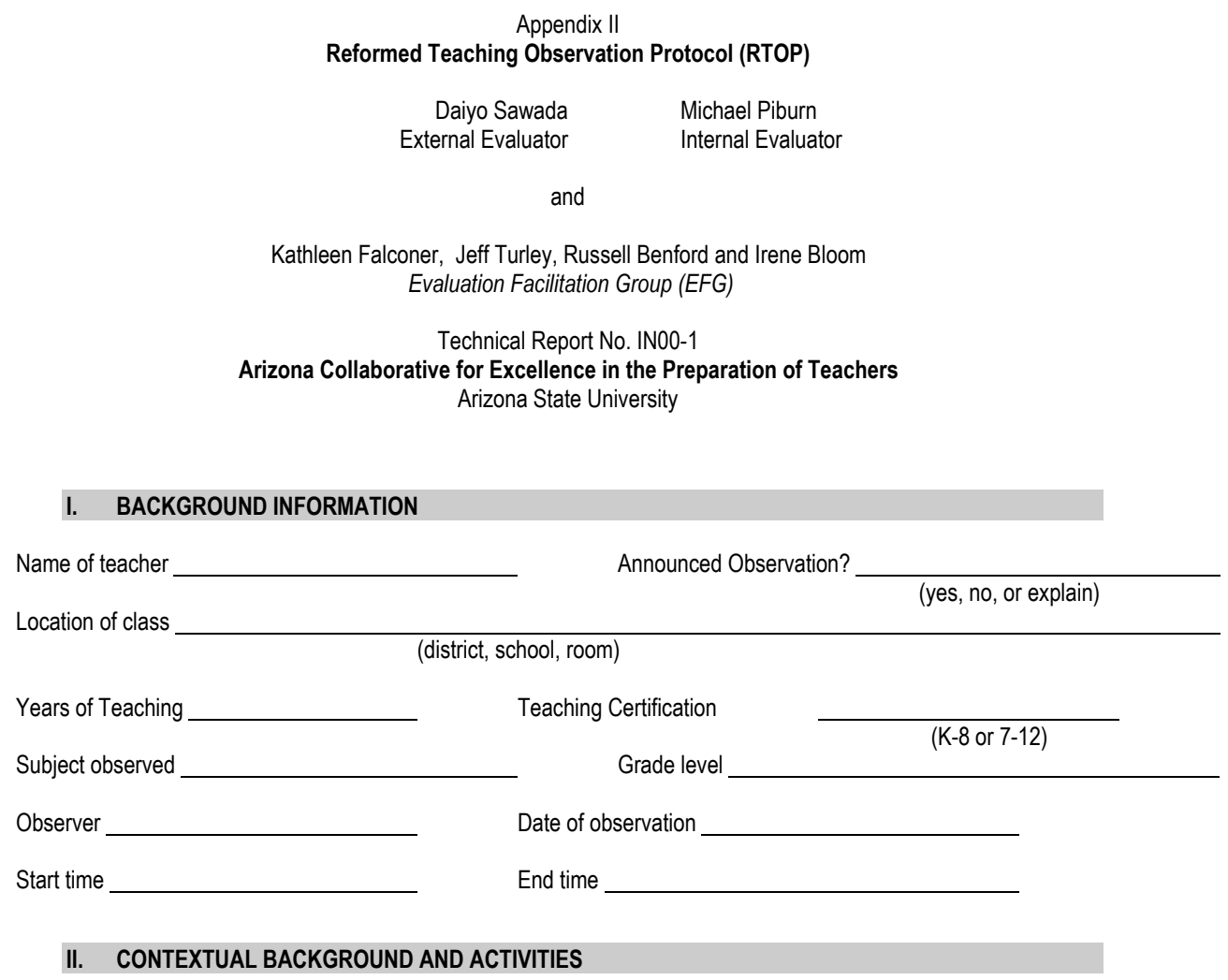

In the space provided below please give a brief description of the lesson observed, the classroom setting in which the lesson bok place (space, seating arrangements, etc.), and any relevant details about the students (number, gender, ethnicity) and teacher that you think are important. Use diagrams if they seem appropriate. 
Record here events that may help in documenting the ratings.

\begin{tabular}{|l|l|}
\hline Time & Description of Events \\
\hline & \\
& \\
& \\
& \\
& \\
& \\
\hline
\end{tabular}




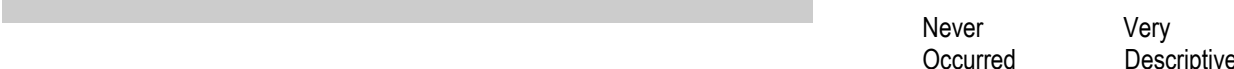

1)

The instructional strategies and activities respected students' prior knowledge and $\quad \begin{array}{lllll}0 & 1 & 2 & 3 & 4\end{array}$ the preconceptions inherent therein.

2) The lesson was designed to engage students as members of a learning community. $\begin{array}{lllll}0 & 1 & 2 & 3 & 4\end{array}$

3)

In this lesson, student exploration preceded formal presentation.

This lesson encouraged students to seek and value alternative modes of

4) investigation or of problem solving

$\begin{array}{lllll}0 & 1 & 2 & 3 & 4\end{array}$

The focus and direction of the lesson was often determined by ideas originating with

5) students.

$\begin{array}{lllll}0 & 1 & 2 & 3 & 4\end{array}$

$\begin{array}{lllll}0 & 1 & 2 & 3 & 4\end{array}$

IV. CONTENT

\section{Propositional knowledge}

6) The lesson involved fundamental concepts of the subject.

7) The lesson promoted strongly coherent conceptual understanding.

8) The teacher had a solid grasp of the subject matter content inherent in the lesson

Elements of abstraction (i.e., symbolic representations, theory building) were

9)

10)

Connections with other content disciplines and/or real world phenomena were explored and valued.

\author{
$\begin{array}{lllll}0 & 1 & 2 & 3 & 4\end{array}$ \\ $\begin{array}{lllll}0 & 1 & 2 & 3 & 4\end{array}$ \\ $\begin{array}{lllll}0 & 1 & 2 & 3 & 4\end{array}$ \\ $\begin{array}{lllll}0 & 1 & 2 & 3 & 4\end{array}$ \\ $\begin{array}{lllll}0 & 1 & 2 & 3 & 4\end{array}$
}

\section{Procedural Knowledge}

11) Students used a variety of means (models, drawings, graphs, concrete materials, $\quad \begin{array}{llllll}0 & 1 & 2 & 3 & 4\end{array}$ manipulatives, etc.) to represent phenomena.

12) Students made predictions, estimations and/or hypotheses and devised means for $\begin{array}{llllllll}0 & 1 & 2 & 3 & 4\end{array}$ testing them.

13) Students were actively engaged in thought-provoking activity that often involved the $\begin{array}{lllllll}0 & 1 & 2 & 3 & 4\end{array}$ critical assessment of procedures.

14) Students were reflective about their learning.

$\begin{array}{lllll}0 & 1 & 2 & 3 & 4\end{array}$

15)

Intellectual rigor, constructive criticism, and the challenging of ideas were valued.

$\begin{array}{lllll}0 & 1 & 2 & 3 & 4\end{array}$ 


\section{Continue recording salient events here.}

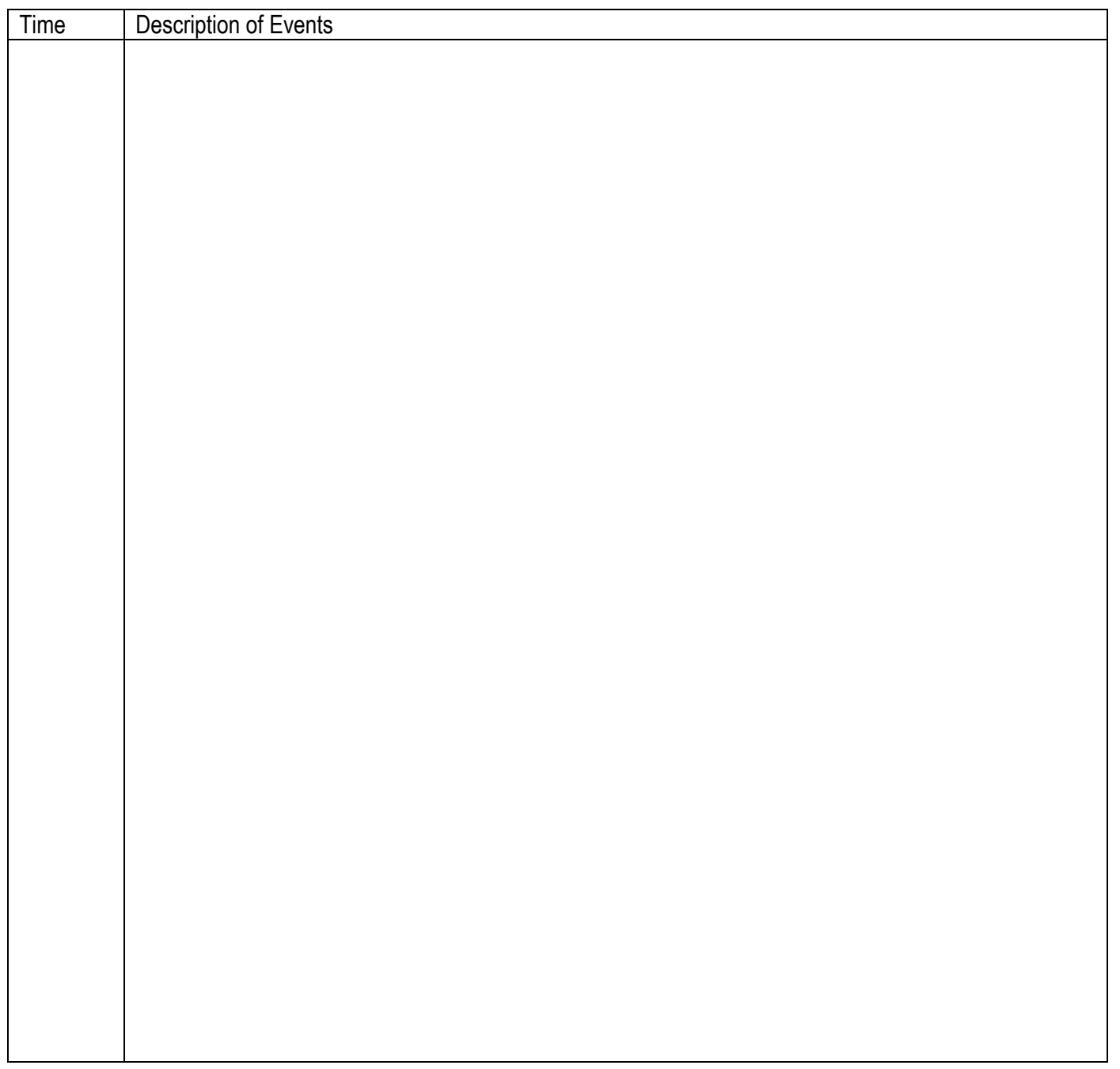




\section{CLASSROOM CULTURE}

$\begin{array}{lll}\text { Communicative Interactions } & \text { Never } & \text { Very } \\ & \text { Occurred } & \text { Descriptive }\end{array}$

16) Students were involved in the communication of their ideas to others using a variety $\quad \begin{array}{lllllll}0 & 1 & 2 & 3 & 4\end{array}$ of means and media.

17) The teacher's questions triggered divergent modes of thinking.

$\begin{array}{lllll}0 & 1 & 2 & 3 & 4\end{array}$

18) There was a high proportion of student talk and a significant amount of it occurred between and among students.

$\begin{array}{lllll}0 & 1 & 2 & 3 & 4\end{array}$

19) Student questions and comments often determined the focus and direction of classroom discourse.

$\begin{array}{lllll}0 & 1 & 2 & 3 & 4\end{array}$

20) There was a climate of respect for what others had to say.

$\begin{array}{lllll}0 & 1 & 2 & 3 & 4\end{array}$

\section{Student/Teacher Relationships}

21) Active participation of students was encouraged and valued.

$\begin{array}{lllll}0 & 1 & 2 & 3 & 4\end{array}$

22) Students were encouraged to generate conjectures, alternative solution strategies,

$\begin{array}{lllll}0 & 1 & 2 & 3 & 4\end{array}$ and ways of interpreting evidence.

23) In general the teacher was patient with students.

$\begin{array}{lllll}0 & 1 & 2 & 3 & 4\end{array}$

24)

The teacher acted as a resource person, working to support and enhance student investigations.

$\begin{array}{lllll}0 & 1 & 2 & 3 & 4\end{array}$

25) The metaphor "teacher as listener" was very characteristic of this classroom.

$\begin{array}{lllll}0 & 1 & 2 & 3 & 4\end{array}$

Additional comments you may wish to make about this lesson. 
Appendix F

Some MAST Project Coach Responsibilities

Meet with school lesson study teams to discuss expectations, lesson study lesson plans, team logs for documentation, using the Moodle, enter participant information into NCMSP database, due dates, and MAST Celebration of Learning.

Observe lesson study lessons, provide appropriate coaching, and facilitate post reflective conferences. (This year there are 48 full period observations and 48 post reflective conferences.) Observations require travel time to the middle schools.

Coordinate scheduling for the 48 observations and conferences between 25 participants. Participants include middle school teachers. (this year-the number varies each year)

Meet with teams when needed or requested to plan/coach on their lesson.

When requested by a team review lessons sent by email and provide feedback to team.

Keep records on each meeting with time and document for entry into the NCMSP database.

Enter observations, post reflective conferences, planning sessions for teams, and content professional development into the NCMSP database.

Plan and coordinate MAST Celebration of Learning. Create brochure and communicate expectations to participants.

Participate on 2 lesson study teams. Meet with each team member to plan and create lesson study lessons, teach lesson or segment of lesson, prepare PowerPoint for presentation, and help present at the Celebration.

Secure locations and refreshments for professional development and Celebration of Learning. Ensure all necessary equipment and materials are available and set up in room.

Created, prepared, and co-presented at state conference on lesson study. Coordinated the presentation with Project Director, and teacher participants and prepared booklet with sample lesson study lessons for distribution at conference.

Collect lesson study team lessons, review them, and prepare them to be printed for distribution to teachers.

Collect all documentation from participates to complete paperwork for CEU credits for content courses and for the lesson study additional CEU credit hours. Also, ensure participants sign in each day for BCS and UNCW documentation purposes. 
Coordinate with various stakeholders when necessary: [outside evaluator], [university] instructors, and NCMSP database coordinator.

Conduct RTOP observations on participants to collect data for outside evaluator, complete necessary paperwork and prepare report for [outside evaluator].

Plan with [university] professors (face to face, through email, and by phone) to design summer content courses. Search for resources, activities, and books for possible material for the pd.

When course is designed, work through all materials to prepare for delivery of content courses.

Help deliver content courses -7 days the first year and monitored Blackboard assignments (other days were online assignments), 19 days the $2^{\text {nd }}$ year (includes 9 days of makeup sessions) and 10 days the $3^{\text {rd }}$ year (includes 5 days of makeup sessions.

Work with Project Director to prepare Annual Report due August 1 each year-sometimes completing sections on Implementation of grant or writing information for these sections.

Meet frequently with Projector Director, for various reasons, throughout the year and the MAST Management Team when needed.

Research materials and prepare detailed list of possible purchases for grant use.

Attend state and national conferences. 


\section{CURRICULUM VITAE}

Eleanor Louise Pusey

\section{Education}

Appalachian Collaborative Center for Learning, Assessment, and Instruction in Mathematics (ACCLAIM) Doctoral Program, University of Louisville, August 2007 - Present North Carolina Teaching License "M", Mathematics 9-12, Middle Grades Mathematics M.S. North Carolina State University, Mathematics Education, 2001-2003

B.S. Radford University, Mathematics, 1988-1992

\section{Teacher Education/Leadership Experience}

North Carolina Council of Teachers of Mathematics Officer,

State Vice President for High School (elected)

Beginning Teacher Mentor, Columbus County Schools

Teacher of the Year, Columbus Career \& College Academy

North Carolina Council of Teachers of Mathematics Officer,

Eastern Region Vice President for High School (elected)

Supervisor of Student Interns, UNC Wilmington

Secondary Mathematics Coach, Columbus County Schools

Writing Team Member, 2009 North Carolina Essential Standards for High School Mathematics, North Carolina State Department of Public Instruction

Secondary Mathematics Facilitator, UNC General Administration, NC Partnership for Improving Mathematics and Science (NC-PIMS), 5 school districts in North Carolina

\section{Professional Development Consultant}

NC Collaborative Project, Algebraic Reasoning for K-5 teachers Statewide Institute for Teaching Excellence: Geometry

New Directions in High School Geometry, Acces Software

\section{Teaching Experience}

Columbus Career \& College Academy, Whiteville NC North Carolina Governor's School East, Meredith College, Raleigh NC Teaching Assistant, North Carolina State University, Raleigh NC Wake Forest-Rolesville High School, Wake Forest NC
2013-2015

2012 - present

$2012-2013$

2009-2011

Jan 2010 - May 2010

August 2007 - July 2010

2007-2009

August 2003 - July 2007

1996 - Present

June 2011

July 2007

1996-2000

July 2010 - present

Summer 2003

Aug 2001 - May 2003

Nov 1992 - June 2001 


\section{Instructional Activities}

High School Mathematics Courses for Students (grades 9-13)

Columbus Career \& College Academy, Columbus County Schools, Whiteville NC

Introductory Mathematics

Integrated Mathematics II

Integrated Mathematics III

Advanced Functions \& Modeling

Trigonometry (Online)

College Mathematics Support

North Carolina Governor's School East, (for rising junior/seniors), Meredith College

Non-Euclidean Geometries

Advanced Geometry Explorations with Geometer's Sketchpad

Teaching Assistant, North Carolina State University

MAT 101 Intermediate Algebra

Wake Forest-Rolesville High School, Wake County Schools, Wake Forest NC

Pre-Algebra

Algebra I, Algebra I: A Process Approach, Algebra I, part II

Geometry

Algebra II

Algebra III \& Trigonometry

Consumer Mathematics

SAT Mathematics Preparation

Mathematics Content Courses for Inservice Teachers

Algebraic Reasoning (K-5)

Partnership for Improving Mathematical Understanding of Students and Teachers (PIMUST)

Developing Number Sense through Data Contexts (6-12)

Making Sense: Teaching \& Learning Mathematics with Understanding (6-12)

Navigating the North Carolina Essential Standards (6-12)

North Carolina Partnership for Improving Mathematics and Science (NC-PIMS)

Algebraic Thinking (6-12)

Data \& Measurement (6-12)

Geometry (6-12)

Mathematical Modeling (6-12)

Mathematics Content/Pedagogy Workshops for Inservice Teachers

North Carolina Partnership for Improving Mathematics and Science (NC-PIMS)

Engaging Students in Algebraic Thinking (6-12)

Exploring Data, Probability, \& Measurement (6-12)

Investigations in Geometry (6-12)

Geometer's Sketchpad (6-12)

Mathematical Modeling (6-12)

Praxis Preparation for Mathematics Teachers (6-8, 9-12) 
Other

Statewide Institute for Teaching Excellence (SITE): Geometry (9-12)

New Directions in High School Geometry (9-12)

SMART Interactive White Board (9-12)

Wimba Classroom PLCs (6-12)

Graphing Calculator (8-12)

Geometer's Sketchpad (6-12)

Acces Test Generator Software (9-12)

\section{Service}

Tech Team Sponsor, Columbus Career \& College Academy, 2011- present

Data Team Chair, Columbus Career \& College Academy, 2011- present

Writing Team Member, 2009 Essential Standards for High School Mathematics, North Carolina

Department of Public Instruction, 2007 - 2009

K-5 Course/PD Content Reviewer - NCPIMS, 2003-2007

Presidential Awardee Committee Reviewer, North Carolina Department of Public Instruction

Advanced Functions \& Modeling Reviewer, University of North Carolina Mathematics and

Science Network- Spring 2004

Journal Reviewer, National Council of Teachers of Mathematics, Mathematics Teaching in the Middle School, 2009-2010

\section{Publications}

Morge, S. \& Pusey, E. (2010). Step up to nonlinear functions. Mathematics Teaching in the Middle School, 15 (6), 310-313.

Pusey, E. \& Sensenich, K. (2007) The promise of a dynamic mathematics classroom: Technology at work. [White paper]. Retrieved from http://ncpims.northcarolina.edu/facil_whitepaper/Dynamic math.html

Pusey, E. L. (2003). The van Hiele Model of geometric reasoning: A literature review. Unpublished masters thesis. North Carolina State University, Raleigh, NC.

Pusey, E. L., Stohl, H., Tarr, J. E., \& Townsend, B. E. (2002). Analyzing written expressions of students' probabilistic reasoning: Development and use of scoring rubrics. Paper presented at the North American chapter for the International group for the Psychology of Mathematics Education, Athens, GA.

\section{Research}

Doctoral Dissertation, University of Louisville Doctoral Candidate, 2010-2013

Action Research, Doctoral Internship, University of North Carolina Wilmington, Spring 2009

Graduate Research Assistant, North Carolina State University, February 2002 - June 2003

\section{Grant Writing}

State Math-Science Partnership Grant, Partnership for Improving Mathematical

Understanding of Students and Teachers, Columbus County Schools, $\$ 300,000$ 


\section{Professional Memberships/Affiliations}

Association of Mathematics Teacher Educators (AMTE)

National Council of Supervisors of Mathematics (NCSM)

2008 - Present

Phi Kappa Phi Honor Society, North Carolina State University

$2004-2008$

National Council of Teachers of Mathematics (NCTM)

Lifetime member (2003)

North Carolina Council of Teachers of Mathematics (NCCTM)

1996 - Present

1994 - Present

\section{Presentations}

National - refereed

National Council of Teachers of Mathematics Annual Meeting, San Diego CA, Podcasting: You Can Do It, We Can Help!, April 2010

National Council of Supervisors of Mathematics, Annual Conference, St. Louis MO, Assessing

Elementary Teachers' Content Knowledge, April 2006

National Council of Teachers of Mathematics Annual Meeting, St. Louis MO, Assessing

Elementary Teachers' Content Knowledge, April 2006

National Council of Teachers of Mathematics Annual Meeting, Orlando FL, Make Geometry a

"Moving” Experience, April 2001

\section{Regional - refereed}

U.S. Department of Education, Regional MSP Conference, New Orleans LA, PIMUST: The Teal K-16 Road, Poster Presentation, March 2010

Appalachian Collaborative Center for Learning, Assessment, and Instruction in Mathematics Research Symposium, Poster Session, Newark OH, Stepping it Up With Nonlinear Functions, May 2009

U.S. Department of Education, Regional MSP Conference, Washington DC, PIMUST

Professional Development Model, January 2009

North American Chapter of the International Group for the Psychology of Mathematics Education (PME-NA) Conference, Poster Session, Athens GA, Analyzing Written Expressions of Students'

Probabilistic Reasoning: Development and Use of Scoring Rubrics, October 2002

\section{State - invited}

K-12 Mathematics Summer Leadership Institute (by invitation), High Point NC, Creating an

Instructional Framework: Methods and Materials, July 2008

\section{State - refereed}

North Carolina Council of Teachers of Mathematics State Conference, Greensboro NC, PIMUST: Coaching Mathematics, Shearing Sheep in the Middle Grades, October 2009

North Carolina Council of Teachers of Mathematics State Conference, Greensboro NC, Planning for Effective Algebra Instruction, October 2008

North Carolina Council of Teachers of Mathematics State Conference, Greensboro NC, Survivor - Oak Island, October 2006

\section{Local - refereed}

North Carolina Council of Teachers of Mathematics Eastern Regional Conference, Rocky Mount NC, Spatial Visualization, February 2007 